\author{
Universidade de São Paulo \\ Escola de Engenharia de São Carlos
}

MIRIÃ CAMARGO FELICIO

PROPOSTA DE UM INDICADOR PARA MONITORAR A EVOLUÇÃO DA SIMBIOSE INDUSTRIAL EM PARQUES ECO-INDUSTRIAIS SEGUNDO A PERSPECTIVA DE SISTEMAS DINÂMICOS

São Carlos

2013 
MIRIÃ CAMARGO FELICIO

\section{PROPOSTA DE UM INDICADOR PARA MONITORAR A EVOLUÇÃO \\ DA SIMBIOSE INDUSTRIAL EM PARQUES ECO-INDUSTRIAIS SEGUNDO A PERSPECTIVA DE SISTEMAS DINÂMICOS}

Dissertação apresentada à Escola de Engenharia de São Carlos, Universidade de São Paulo, como parte dos requisitos para obtenção do título de Mestre em Engenharia de Produção.

Área de concentração: Processos de Gestão e Operações.

Orientador: Prof. Dr. Kléber Francisco Esposto

São Carlos 
AUTORIZO A REPRODUÇÃO TOTAL OU PARCIAL DESTE TRABALHO, POR QUALQUER MEIO CONVENCIONAL OU ELETRÔNICO, PARA FINS DE ESTUDO E PESQUISA, DESDE QUE CITADA A FONTE.

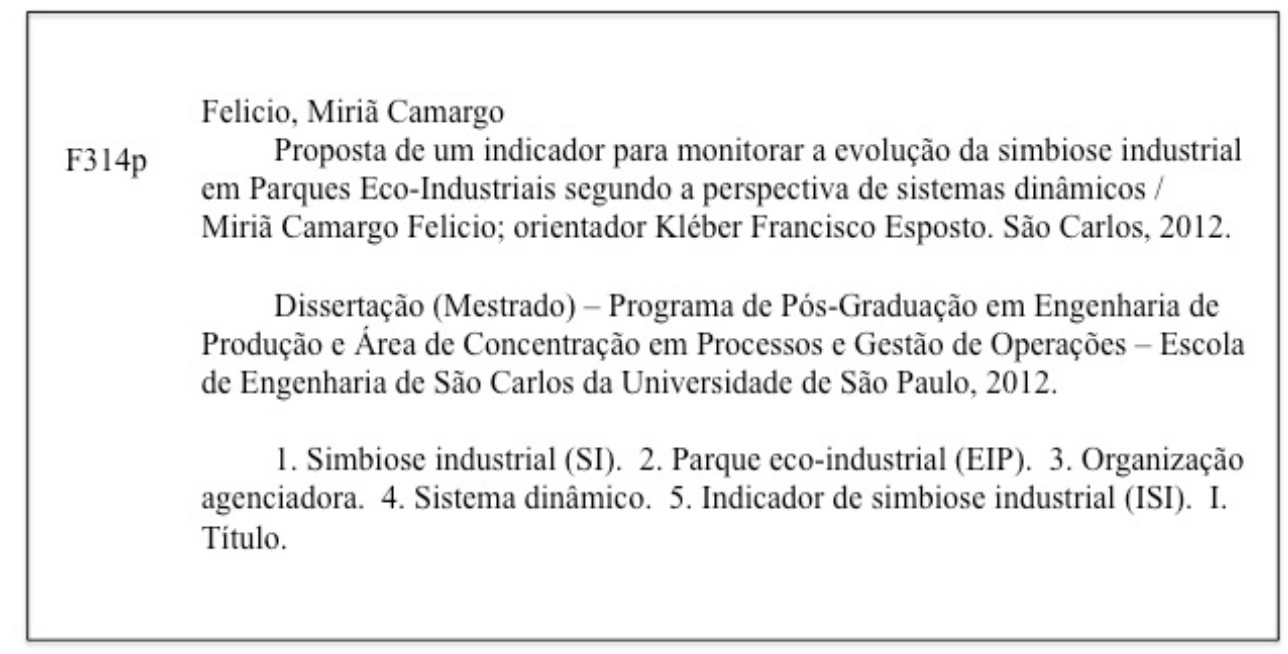




\section{FOLHA DE JULGAMENTO}

\section{Candidata: Engenheira MIRıÃ CAMARGO FELıCıO.}

Titulo da dissertaçà Troposta de um indicador de simbiose industrial para apoiar a auto-organizaç̧o em um EIP segundo a perspectiva de sistemas dinaimicos",

Data da defesa: 23/01/2013

\section{Comissĩo Julgadora:}

Prof. Dr. Kleber Francisco Espôsto (Orientador)

(Escola de Engenharia de Slo Carlos/EESC)

Prof. Dr. Aldo Roberto Ometto

(Escola de Engenharia de Sšo Carlos/EESC)
Resultado:
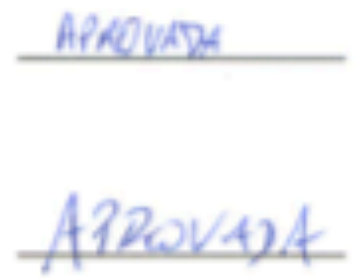

Prof. Dr. Xavier Gabarrell Durany

AProuapa

(Universitat Autônoma de Barcelona/UAB-(participaç̃o por videoconferểncia))<smiles>CC1CC2CCCCC(C1)C2C</smiles><smiles>CCCCCCCCCCCCCC</smiles>

Coordenador do Programa de Pós-Graduação em Engenharia de Produçio:

Prof. Titular Henrique Rozenfeld

Presidente da Comissão de Pós-Graduaçăo:

Prof. Titular Denis Vinicius Coury 
iv Proposta de um indicador para monitorar a evolução da simbiose industrial em EIPs segundo a perspectiva de sistemas dinâmicos.

"O temor do Senhor é o princípio da sabedoria; têm bom entendimento todos os que cumprem os seus preceitos; o seu louvor subsiste para sempre." 


\section{AGRADECIMENTOS}

À Deus por ser presente em cada instante de minha vida, me fazendo compreender, esperar, lutar, perseverar, superar, crescer e agradecer em meio a situações positivas e negativas.

Aos meus pais, Eli e Teca, meus exemplos de vida, por me ensinarem com grande diferencial e excelência o verdadeiro sentido da vida e pelo constante incentivo ao aprimoramento intelectual para o sucesso de minha carreira profissional.

Ao meu marido, Renan, que sempre me apoiou com amor, sabedoria e paciência, sendo peça fundamental da minha vida.

Às minhas irmãs, Danatielle e Priscilla, de quem me orgulho muito e que sempre serão exemplos de persistência e conquista para mim. Aos meus cunhados, Leandro e Gustavo, pelos momentos de descontração e alegria.

A todos meus familiares, amigos e colegas que me incentivaram e apoiaram nos momentos de alegria e tristeza.

Aos orientadores, Dr. Daniel e Dr. Kléber, pelos ensinamentos, paciência e confiança que demonstraram durante todo o desenvolvimento deste trabalho.

Aos amigos do NUMA pelos bons momentos de conversas, conselhos, ensinamentos e torcida.

À coordenação do Programa de Pós-Graduação em Engenharia de Produção pelo apoio e auxílio confiados a mim para desenvolver esta pesquisa e crescer em experiência e conhecimento.

E finalmente, gostaria de agradecer a CAPES (Coordenação de Aperfeiçoamento de Pessoal de Nível Superior) pela concessão da bolsa e apoio financeiro para realização desta pesquisa. 


\section{RESUMO}

FELICIO, M.C. Proposta de um indicador para monitorar a evolução da simbiose industrial em Parques Eco-Industriais segundo a perspectiva de sistemas dinâmicos. São Carlos: EESC-USP, 2013. 110p. Dissertação (Mestrado em Engenharia de Produção) - Programa de Pós-Graduação em Engenharia de Produção, Escola de Engenharia de São Carlos, Universidade de São Paulo, 2013.

Os Parques Eco-Industriais (EIP - Eco-Industrial Park) surgiram como um novo modelo de organização espacial para arranjos industriais. Uma característica importante para um EIP é a adoção do conceito de simbiose industrial (SI), em que as empresas reutilizam resíduos em busca de um sistema fechado, diminuindo impacto ambiental. Há propostas para avaliar o fluxo de resíduos e a simbiose de um EIP por meio de indicadores detalhados em um determinado momento. Porém, trata-se de uma visão estática do parque na qual seria possível que os agentes implementassem mudanças para construir uma situação de sistema fechado ideal. Pesquisas recentes demonstram que essa abordagem enfrenta algumas limitações, uma vez que o processo de simbiose depende das decisões rotineiras e individuais de cada ator, empresários, técnicos e agenciadores, as quais podem alterar a dinâmica do fluxo de material no decorrer do tempo. A fim de contribuir, propõe-se um indicador de simbiose industrial diferente, elaborado segundo a abordagem do parque como um sistema dinâmico. Trata-se de uma ferramenta capaz de monitorar o nível de simbiose de um parque ao longo do tempo. Diferencia-se por permitir que a organização agenciadora possa implementar políticas de incentivo à simbiose industrial, influenciando nas decisões rotineiras dos diversos agentes do parque, em prol da simbiose. Empregaram-se estudos de caso, revisão sistemática da literatura e análise teórico-conceitual. Os primeiros resultados foram dois estudos de casos em parques que se autodenominavam EIPs, identificando oportunidades para a promoção da simbiose. O segundo resultado foi a proposta teórico-conceitual do Indicador de Simbiose Industrial (ISI) que pode ser utilizado como instrumento para o ambiente industrial dinâmico. Por fim, apresenta-se a análise das propriedades do indicador a partir de dados obtidos em um dos casos. Os resultados indicaram que o ISI pode identificar níveis de simbiose distintos para um mesmo parque, conforme sua evolução em direção a uma simbiose perfeita. A avaliação da coerência do ISI permitiu demonstrar sua capacidade em captar a ausência e a presença do processo de simbiose, atendendo as expectativas iniciais da construção do indicador. A avaliação do comportamento do ISI por meio da variação dos seus elementos permitiu analisar o indicador sob diferentes possibilidades, correspondendo positivamente às expectativas da pesquisa. Indica-se também várias questões que precisam ser verificadas para a validação do indicador e os próximos passos para torná-lo uma ferramenta útil para o gerenciamento de parques industriais interessados em aprimorar o seu nível de simbiose industrial.

Palavras-chave: Simbiose Industrial, Parque Eco-Industrial (EIP), Organização agenciadora, Sistema dinâmico, Indicador de Simbiose Industrial (ISI). 


\begin{abstract}
The Eco-Industrial Parks (EIP - Eco-Industrial Park) emerged as a new model of spatial organization for industrial arrangements. An important feature for an EIP is the adoption of the concept of industrial symbiosis (IS), in which companies reuse waste to reach a closed system, reducing environmental impact. There are proposals to assess the waste stream and the symbiosis of an EIP through detailed indicators at a determined time. However, it is a static view of the park in which would be possible to the managers implement changes to construct a state of ideal closed system. Recent researches show that this approach faces some limitations, once the process symbiosis depends on the routine and individual decisions of the actors, managers, technicians and agents, which can alter the dynamics of the material flow through time. In order to contribute, it is proposed an different indicator of industrial symbiosis, prepared according to the approach of the park as a dynamic system. This is a tool that can monitor the level of symbiosis of a park during a determined time. This is different because allow the agent organization to implement policies to encourage industrial symbiosis influencing the routines decisions of the park's agents in favor of symbiosis. It was made case studies, systematic review of the literature and theoretical and conceptual analysis. The first results were two case studies in parks that called themselves EIPs, identifying opportunities to promote symbiosis. The second result was the proposed theoretical-conceptual Indicator Industrial Symbiosis (ISI) which can be used as a tool for the dynamic industrial environment. Finally, it shows the analysis of the indicator properties considering data obtained in one of the cases. The results indicated that the ISI can identify different levels of symbiosis for the same park as its evolution toward a perfect symbiosis. The assessment of the consistency of the ISI has demonstrated its ability to capture the absence and presence of the symbiosis process, confirming the expectations of the initial construction of the indicator. The performance evaluation of the ISI through the variation of its elements, allowed us to analyze the indicator under different possibilities, corresponding positively to the expectations of the research. Also, it indicates that several issues need to be checked to validate the indicator and the next steps to make it a useful tool for managing industrial parks interested in improving their level of industrial symbiosis.
\end{abstract}

Keywords: Industrial Symbiosis, Eco-Industrial Park (EIP), Agent Organization, Dynamic System, Indicator of Industrial Symbiosis (ISI). 


\section{LISTA DE FIGURAS}

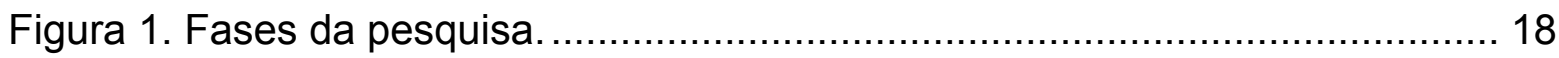

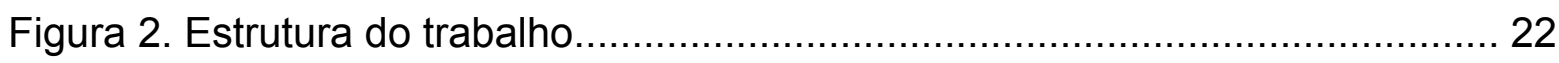

Figura 3. Abrangência da Ecologia Industrial .......................................... 25

Figura 4. Simbiose entre algas e fungos................................................ 26

Figura 5. Comparação entre simbiose industrial ideal e real, respectivamente...... 27

Figura 6. Decomposição de um problema em uma estrutura hierárquica. ............. 41

Figura 7. Construção do Indicador. ........................................................... 58

Figura 8. Integração dos resultados e resultados. ..................................... 59

Figura 9. Usuários do Indicador de Simbiose. ............................................ 68

Figura 10. Esquema do funcionamento do indicador.................................. 70

Figura 11. Decomposição de um problema em uma estrutura hierárquica. ........... 75 


\section{LISTA DE TABELAS}

Tabela 1. Escala fundamental de julgamento em grau de importância. 42

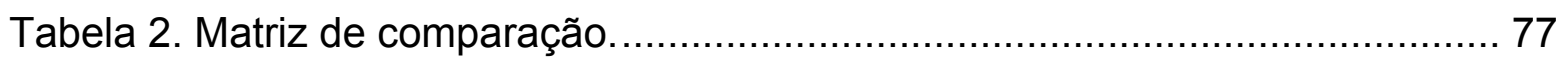

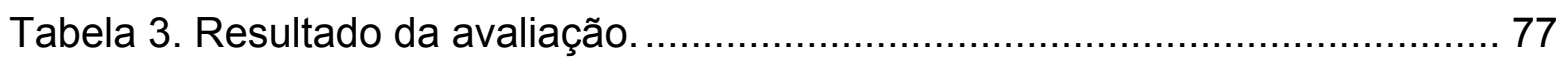

Tabela 4. Avaliação dos critérios para cada resíduo - GRC. ......................... 80

Tabela 5. Valores do cálculo do grau do resíduo circulante. ............................ 81

Tabela 6. Avaliação dos critérios para cada resíduo - GRS. ........................... 81

Tabela 7. Valores do cálculo do grau do resíduo de saída.............................. 81

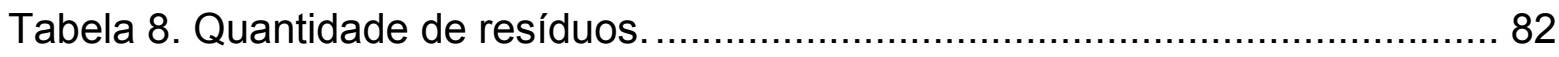

Tabela 9. Situação 1 - Nenhuma simbiose. ................................................ 82

Tabela 10. Quantidade de resíduos circulantes e de saída............................. 82

Tabela 11. Situação 2 - Situação equilibrada.............................................. 83

Tabela 12. Situação 3 - Simbiose perfeita. ............................................. 83

Tabela 13. Cálculo do valor do ISI frente ao aumento em 10\% da QRC............... 85

Tabela 14. Cálculo do valor do ISI frente à diminuição em $10 \%$ da QRC. ............ 85

Tabela 15. Avaliação do comportamento do indicador - Variação da QRC........... 86

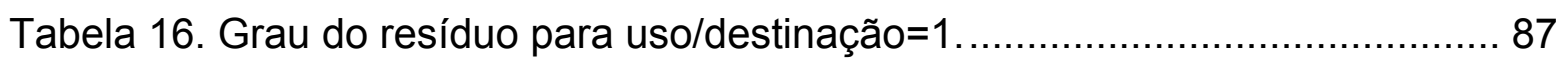

Tabela 17. Avaliação dos critérios para cada resíduo. ................................... 87

Tabela 18. Valores do cálculo do grau do resíduo (circulante e saída)................ 87

Tabela 19. Grau do resíduo para uso/destinação $=3 \ldots \ldots \ldots \ldots \ldots \ldots \ldots \ldots \ldots \ldots \ldots \ldots . \ldots \ldots$

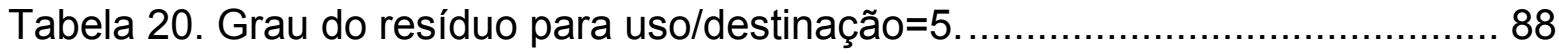

Tabela 21. Cálculo do valor do ISI com o GRC=GRS=1 como mês referência...... 89

Tabela 22. Cálculo do valor do ISI com uso do resíduo= 3 do GRC. .................. 89

Tabela 23. Cálculo do valor do ISI com uso do resíduo= 5 do GRC. ................... 90

Tabela 24. Avaliação do comportamento do indicador - Variação da GRC........... 90

Tabela 25. Cálculo do valor do ISI com destinação do resíduo= 3 do GRS .......... 91

Tabela 26. Cálculo do valor do ISI com destinação do resíduo= 5 do GRS .......... 92

Tabela 27. Avaliação do comportamento do indicador - Variação da GRS........... 92

Tabela 28. Cálculo do valor do ISI frente ao aumento em 10\% da QRS............... 93

Tabela 29. Cálculo do valor do ISI frente a diminuição em 10\% da QRS.............. 94

Tabela 30. Avaliação do comportamento do indicador - Variação da QRS........... 94 


\section{LISTA DE QUADROS}

Quadro 1. Resultado da avaliação dos elementos de um EIP nos casos I e II ...... 47

Quadro 2. Condições para um indicador ideal. ............................................ 54

Quadro 3. Indicadores utilizados para avaliar os benefícios da SI em cada dimensão de análise segundo Kurup e Stehlik (2009). 61

Quadro 4. Indicadores usados para analisar a sustentabilidade do sistema segundo Pakarinen et al. (2010). 62

Quadro 5. Sistema de indicadores aplicados em EIPs segundo Zhu et al. (2010). 63 Quadro 6. Paralelo entre as características ideais de um indicador com os atributos do indicador de simbiose industrial proposto. 67

Quadro 7. Critérios utilizados na variável "Grau do resíduo (circulante e saída)". . 75

Quadro 8. Lista de base de dados utilizada na pesquisa 107 


\section{LISTA DE ABREVIATURAS E SIGLAS}

ACV: Avaliação do Ciclo de Vida

AHP: Método de Análise Hierárquica

DMI: Entrada Direta de Material

DMC: Consumo Doméstico de Material

DPO: Saídas Domésticas de Processo

EDIP: Environmental Design of Industrial Products

EIP: Parque Eco-Industrial (Eco-Industrial Park)

EPA: United States Environmental Protection Agency

GRC: Grau do Resíduo Circulante

GRS: Grau do Resíduo de Saída

ISI: Indicador de Simbiose Industrial

MFA: Análise de Fluxo de Materiais (Material Flow Analysis)

NISP: National Industrial Symbiosis Programme

OECD: Organization for Economic Co-operation and Development

PCSD: President's Council on Sustainable Development

PIB: Produto Interno Bruto

PTB: Balanço Físico de Comércio

QRC: Quantidade de Resíduo Circulante

QRS: Quantidade de Resíduo de Saída

RBS: Revisão Bibliográfica Sistemática

SFA: Análise do Fluxo de Substâncias

SGA: Sistema de Gestão Ambiental

SI: Simbiose Industrial

SNA: Sistema Nacional de Contabilidade

TMC: Consumo Total de Material

TMR: Total Requerido de Material 


\section{SUMÁRIO}

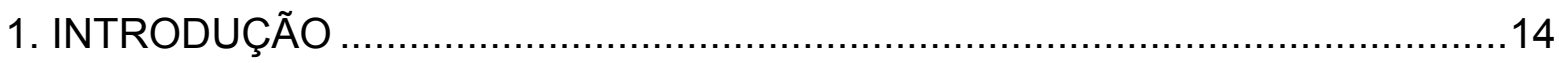

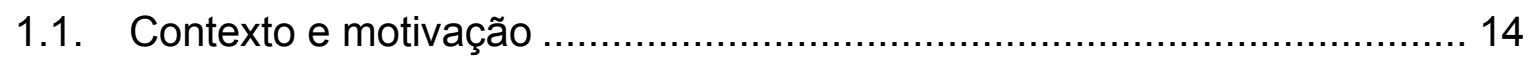

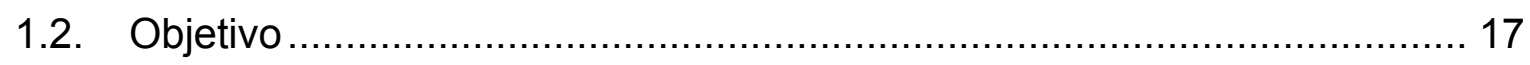

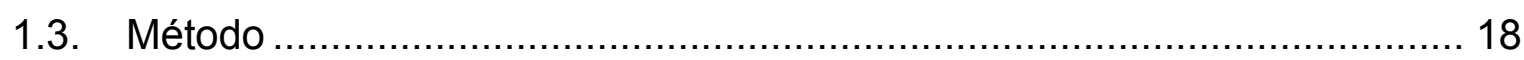

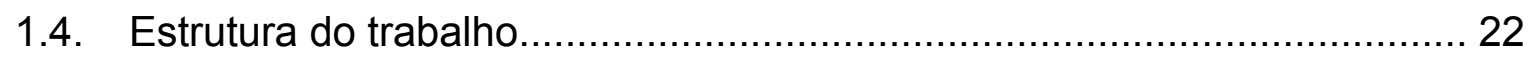

2. O PAPEL DA SIMBIOSE INDUSTRIAL NOS PARQUES ECO-INDUSTRIAIS

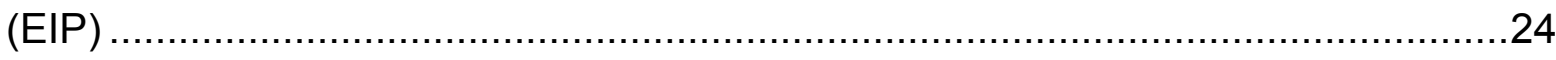

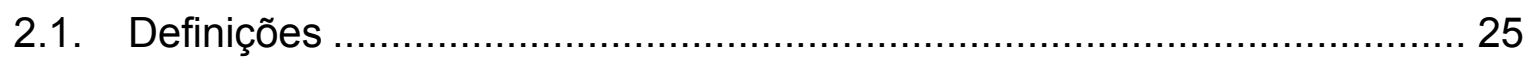

2.2. Auto-organização e Sistemas Dinâmicos Complexos ............................... 30

2.3. Simbiose Industrial e os Impactos Ambientais.......................................... 32

2.4. Métodos empregados em análises de simbiose industrial ....................... 33

2.4.1. Avaliação do ciclo de vida (ACV) .................................................. 34

2.4.2. Análise de Fluxo de Materiais (MFA) ……….................................... 37

2.4.3. Método de análise hierárquica (AHP) …………............................ 40

3. A SIMBIOSE EM DOIS PARQUES INDUSTRIAIS BRASILEIROS .................44

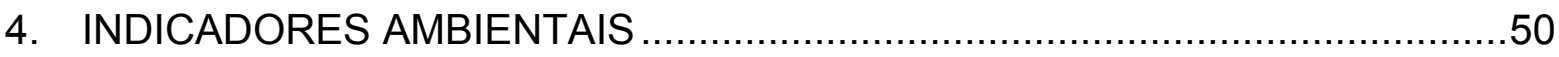

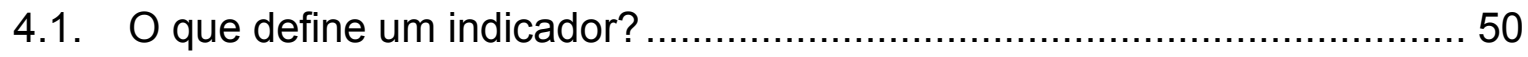

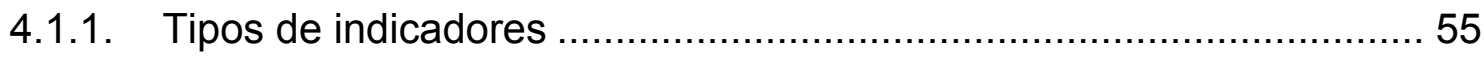

4.1.2. Indicadores de desempenho ambiental ......................................... 56

4.2. Processo de desenvolvimento de Indicadores ambientais ........................5 57

4.3. Indicadores Ambientais na realidade dos EIPs......................................... 60

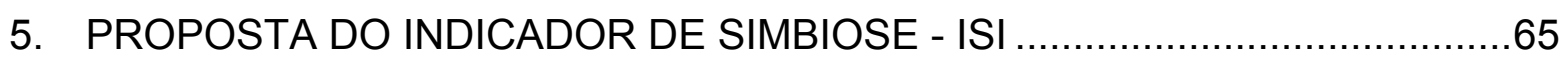

5.1. Princípios e requisitos para um indicador de simbiose para EIP .............. 65

5.2. Papel do indicador de simbiose e a dinâmica do EIP.............................. 68

5.3. Desenvolvimento do indicador de simbiose .......................................... 71 
5.3.1. Conceito geral do indicador ............................................................ 71

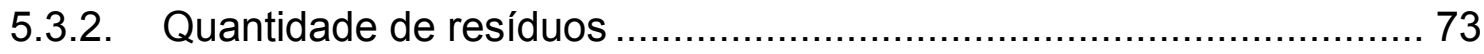

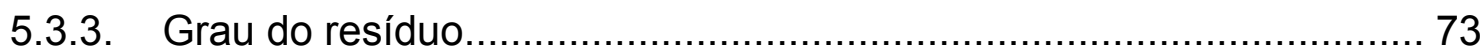

5.3.4. Quantidade de Impacto Circulante (QIC) e Quantidade de Impacto de

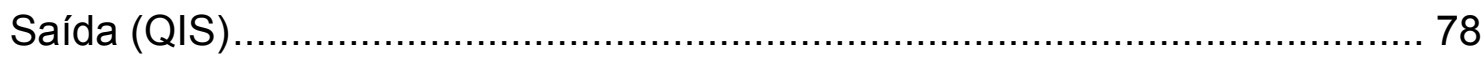

5.3.5. Formulação matemática do indicador .............................................. 78

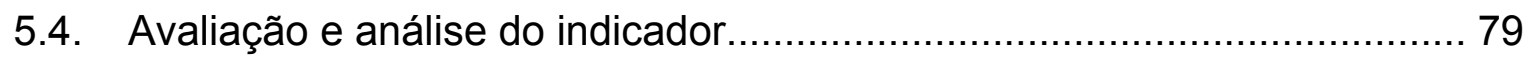

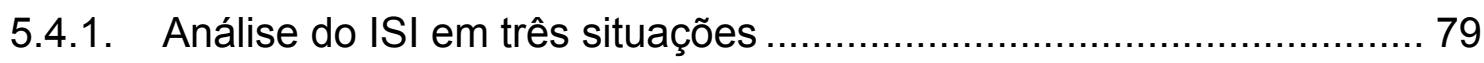

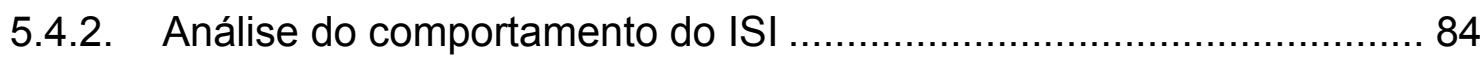

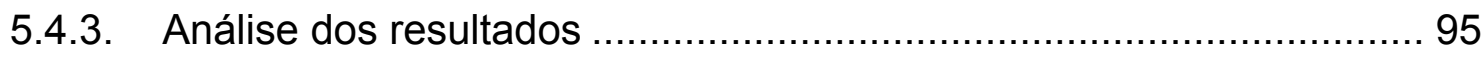

6. CONCLUSÃO E CONSIDERAÇÕES FINAIS …….....................................

6.1. Considerações sobre $\mathrm{o}$ indicador proposto............................................... 98

6.2. Sugestões para futuras pesquisas ........................................................ 99

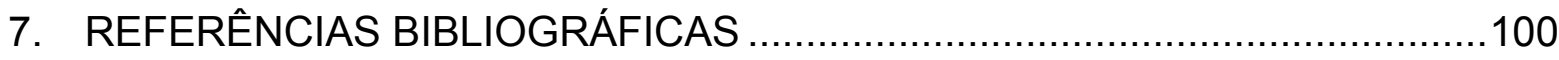

APÊNDICE A: PROTOCOLO DE REVISÃO BIBLIOGRÁFICA SISTEMÁTICA ....107 APÊNDICE B: PROTOCOLO DA VISITA DE CAMPO AO PARQUE

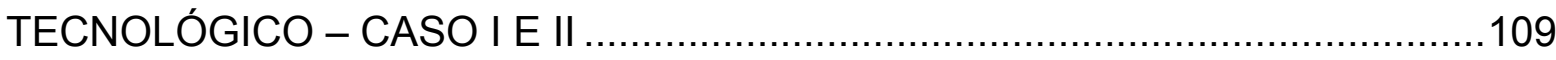

ANEXO A: CRITÉRIOS DE AVALIAÇÃO DO GRAU DO RESÍDUO CIRCULANTE E EXTERNO 


\section{INTRODUÇÃO}

Esta seção apresenta o contexto e motivação (seção 1.1), o objetivo (seção 1.2), o método aplicado (seção 1.3) e a estrutura do trabalho (seção 1.4).

\subsection{Contexto e motivaçÃo}

A mudança no comportamento das empresas e dos consumidores com relação às questões ambientais fez surgir um conjunto significativo de arranjos industriais e parques tecnológicos inseridos num novo contexto de organização espacial, tendo como foco a sustentabilidade.

Os chamados Parques Eco-Industriais (EIP) tem chamado a atenção como uma nova tendência na realidade industrial. $O$ conceito propõe um modelo de organização integrado de negócios empresarias que abrange a ideia de cooperação entre as empresas do parque e o compartilhamento de serviços para redução de custos.

Buscando melhor aproveitamento de subprodutos e o tratamento de resíduos, os EIPs apoiam o desenvolvimento do processo de simbiose industrial (SI), destacando-o como principal atividade a ser desenvolvida num EIP.

A expressão "simbiose" refere-se ao tipo de associação biológica entre seres na natureza que, passando a permutar materiais, energia ou informações, obtém benefícios coletivos maiores que a soma dos benefícios individuais, isto é, dos resultados que obteriam se existissem isoladamente (STARLANDER, 2003).

Análogo ao termo conhecido na Biologia, a Simbiose Industrial (SI) busca a realização de intercâmbio de materiais, energia e água entre empresas, gerando um benefício coletivo maior do que a soma dos benefícios individuais. A SI se apresenta como uma metáfora de um ecossistema industrial que busca imitar um ecossistema natural, onde o ideal seria alcançar o ciclo fechado no sistema.

Existe um interesse mundial pela implantação e desenvolvimento de EIPs. Conforme o instituto Indigo Development (2005), tanto os setores públicos como privados iniciaram mais de 100 (cem) projetos de EIPs pela Ásia, Europa, África, América do Norte, América Latina e Austrália. Nota-se que as iniciativas estão em estágios diferentes de desenvolvimento, devido às disparidades da realidade 
econômica de cada país. Nos países em desenvolvimento, como o Brasil, o governo tem apoiado projetos de construção de novos parques industriais, financiando partes da infra-estrutura. Já em países desenvolvidos e ligados diretamente a atual crise econômica, esta nova tendência trouxe a adaptação de parques industriais existentes, visando transformá-los em EIPs.

Uma questão importante na análise desses projetos é que, de forma geral, eles não adotam todos os elementos que caracterizam um EIP. Peck (2002) revela a ausência de uma metodologia específica que defina o que é um EIP, e aponta que o desenvolvimento de uma definição clara poderia não só manter a sua legitimidade, mas também permitir ao parque adaptações relativas às suas próprias circunstâncias locais. Os parques industriais tem aproveitado esta lacuna para se autodenominarem como EIPs.

Outra questão colocada em pauta diz respeito à ausência de instrumentos que apoiem os sistemas e as práticas de gestão num EIP (ZHU et al., 2010; CHIU; YANG, 2004; SOPHA et al., 2010; OH;KIM;JEONG, 2005) e como consequência, a dificuldade de medir com precisão o desenvolvimento e funcionamento desses parques.

Há vários trabalhos que sugerem o uso de métodos e ferramentas como Avaliação do Ciclo de Vida (ACV), Análise de Fluxo de Materiais (MFA) e indicadores ambientais para caracterizar um EIP, medir o nível de reutilização de resíduos, a eco-eficiência e os impactos ambientais em parques industriais. (GENG,Y et al., 2009; GENG,Y et al., 2012; KURUP, B.;STEHLIK, D., 2009; PAKARINEN,S. et al., 2010). Entretanto, esses esforços apresentam limitações que devem ser consideradas.

As ferramentas possuem características importantes: resultam em números absolutos, são precisos e podem ser comparados entre parques com cálculos distintos. Entretanto, no caso da ACV por exemplo, existe uma grande variação com o uso dos critérios na avaliação dos impactos ambientais, exigindo tempo de análise e dificultando a comparação de séries históricas com a variação dos tipos de impactos.

Este tipo de ferramenta no fundo, reflete uma visão estática segundo Chertow e Ehrenfeld (2012), uma vez que provê um retrato da situação do EIP em um dado momento, permitindo capturar e "congelar" a situação em termos de nível 
de impacto em um EIP em um tempo determinado. Essas propostas permitem também projetar uma situação teórica futura "mais" simbiótica, indicando mudanças em processos e produtos para um conjunto de empresas específicas. A limitação desta abordagem esta na forma de análise do problema, em que o EIP é encarado sob um ponto de vista estático, não permitindo desencadear um conjunto de ações no sentido de promover mudanças no EIP em direção à melhoria da situação identificada. Isto é notado pelos próprios autores das propostas mais recentes, como Wang, Feng e Chu (2013) que admitem a instabilidade como uma barreira grave para o bom desenvolvimento e evolução do processo de simbiose industrial. Além disso, são ferramentas complexas e que exigem tempo para aplicação e análise.

A solução para esta questão, e para o próprio desenvolvimento da área de ecologia industrial, seria abordar os EIPs como sistemas dinâmicos (Chertow e Ehrenfeld, 2012). Segundo esta abordagem, o ambiente industrial é considerado um sistema dinâmico (complexo e adaptativo), composto por empresas e atores cujos objetivos e focos estão constantemente mudando, uma vez que dependem das condições de mercado e buscam conciliar várias questões, como vantagens econômicas e até mesmo desejos pessoais. Abreu, Figueiredo Junior e Varvakis (2002) explicam que as empresas são sistemas abertos e estão sujeitas a mudança de valores e ideologias vigentes na sociedade em que está inserida.

Chertow (2009) expõe que os ecossistemas industriais possuem forte dependência das forças de mercado, sendo sujeitas a transformações rápidas, não-lineares e descontínuas mudanças de direção, e precisam ser vistos como sistemas complexos adaptativos. Para Tuddor et al. (2007) as empresas podem, ao longo do tempo, tomar rumos diferentes e mudar seus objetivos, afetando assim a funcionamento de toda a cadeia, desenvolvendo uma certa "fragilidade" potencial do sistema, uma vez que a relação de dependência entre as empresas não garante, necessariamente, sua sobrevivência, como na simbiose natural. A mudança da empresa para outro parque pode representar maiores vantagens que a condição atual simbiótica pode oferecer. O convívio em parques industriais é uma oportunidade neste sentido.

Diante disso, Chertow e Enrhefeld (2012), Spiegelman (2003) e Sopha et al. (2010) demonstram que um EIP deve ser visto como um sistema complexo, caracterizado pela mudança contínua e constante, seguindo as teorias 
administrativas da área de gestão de mudanças, iniciadas com o trabalho seminal de Brown e Einhardt (1997). Enfim, um EIP deve ser visto como um parque em contínua mudança.

A solução que mais se aproxima deste contexto foi proposta por Zhu et al. (2010). Trata-se da criação de um sistema contendo sete indicadores primários que poderiam ser utilizados para selecionar potenciais empresas a um parque. Estes indicadores poderiam ser utilizados por uma entidade para avaliar empresas candidatas e escolhê-las. Mas há dois problemas com esta proposta: primeiro, ela não garante que a empresa candidata, uma vez escolhida, não venha a modificar o seu perfil de produção e consumo de matéria-prima e resíduos, levando a novos desequilíbrios; o segundo problema é que, entre os indicadores escolhidos pelos autores, há aqueles de impactos ambientais diversos e de reciclagem, mas não se verifica o nível de simbiose entre as empresas.

Conforme observado por Chertow e Ehrenfeld (2012), o desafio é criar ferramentas que tratem a situação de um ponto de vista dinâmico, isto é, que considere a dinâmica dos parques e que seja de simples aplicação.

Uma solução para aprimorar a proposta de Zhu et al. (2010) seria incluir um indicador de simbiose. Ao avaliar o processo, o indicador poderia ser utilizado para a implantação de políticas de incentivo para aumentar o nível de simbiose. A ligação com os outros indicadores poderia fornecer um sistema de avaliação consolidado, tornando o EIP um sistema mais próximo do ideal de ciclo fechado. Assim, além do parque melhorar como um todo o desempenho ambiental, ele poderia estimular mais simbiose entre as empresas.

\subsection{OBjetivo}

Esta dissertação propõe a criação de um indicador de simbiose industrial que sirva como um parâmetro de avaliação da evolução do nível de simbiose de um parque ao longo do tempo, em uma série temporal, tal que possa ser utilizado como instrumento de decisão num ambiente dinâmico para a implantação de políticas de incentivo à simbiose dentro de um determinado parque industrial. 


\subsection{MÉTOdo}

A pesquisa utiliza três procedimentos metodológicos de pesquisa. O primeiro deles é a revisão bibliográfica juntamente com os estudos de casos. O segundo é a revisão bibliográfica sistemática e o terceiro a análise teórica conceitual para a proposição do indicador.

O trabalho está dividido nas seguintes etapas (Figura 1): (1) revisão bibliográfica inicial e estudos de casos; (2) revisão bibliográfica sistemática; (3) estudo sobre indicadores ambientais aplicados à realidade dos EIPs; (4) proposta dos princípios e requisitos do indicador de simbiose industrial; (5) desenvolvimento do indicador de simbiose; (6) avaliação do indicador proposto; (7) análise e síntese dos resultados.

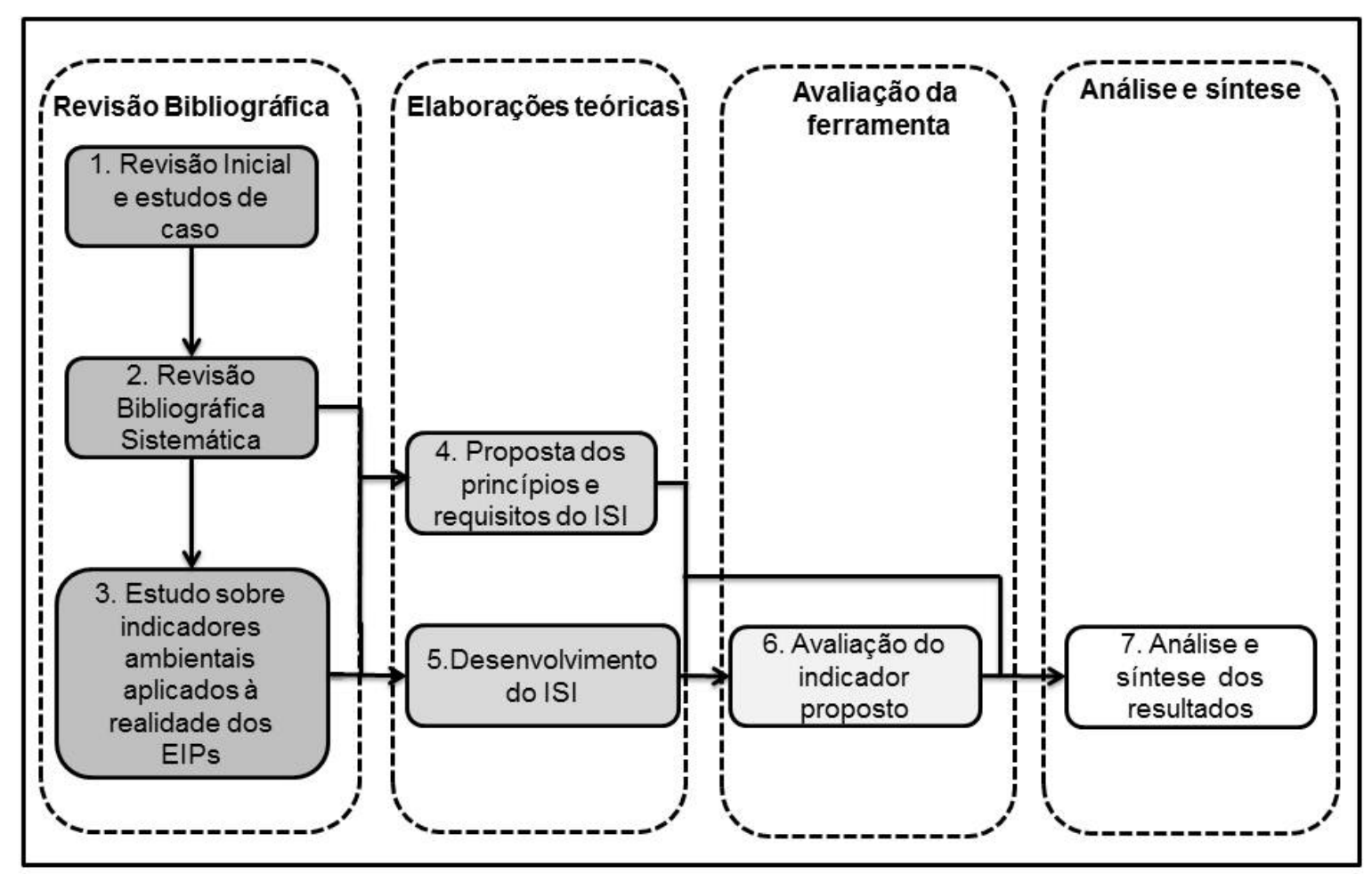

Figura 1. Fases da pesquisa.

(1) Revisão bibliográfica inicial e estudos de casos: o objetivo desta fase foi descrever sobre o tema EIPs, de forma a prover uma estrutura teórica para o trabalho e conduzir a questionamentos e problemas relativos a lacunas teóricas e práticas apropriadas para a construção da presente investigação. Foram identificados, organizados e analisados os principais conceitos e autores na literatura relacionados com o tema, tais como Chertow (2000, 2009, 2012), Côté 
(1998), Cohen (2000), Christensen (1998), Ehrenfeld e Gertler (1997), Gertler (1995), Gibbs e Deutz (2005), Hewes e Lyons (2008), Martin et al. (1996), Lowe (2001) e Jacobsen (2006).

Foram realizados dois estudos de caso em parques que se autodenominavam EIPs, chamados aqui de casos I e II, para analisar se os mesmos apresentavam as características constituintes de um EIP encontradas na literatura e para compreender seus principais problemas e desafios. Foram selecionados parques em estágio inicial de construção para analisar os elementos considerados no planejamento e as ferramentas utilizadas para selecionar as empresas interessadas no parque. Foi elaborado um questionário com o objetivo de descrever o perfil do parque, o processo de atração e inclusão das empresas, o papel do agenciador, a motivação e critérios utilizados para se autodenominar EIP e as principais dificuldades. Os objetivos centrais do questionário foram desdobrados em uma série de catorze perguntas (Apêndice B). Os questionários foram respondidos pelo responsável do Parque após visitas guiadas, onde o pesquisador conhecia as instalações. As principais características dos dois casos foram descritas e, por fim, os resultados comparados com os elementos constituintes de um EIP.

Por meio da pesquisa inicial exploratória e dos estudos de caso, foi possível caracterizar as dimensões de análise do assunto em questão e destacar duas principais lacunas: ausência de uma definição precisa dos elementos que caracterizam um EIP e ausência de instrumentos que apoiem os sistemas e as práticas de gestão num EIP na perspectiva de um sistema industrial dinâmico. Diante disto, notou-se a necessidade de uma revisão bibliográfica sistemática para identificar indicadores ambientais aplicados à EIPs que poderiam suprir tais lacunas.

(2) Revisão bibliográfica sistemática (RBS): o objetivo desta fase foi verificar a existência de indicadores que analisassem, avaliassem ou colaborassem para a gestão de um EIP. Assim, ocorreu a identificação desses indicadores, seguindo a metodologia de RBS de Biolchini et al. (2005). Por se tratar de uma avaliação rigorosa e confiável das pesquisas já realizadas dentro de um tema de pesquisa, a RBS é utilizada como instrumento para mapear e gerar uma síntese dos trabalhos já publicados de um tema especifico (BIOLCHINI et al., 2007). Neste sentido, 
desenvolveu-se um protocolo de revisão bibliográfica sistemática (Apêndice A), o qual definiu critérios para a inclusão/exclusão de artigos, e critérios para a seleção dos indicadores. A intenção foi responder, sobretudo, a seguinte questão: Quais indicadores são utilizados para avaliar, analisar ou colaborar para a gestão de um EIP?

O modelo de RBS adotado nesta pesquisa envolve as seguintes etapas: planejamento, execução e análise dos resultados. Na fase de planejamento são definidos os objetivos da pesquisa, questões de pesquisa e o método adotado na RBS. Dessa fase deriva-se o protocolo de pesquisa. A fase de execução consiste das atividades de busca, seleção e qualificação dos estudos para posterior extração das informações relevantes para o objeto de estudo. Na fase de análise dos resultados são apresentadas as informações provenientes da RBS, estudos selecionados, principais autores, etc.

Dos artigos identificados, foram selecionados para estudo aqueles que abordavam os indicadores ambientais aplicados em EIPs. O resultado da aplicação da RBS está presente na seção 2.4 e 4.3, composta pelos métodos empregados em análises de SI e pelos indicadores aplicados na realidade dos EIPS, respectivamente.

(3) Estudo sobre indicadores ambientais: o propósito desta fase foi revisar os trabalhos fundamentais que abordavam indicadores ambientais aplicados a EIPs. $O$ foco sobre indicadores surgiu para verificar as suas potencialidades no apoio à construção da solução dos problemas encontrados nesta pesquisa de caracterização dos EIPs envolvendo seus principais elementos, e da ausência de instrumentos que apoiem os sistemas e as práticas de gestão, dificultando a avaliação de desempenho do EIP. Além disso, um dos diferenciais do indicador proposto é que analisa tendências e relações de causa e efeito, podendo ser utilizados para avaliar o desempenho e o gerenciamento dos negócios, para verificar se a empresa está realizando os objetivos e metas estabelecidos e/ou para estabelecer comparações dentro do mesmo setor, e por ser um método possível de suprir as lacunas apresentadas neste trabalho.

Ao final do estudo, identificou-se a necessidade do desenvolvimento de um indicador específico que caracterizasse o EIP por meio da seleção de um processo fundamental e avaliasse seu desempenho ao longo de uma série temporal. 
(4) Proposta dos princípios e requisitos do ISI: nesta fase foi possível estruturar o modelo conceitual do indicador de simbiose. O propósito aqui foi delinear as características do indicador por meio da elaboração de princípios e requisitos, direcionada pela RBS. Primeiramente, definiu-se o processo de simbiose industrial como o elemento fundamental do indicador e de caracterização do EIP, consequentemente, criou-se o nome da ferramenta escolhida: Indicador de Simbiose Industrial (ISI). Em seguida, definiu-se o papel do indicador num EIP, bem como a forma de utilização para os diferentes usuários envolvidos, e a dinâmica do funcionamento da ferramenta.

(5) Desenvolvimento do ISI: o propósito desta fase foi desenvolver a estrutura matemática do indicador de simbiose industrial baseado no processo proposto por Cardoso (2004) e Martínez (2009). Foram definidas as variáveis de investigação envolvidas no indicador e em seguida, sua formulação matemática.

(6) Avaliação do indicador proposto: o propósito desta fase foi averiguar a aplicabilidade do indicador proposto diante de diferentes situações, com dados reais de quantidade de resíduos. Esta fase foi desdobrada em dois objetivos: avaliar a coerência do ISI em situações de simbiose e não simbiose, e avaliar seu comportamento diante de diferentes variações.

O exemplo de aplicação pode ser classificado como descritivo com elementos de estudo exploratório. As pesquisas descritivas objetivam a descrição de determinado fenômeno, estabelecendo relações entre as variáveis e levantar opiniões e atitudes de uma população; enquanto as pesquisas exploratórias visam um entendimento maior do problema, para o aprimoramento de ideias (GIL,2010).

(7) Análise e síntese dos resultados: o propósito desta fase foi analisar e sumarizar os resultados obtidos na avaliação do ISI, para identificar se as respostas proporcionadas podem contribuir para a análise de desempenho do processo de SI e para a tomada de decisão dos organismos gestores quanto ao incentivo de políticas de aplicação no EIP. Além disso, analisaram-se as limitações da pesquisa e propôs-se trabalhos futuros com a intenção de solucionar algumas dessas restrições. 


\subsection{Estrutura do tRABALHO}

O trabalho está estruturado em sete capítulos, de acordo com a Figura 2 e conforme a descrição a seguir.

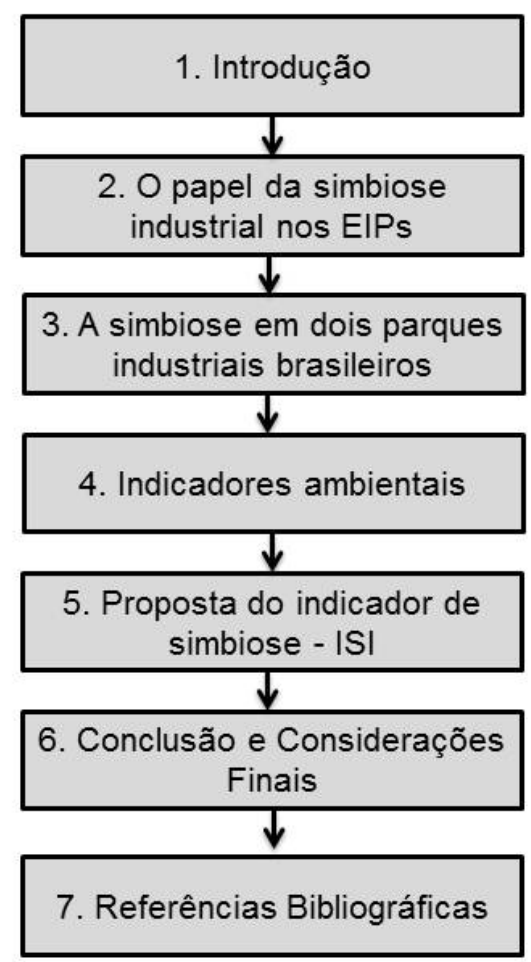

Figura 2. Estrutura do trabalho

Capítulo 1. Contextualiza e introduz o problema de pesquisa, justificando-o e delimitando-o. Apresenta os objetivos e o método utilizado durante a pesquisa. Finaliza com a apresentação estrutural que apoiará o desenvolvimento do trabalho.

Capítulo 2. Apresenta uma síntese da literatura sobre Parques EcoIndustriais e o processo de Simbiose Industrial, bem como as definições utilizadas, os paradigmas encontrados relacionados aos EIPs e as dimensões que o tema abrange. Em seguida, são apresentados os métodos empregados em análises de SI que colaboraram para a construção teórica-conceitual do ISI.

Capítulo 3. Apresenta estudos de caso em dois parques industriais brasileiros que se autodenominam EIPs. Os elementos que compõem os parques são analisados criticamente e comparados com as características constituintes de um EIP encontrados na literatura.

Capítulo 4. Apresentam as definições de indicadores ambientais, bem como os tipos e categorias, e mais especificamente, sobre indicadores de desempenho. 
São descritos os procedimentos relacionados ao desenvolvimento de indicadores ambientais, conforme indicado nos trabalhos revisados. Ao término, é apresentado parte do resultado da RBS, ou seja, os indicadores ambientais encontrados na literatura aplicados à realidade dos EIPs.

Capítulo 5. Apresenta a proposta do ISI por meio da descrição dos princípios e requisitos do indicador, da definição seu papel num EIP, bem como a forma de utilização para os diferentes usuários envolvidos, e da descrição da dinâmica do funcionamento da ferramenta. Apresenta-se o desenvolvimento da estrutura do indicador, por meio da definição das variáveis de investigação envolvidas, da sua formulação matemática e da avaliação da aplicabilidade do indicador proposto diante de diferentes situações e variações. Por fim, são analisados os resultados da aplicação do ISI.

Capítulo 6. Apresenta as conclusões do trabalho. Mostra a análise dos resultados obtidos na avaliação do indicador, as limitações da pesquisa e proposta de trabalhos futuros. 


\section{O PAPEL DA SIMBIOSE INDUSTRIAL NOS PARQUES ECO- INDUSTRIAIS (EIP)}

Os ciclos e os fenômenos naturais sempre foram fontes de inspiração para o desenvolvimento de utilidades e tecnologias frente às necessidades humanas. A criação de termos metafóricos tentando conectar o real e o artificial tornou-se uma estratégia comum entre os cientistas.

A Ecologia industrial (EI) surgiu para conciliar o desenvolvimento industrial às questões ambientais. A célebre lei da conservação da matéria criada por Antoine Lavoisier "na natureza nada se cria, nada se perde, tudo se transforma" representa a ideia proposta por este campo.

Proposta por Frosh e Gallopoulos (1989), o campo tem como objetivo fundamental transformar a lógica das atividades industriais em um modelo mais integrado, semelhante aos fluxos cíclicos dos ecossistemas naturais proposto por Lavoisier. Esta integração surgiu em meio a mudanças no comportamento das empresas e dos consumidores com relação às questões ambientais e a nova visão da formação de um ciclo fechado.

Lifset e Graedel (2002) apontam a analogia biológica, a perspectiva dos sistemas e o papel das empresas, como parte dos elementos centrais da El. Costa (2002) explica que a reestruturação dos sistemas industriais em direção à sustentabilidade ambiental deveria ter como base os princípios organizacionais dos ecossistemas naturais, onde existe a reciclagem dos materiais, a interdependência das espécies e a utilização solar como fonte energética. Segundo o autor, o objetivo da El é analisar os processos industriais do parque de forma integrada para buscar a otimização do fluxo energético e dos materiais. Ayres (1994), ao comparar os dois sistemas, traça um paralelo entre os ecossistemas naturais e industriais afirmando que cada unidade industrial deveria agir como "um ser vivo" no ambiente natural.

A ecologia industrial pode ser abordada de três formas diferentes, dependendo da abrangência de atuação, como mostra na figura 3 a seguir. 


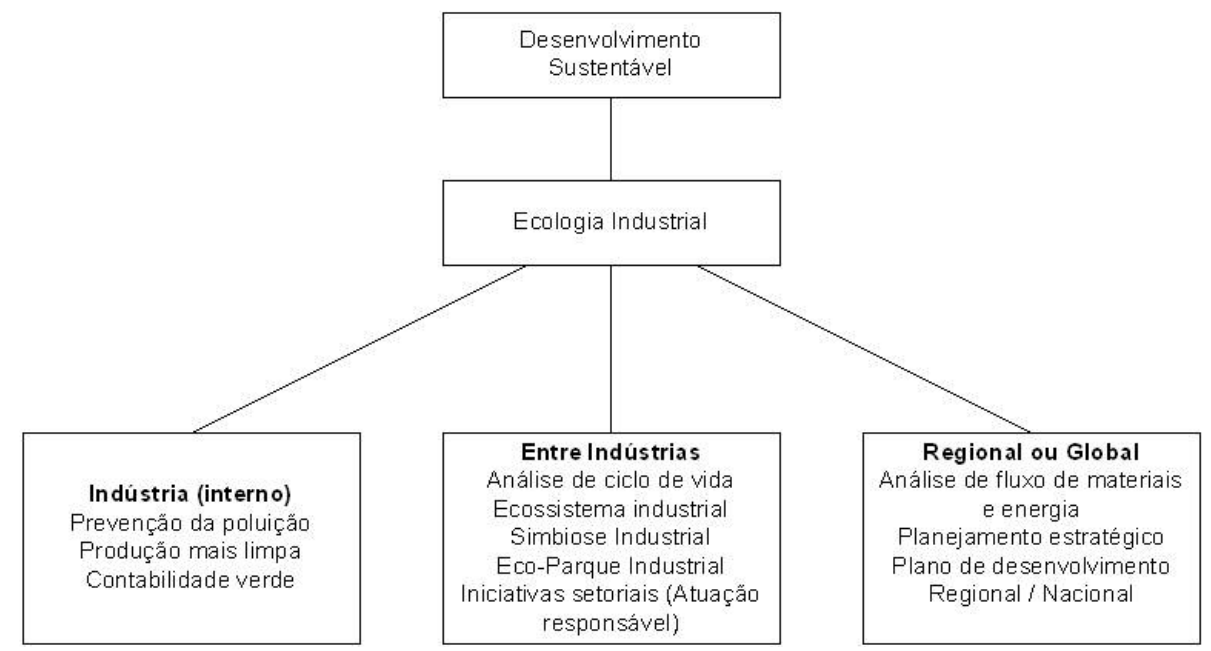

Figura 3. Abrangência da Ecologia Industrial Fonte:Chertow (2000)

Os Parques eco-industriais e o processo de simbiose industrial inserem-se no campo da El como ferramentas fundamentais, na medida em que integram harmonicamente a visão do ciclo fechado num ecossistema empresarial.

Neste capítulo são analisados estes dois conceitos, bem como as definições mais utilizadas neste campo de estudo, os temas que abrangem estas ferramentas e os métodos utilizados em análises de SI.

\subsection{Definições}

O termo biológico simbiose foi utilizado pela primeira vez pelo Botânico Alemão Anton de Bary por volta de 1873 para descrever a relação de associação entre algas e fungos, que resultava no desenvolvimento dos líquens. A relação de mutualismo entre os seres garantia sua sobrevivência. Os fungos revestiam e protegiam as células das algas, e as mantinham hidratadas, por absorverem com facilidade grandes quantidades de água. As algas, por sua vez, produziam nutrientes para os fungos por meio da fotossíntese.

A relação entre os fungos e algas formando os líquens é um exemplo clássico de relacionamento simbiótico, onde juntos, completam-se. A alga aproveita os resíduos das funções vitais dos fungos na forma de um revestimento que lhe garante proteção e hidratação. Os fungos, por sua vez, aproveitam-se dos resíduos das algas para sua nutrição. Isso cria um sistema fechado que os mantêm vivos, beneficiando-os mutuamente, conforme esquematizado na Figura 4. 


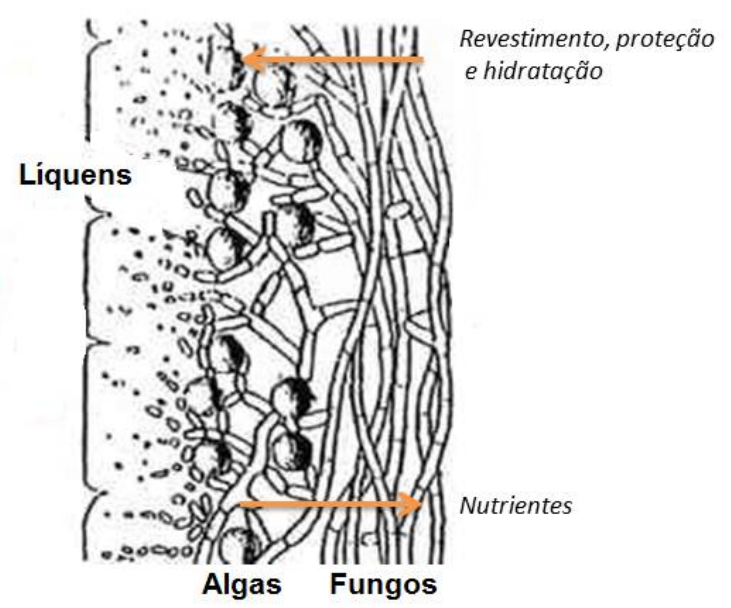

Figura 4. Simbiose entre algas e fungos. Fonte: jmelobiologia.zip.net

A simbiose industrial é a aplicação deste conceito na relação entre as empresas. A ideia é a de um ambiente onde uma empresa se aproveita dos resíduos gerados pela outra. Propõe-se então um sistema fechado na realidade industrial.

A SI é tratada aqui, como um processo, uma vez que ela proporciona uma análise longitudinal da ação, exigindo um período para se desenvolver, conforme esclarecido por Boons, Spekkink e Mouzakitis (2011).

A proposta de um sistema fechado na realidade industrial engloba um grande paradigma especificamente no processo de Simbiose Industrial. Considerada simbiose natural perfeita, a relação entre os fungos e algas formando os líquens, é permanente e garante a sobrevivência de cada um deles. Seguindo o mesmo raciocínio natural, a SI ideal deveria formar um ciclo fechado reutilizando o máximo de resíduos possíveis.

Diferentemente da realidade natural simbiótica dos líquens, a relação de dependência entre as empresas de um parque por meio da simbiose, não garante, necessariamente, a sobrevivência delas. A mudança da empresa para outro parque pode representar maiores vantagens que a condição atual simbiótica pode oferecer.

A Figura 5 apresenta uma comparação entre o processo de simbiose industrial real e o ideal. 

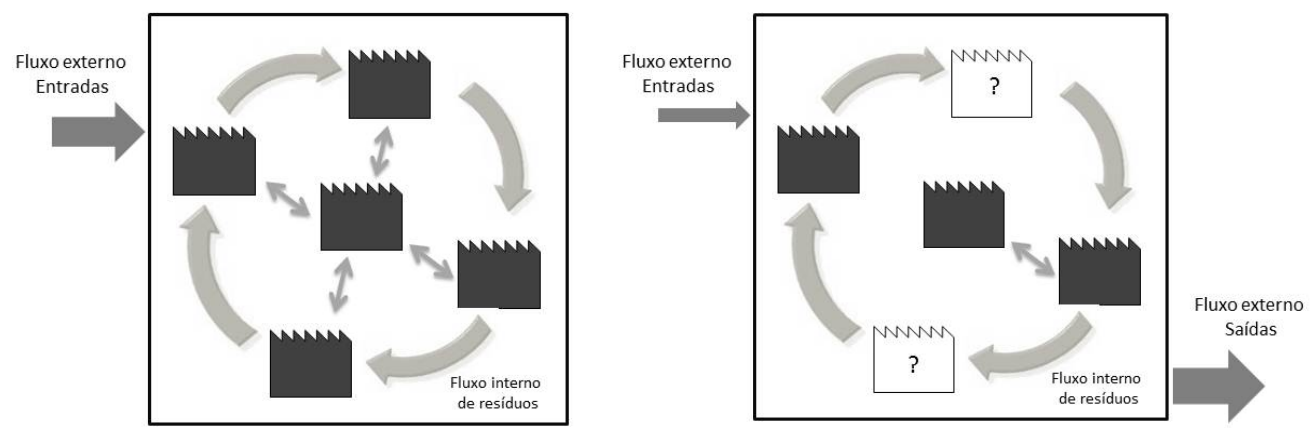

Figura 5. Comparação entre simbiose industrial ideal e real, respectivamente.

$\mathrm{Na}$ SI ideal as empresas participantes, de maneira integrada, formam um ciclo fechado, garantindo a reutilização dos resíduos no interior do parque, sem fluxos de saída. Na SI real, a maior dificuldade enfrentada pelos gestores é a integração total das empresas componentes do EIP, uma vez que nem todas participam das trocas de materiais ou mesmo compartilham serviços. Assim, o sistema torna-se deficiente quanto ao equilíbrio das entradas e saídas, representadas na Figura 5 por setas de diferentes espessuras.

Segundo Chertow (2000), a SI conta com o envolvimento de indústrias tradicionalmente separadas em uma abordagem coletiva para a vantagem competitiva envolvendo intercâmbio físico de materiais, energia, água e subprodutos. A autora considera a colaboração e as possibilidades de sinergia oferecidas pela proximidade geográfica fatores chaves para o processo de SI.

Para Pereira et al. (2007), a SI está baseada em três pilares:

- Informação geográfica, ou seja, informações sobre a localidade e região que está situada a empresa;

- Informação organizacional, ou seja, acesso a informações sobre as atividades da empresa e sua atuação no mercado;

- Informação sobre processos, ou seja, conhecimento sobre as atividades produtivas das empresas e como são seus processos.

A conexão entre os pilares dá suporte e favorece as relações de intercâmbio, destacando os três aspectos relevantes para o desenvolvimento da SI.

Um ambiente propício para o surgimento da simbiose são os parques industriais, formado por indústrias carentes dessa visão proposta pela Ecologia Industrial.

O exemplo clássico de EIP é o caso de Kalundborg, na Dinamarca, onde o termo simbiose industrial foi utilizado pela primeira vez. O processo surgiu de 
maneira voluntária e auto organizada entre as indústrias, formando um sistema altamente integrado. O caso não ofereceu um modelo tecnológico a ser seguido, mas serviu como uma inspiração para outras comunidades. Existem alguns exemplos de EIPs como em Baltimore - Maryland (GIBBS E DEUTZ,2005), Cape Charles - Virgínia(ESPEY et al., 1995), Brownsville - Texas (MARTIN et al., 1996), Chattanooga - Tennessee(KAZEMERSKY E WINTERS, 1999), Rotterdam Holanda (BAAS, 1998), Forth Valey - Escócia (HARRIS E PRITCHARD, 2004), Tampico - México (YOUNG, 1999) e Guitang Eco-park - China(ZHAOHUA W.;BIN Z.;GUILONG L., 2010). Estes autores admitem que as mudanças de mercado podem influenciar negativamente as relações simbióticas, sendo este o principal obstáculo e risco.

O President's Council on Sustainable Development - PCSD ${ }^{1}$, no documento Sustainable America: A New Consensus for Prosperity, Opportunity, and a Healthy Environment, de 1996, definiu EIP como um grupo de negócios integrados à comunidade para compartilhar eficientemente recursos (materiais, água, energia, infraestrutura, habitat e informações), incrementar a prosperidade econômica e desenvolver o meio ambiente.

A United States Environmental Protection Agency - EPA conceitua EIP como sendo uma comunidade de indústrias e negócios de serviços que objetivam aumentar o desempenho ambiental e econômico, por meio da gestão colaborativa do meio-ambiente e dos recursos. A comunidade de negócios, trabalhando em cooperação, procura produzir um benefício coletivo maior do que a soma dos benefícios individuais de cada empresa caso estas aperfeiçoem suas performances isoladamente. Utilizando os princípios da ecologia industrial, a comunidade empresarial trabalha em conjunto para se tornar um ecossistema industrial.

O instituto Indigo Development apresenta um conceito semelhante aos do PCSD e da EPA, contudo mais completo. O conceito é o mais aceito internacionalmente e foi formulado por uma equipe de pesquisadores da Universidade de Dalhousie e da Universidade de Cornell.

De acordo com o Indigo Development (2005), um parque eco-industrial é:

"(...) uma comunidade de indústrias, negócios e serviços situados em uma propriedade comum. Seus membros buscam o melhor desempenho ambiental, econômico e social

\footnotetext{
${ }^{1}$ Entidade criada em 1993 na administração Clinton para desenvolver estratégias de ação para o desenvolvimento sustentável.
} 
através da cooperação e gerenciamento ambiental e dos recursos naturais. Trabalhando junto, a comunidade de negócios procura um benefício coletivo que seja maior do que a soma dos benefícios individuais que cada empresa obteria se somente aperfeiçoasse seu desempenho individual." (INDIGO DEVELOPMENT, 2005).

O termo EIP pode incluir muitas metas ecologicamente desejáveis, como mecanismos para reduzir os impactos ambientais globais, economizar energia e materiais, e promover a cooperação, a eficiência de recursos e a gestão ambiental. EIPs tem sido visto como uma oportunidade para as empresas reduzirem seus resíduos, recuperarem valores e alcançarem economias de escala nos seus processos produtivos. Seuring (2001) constatou que o aumento da concorrência no mercado internacional tem sido um dos principais motores para o estabelecimento de EPIs.

Os temas SI e EIP se entrelaçam na medida em que o processo de SI é considerado uma das principais atividades a ser desenvolvida num EIP. Com base na investigação minuciosa de treze projetos que foram realizadas por grupos de alunos durante o período de dois anos, Chertow (1999) afirmou que os EIPs são uma parte da simbiose industrial, destacando-a como característica fundamental. Agarwal e Strachan (2006) sugerem que o EIP seja um subconjunto de simbiose industrial.

Um fator determinante para o sucesso de um EIP é a determinação de uma organização para gerenciar o EIP, conhecido como "agenciador", cujo papel é o de introduzir o conceito de simbiose industrial e fomentar esta prática. Além disso, ele é responsável em atrair empresas viáveis e ganhar a cooperação de todas as agências reguladoras. Segundo Massard e Erkman (2007), a função dele é informar os agentes econômicos na questão da eficiência dos recursos e intercâmbio de resíduos, promovendo a partilha de experiências sobre a gestão do fluxo, identificando, avaliando e implementando a potencial SI. Porém, o desafio mais significativo está em planejar um EIP com flexibilidade suficiente para alcançar a longevidade. Para Martin et al. (1996) o sucesso de uma EIP pode ainda depender das indústrias envolvidas, da localização da EIP, do perfil econômico da região, da abertura dos participantes locais para uma nova estratégia de desenvolvimento, do ambiente legislativo e político local, e da vontade da comunidade empresarial em trabalhar em conjunto. 
O esclarecimento das vantagens da SI é essencial na formação dos Parques Eco-Industriais, pois funciona como atrativo para implantação do processo nesses ambientes. Benefícios como a redução na utilização de materiais virgens, redução da poluição, redução de custos com transporte de matérias-primas e de gerenciamento de resíduos, maior participação da comunidade, marketing verde, sustentabilidade, aumento da eficiência energética, aumento da quantidade e tipos de saídas de processo com valor de mercado são reconhecidos por muitos autores como Chertow e Lombardi (2005), Geng et al. (2009), Lowe (2001) e Tudor et al. (2007).

\subsection{Auto-organização e Sistemas DinÂmicos Complexos}

Costa et al. (2010) argumentam que o desenvolvimento da simbiose industrial depende de todo um contexto formado por aspectos estruturais, culturais, políticos, espaciais e temporais. Os autores consideram a auto-organização como uma estratégia mais viável para o desenvolvimento da simbiose industrial.

Com base nas descobertas e avaliações do NISP (National Industrial Symbiosis Programme) no Reino Unido por Mirata (2004), observou-se que na abordagem top down os órgãos de coordenação e políticas governamentais podem promover ou impedir o desenvolvimento da simbiose industrial. Hewes e Lyons (2008) contam que Jorgen Christensen (antigo Facility Manager da Usina Asnaes, empresa âncora do processo de SI em Kalundborg), ao tentar implantar um sistema EIP na Ucrânia, seguiu a abordagem top-down, onde foram reunidos altos funcionários do governo em seu projeto, porém os participantes eram movidos mais pela satisfação pessoal que pelo desejo de desenvolver um projeto bem sucedido de EIP. Como resultado, ele alterou sua estratégia de desenvolvimento local através da abordagem bottom-up, estimulando a auto-organização entre as indústrias.

A fim de promover um processo interativo capaz de integrar as contribuições de cada abordagem, Costa e Ferrão (2010) sugeriram a chamada abordagem middle-out. O conceito tem como objetivo criar um contexto favorável para o desenvolvimento de SI através de um processo de feedback que possa orientar os agentes envolvidos em suas ações. À medida que decisões são tomadas, os efeitos são observados e geram-se informações que são enviadas de volta para os 
agentes. Assim, estes podem introduzir ou reajustar suas intervenções. Por meio de um processo interativo entre o governo, as indústrias e as outras instituições, estes atores são estimulados a alinhar as suas estratégias individuais às estratégias dos negócios integrados. Para que essa abordagem de middleout tenha sucesso no estímulo das sinergias é importante que os contextos nacionais e locais sejam estudados, assim como é preciso identificar quais são os principais agentes que devem estar envolvidos e também quais são as intervenções esperadas. Em seguida, o monitoramento das ações e dos impactos deve resultar em feedbacks que auxiliem os agentes nas próximas intervenções.

O modelo de auto-organização proposto por Chertow (2007) admite que as decisões de troca de recursos pelos atores privados, surgem pelo interesse em reduzir custos, aumentar a renda e expandir os negócios, sendo que a consciência do processo de SI é adquirida ao longo do tempo.

A auto-organização está intimamente ligada aos sistemas dinâmicos complexos. Chertow e Ehrenfeld (2012) revela que estes sistemas têm como característica fundamental a formação de estruturas estáveis com links interativos que passam energia, material e informações entre as entidades de componentes diversos. Por se tratar de um sistema dinâmico, o processo de SI necessita de ferramentas flexíveis, que se adaptem as possíveis mudanças do processo. Assim, a autora defende a aplicação dos sistemas adaptativos complexos como principal estratégia adotada pelos ecossistemas industriais robustos.

O método sobre sistemas dinâmicos foi desenvolvido pela primeira vez em 1950 por Jay W. Forrester (STERMAN, 2000) para a compreensão do comportamento dinâmico de sistemas complexos ao longo do tempo. Sopha et al. (2010) afirmam que os loops de feedback internos e os atrasos afetam o comportamento de todo o sistema e os sistemas relacionados, evoluindo para um modelo não linear, os sistemas dinâmicos.

Gertler (1995) afirma que, quando o EIP é totalmente planejado, as indústrias que ali se instalam estão cientes dos princípios e diretrizes a serem seguidos e estão dispostas a cooperar e a desenvolver parcerias umas as outras. Ainda para o autor, a possibilidade de ocorrerem sinergias entre as indústrias deve ser prevista ainda na etapa de planejamento, permitindo assim maior flexibilidade e, integração e cooperação entre indústrias de forma muito mais natural. 
Contraponto a esta ideia, Chertow e Ehrenfeld (2012) apresenta um modelo robusto reunindo a teoria dos sistemas adaptativos complexos em vez de um sistema central planificado que tenta predeterminar inquilinos. O modelo foca na evolução da SI voltado para o aspecto organizacional, considerando a conscientização dos atores envolvidos como principal fator de análise. O modelo é composto por três estágios, partindo da auto-organização dos participantes do EIP até a construção de uma entidade institucional.

Segundo Wang, Feng e Chu (2013) a estabilidade de um sistema de simbiose industrial pode ser definido de duas diferentes maneiras. Na primeira delas, a estabilidade é encarada como resistência às alterações externas. Na outra forma de análise, a estabilidade do sistema é expressa como resiliência, ou seja, mostra a sua capacidade de recuperar de perturbações externas e de reparar danos provocados pelas forças externas.

Para Spiegelman (2003) o quadro dos sistemas complexos pode adicionar profundidade e sofisticação ao campo da Ecologia Industrial, propondo uma nova vertente de estudo. O autor enfatiza que os sistemas industriais não devem ser vistos apenas com o objetivo de atingir os ecossistemas naturais, mas como sistemas dinâmicos.

Sopha et al. (2010) consideram o processo de simbiose industrial como um sistema complexo, com um grande número de componentes que interagem entre si, cuja a atividade de agregação é não-linear e, tipicamente, apresenta uma autoorganização hierárquica. Mesmo assim, contrariando a ideia de Chertow e Ehrenfeld (2012), os autores insistem na necessidade do planejamento e gerenciamento do EIP propondo uma modelagem e simulação destes sistemas complexos para apoiar a tomada de decisão do processo e compreender os comportamentos das interações.

\subsection{Simbiose IndUStRIAL E OS ImpaCtos AmbientaIS}

O desenvolvimento de EIPs procura incentivar as empresas individuais ao longo da cadeia de abastecimento para reduzir os impactos ambientais por meio de inovação tecnológica, substituição de materiais, e encontrar alternativas para disposição de subproduto por meio de relações de intercâmbio com outras empresas. 
A implantação de EIPs auxilia as empresas participantes a alcançarem seus objetivos ambientais, uma vez que toda sua estrutura e forma de gestão direcionam os envolvidos a um novo modelo de organização integrado que visa, através de suas ações sustentáveis e processos de simbiose industrial, reduzir os impactos ambientais.

Segundo Boeri e Longo (2011), o modelo de produção das empresas participantes do EIP baseia-se nos princípios de baixo de impactos ambientais, assegurada através do planejamento de infraestrutura, do controle da poluição ambiental e da visão do ciclo fechado no ambiente industrial. É de extrema importância que cada empresa individualmente, tenha consciência ambiental e procure utilizar métodos e ferramentas que apoiem a produção mais limpa, alinhando seus objetivos aos do EIP.

O modelo eco-friendly citado pelos autores, sugere que o desempenho ambiental dos EIPs sejam monitoradas por um agente gestor, responsável por coordenar a implementação de um plano ambiental relacionada ao benefício comum de todas as empresas. Dentre as ações de planejamento ambiental estão, por exemplo, implementar a reciclagem de resíduos, tratar os efluentes, e administrar as redes de iluminação e água, ou seja, administrar os aspectos que estão ligados aos uso de infraestrutura comuns.

O desenvolvimento da qualidade ambiental desses ambientes pode oferecer economia de custos, infraestrutura e serviços em comum, uma gestão ambiental compartilhada e redução de custos para o fornecimento de energia.

Tratando-se de simbiose industrial, é sabido que a grande vantagem em termos de impacto ambiental é a diminuição de saída de resíduos do parque para a natureza. Entretanto, isso não significa, necessariamente, menos impacto ambiental. Por exemplo, se as empresas produzirem produtos de alto impacto ambiental ou se revelem de consumo supérfluo ou desnecessário, o impacto do parque como um todo poderia ser grande, mesmo havendo simbiose perfeita, isto é, o parque diminuiu o descarte do resíduo com o reuso, mas mesmo assim os produtos gerados por essas empresas estariam gerando grande impacto.

\subsection{MÉtodos EMPREgAdos EM ANÁLISES DE SIMBIOSE INDUSTRIAL}


Os métodos descritos nesta seção foram encontrados de artigos da revisão bibliográfica inicial e revisão bibliográfica sistemática, e foi dada importância pela potencial contribuição desses métodos na construção teórica-conceitual do ISI.

\subsubsection{Avaliação do ciclo de vida (ACV)}

Segundo a ABNT (2001), ACV é uma técnica para a compilação e a avaliação das entradas, das saídas e dos impactos ambientais potenciais de um sistema de produto ao longo de seu ciclo de vida.

Ardente et al. (2010) aplicaram a metodologia de ACV em um estudo de caso num eco-industrial cluster no sul da Itália a fim de determinar a possibilidade de alcançar o processo de SI. Neste estudo de caso, os autores verificaram que a reciclagem do polipropileno (PP) para estofado de carro reduziria significativamente o impacto local (consumo de matérias-primas e geração de resíduos) e o impacto global (efeito estufa e as emissões de gases acidificantes), a partir da comparação entre a utilização de polipropileno virgem, de 50\% de PP reciclado e de $90 \%$ de PP reciclado. O uso de polipropileno reciclado, utilizado nos cenários 2 e 3, mostrou uma grande diminuição no consumo de energia, sendo no cenário 3 , onde foi utilizado $90 \%$ de material reciclado, em que o consumo de energia diminuiu em até um terço. Quanto ao transporte, sua contribuição foi muito baixa, sugerindo que o material reciclado poderia ser ainda coletado de empresas que estão distantes, mantendo-se quase inalterado o equilíbrio do ciclo de vida do consumo de energia e das emissões de gases de efeito estufa. Os autores apontam também a vantagem econômica, uma vez que os custos de resíduos diminuíram. Ardente et al. (2010) sugerem que mais estratégias poderiam ser incentivadas pela disseminação de informações ambientais em todos os níveis (público, autoridades, empresas, usuários) e poderia incentivar a produtores a recolher, partilhar e comunicar dados quantitativos e qualitativos sobre a sua gestão ambiental. Segundo Ardente et al. (2010), o processo de SI está relacionado com integração de dados e cooperação entre os atores envolvidos, exigindo uma abordagem multidisciplinar na tomada de decisão. Portanto, a ACV pode representar a ferramenta de condução e de metodologias do processo de SI.

Eckelman e Chertow (2009) e Mattila et al. (2010) utilizaram a ACV para quantificar e analisar os benefícios ambientais da reutilização de subprodutos, mais 
especificamente, utilizando a base de dados do inventário do ciclo de vida como fonte de dados. Foi avaliada a diferença de impactos ambientais entre a reutilização de materiais e produção de material virgem, constatando que o uso de materiais secundários para a produção tem menos impactos ambientais no ciclo de vida do que o uso primário (ou materiais virgens), uma vez que o primeiro já está parcialmente refinado. Eckelman e Chertow (2009) destacam que existem algumas barreiras para a reutilização de subprodutos, como resíduos contaminados, em que a única opção é a deposição em aterro sob uso de tecnologias, além do fato de existirem perdas inevitáveis quando ocorre a recuperação e reprocessamento de materiais. Em outros casos, a quantidade de resíduo pode exceder em muito a capacidade de reutilizá-lo. Outra barreira diz respeito à legislação local, que pode possuir uma série de proteções sobre a reutilização dos materiais residuais. Neste estudo, a reutilização de óleo de resíduos para valorização energética teve a maior economia de energia primária. O papel virgem requer mais energia primária do que o papel reciclado e produz cerca de três vezes mais $\mathrm{SO}_{2 \mathrm{eq}}$ e duas vezes mais $\mathrm{NO}_{\mathrm{x}}$. Quase todas as substituições de material considerado neste estudo tiveram efeitos ambientais positivos. Uma exceção foi a substituição de óleo combustível pesado por óleo de resíduos, o que levou a maiores emissões de $\mathrm{SO}_{2}$ do que apenas a queima de combustíveis fósseis virgem. Para $\mathrm{CO}_{2}$, a reutilização de resíduos representa uma economia de $0,6 \%$ do total da carga industrial deste poluente.

Liu et al. (2011) analisaram o desempenho ambiental do processo de simbiose industrial através da comparação da ACV em sete cenários. Neste caso, foi comparado o impacto ambiental de uma simbiose industrial onde a energia contida no gás combustível e no vapor seria usado para secar lodo de esgoto municipal e re-refinados de petróleo. Para a AICV foram utilizadas quatro categorias do método EDIP (Environmental Design of Industrial Products): potencial de aquecimento global, acidificação, eutrofização e ecotoxidade humana no ar. No que diz respeito ao consumo de energia, o menor valor foi alcançado pelo cenário que possuía o carvão como único combustível, enquanto os outros cenários, que utilizavam re-refino de óleo e lodo tiveram os maiores valores de consumo de energia. Tal resultado é justificado pelo autor devido à energia extra consumida no processo de desidratação, transporte e secagem do lodo, bem como o refino de óleo usado. Quanto à categoria de aquecimento global, seus maiores valores foram 
quando todos os combustíveis fósseis foram substituídos por resíduos, ou seja, quando todo o carvão foi substituído por lodo, grandes quantidades de CO2 e NOx foram gerados devido à incineração de lodo em grandes quantidades. Assim, os resultados mostraram que, com o aumento da utilização de lodo reciclado, os impactos ambientais aumentaram significativamente.

Soratana e Landis (2011) avaliaram a utilização potencial de dióxido de carbono e nutrientes a partir de resíduos industriais durante o cultivo de microalgas num comparativo de 20 diferentes cenários. Para a AICV foi utilizada o Traci versão 3.01, onde nove categorias foram avaliadas: potencial de aquecimento global, acidificação, carcinogênicos, não carcinogênicos, efeitos respiratórios, eutrofização, ecotoxidade, exaustão e nevoeiro de fumaça. Os resultados mostraram que os impactos ambientais, como potencial de aquecimento global e eutrofização poderiam ser evitados através da utilização de nutrientes e $\mathrm{CO}_{2}$ a partir de fluxos de resíduos para cultivar microalgas. A utilização de $\mathrm{CO}_{2}$ do gás de combustão evitou apenas o potencial de aquecimento global, enquanto a utilização de $\mathrm{N}$ e P de efluentes evitou principalmente a eutrofização.

Sokka et al. (2011) quantificaram os benefícios ambientais e econômicos da SI utilizando o ACV antes e depois da implantação do processo de simbiose industrial, o software utilizado na fase do ICV foi o KCL - ECO LCA. Os resultados indicaram que os sistemas que não utilizaram a SI tinham altos valores na maioria das categorias de impactos. Uma implicação do estudo foi que, ao desenvolver ou iniciar uma simbiose industrial, a análise deveria ser estendida para fora do local de impactos, bem como, uma vez que estes poderiam ser elevados em relação aos impactos na simbiose. Singh e colegas (2007) concluíram em seu estudo que a $\mathrm{ACV}$ é uma ferramenta extremamente útil para analisar e comparar diferentes projetos de simbiose industrial. Da mesma forma, ACV poderia ser aplicada quando se olha para simbioses industriais já em operação.

Singh et al. (2007) compararam um projeto atual de um complexo agroquímico com um novo modelo proposto utilizando a ACV. As categorias de impacto que mais mostraram diferenças significativas entre os dois cenários foram o aquecimento global, cuja redução chegou em $66 \%$ para o cenário que utilizou material reciclado, o consumo de água, que reduziu em $40 \%$, a saúde humana, que teve um aumento de $90 \%$ no impacto para o cenário ecologicamente correto. Isso ocorreu devido ao propeno residual liberado na atmosfera e o uso de combustíveis 
fósseis, cujo aumento no cenário ecológico foi de $75 \%$, devido ao uso de energia das novas usinas do complexo agro-químico.

Geng Y. et al. (2010) usaram um estudo de caso de Kawasaki. Os autores simularam e avaliaram uma iniciativa de gestão de resíduos inovadores por um modelo de simulação de cenários com base na abordagem LCA utilizando um novo conceito: Simbiose Urbana - definida como o uso de subprodutos (resíduos) de cidades ou áreas urbanas como matérias-primas alternativas ou fontes de energia para as operações industriais. Essa simbiose é uma oportunidade específica decorrente da proximidade geográfica das zonas urbanas e industriais. Simbiose urbana apresenta um novo modelo para um desenvolvimento urbano sustentável, tanto econômico quanto industrial em nível regional. Através de políticas adequadas e apropriadas, com uma estrutura organizacional flexível e instrumentos eficazes para a gestão integrada dos recursos, a simbiose urbana visa alcançar resultados positivos simultâneos para a economia, sociedade e meio ambiente. Os resultados mostraram que a reciclagem de papel misturado, plástico misturado, resíduos orgânicos e utilização da soma dos materiais reciclados dos cenários anteriores na produção industrial reduziram potencialmente as emissões de cinzas de incineração.

Os autores destacam a importância de estudar as empresas participantes, coletar dados, analisar os processos, selecionar as estratégias viáveis para o processo de $\mathrm{SI}$ e avaliar os aspectos energéticos e ambientais a partir de cenários de produção. É importante notar que estes estudos tem algo em comum. Todos eles analisaram casos de parque e conseguiram, utilizando a ACV, realizar uma análise detalhada da situação e das barreiras. Entretanto, os casos não demonstram como estes dados poderiam ser úteis para modificar a situação, pois conforme visto, o EIP é encarado como um sistema dinâmico.

\subsubsection{Análise de Fluxo de Materiais (MFA)}

A análise de fluxo de materiais é um método usado para análise de fluxos totais em grandes setores ou sistemas funcionais, mas pode ser usado em menor 
escala, visando a melhoria da eficiência de uma cadeia de produção industrial. A análise fornece suporte para a tomada de decisão, em nível global, regional ou para melhoria da eficiência da produção de forma local. Também fornece dados para o cálculo de custos de uma produção e funciona também como indicador ambiental e de produção (SABLOWSKI, 2008).

Para Chertow (2004), é essencial considerar o rastreamento de materiais, água e os fluxos de energia no estudo do processo de simbiose industrial. Várias ferramentas específicas foram produzidas para o monitoramento destes fluxos, tais como, análise de fluxo de materiais (MFA) e análise de fluxo de substância (SFA). Segundo a autora, o rastreamento de materiais para a simbiose identifica e quantifica todas as entradas e saídas de materiais significativos de cada empresa do sistema. Os resultados são analisados para sugerir oportunidades para troca de materiais entre as empresas, bem como oportunidades para o uso mais eficiente dos recursos no ecossistema industrial.

Além disso, outros aspectos da ferramenta podem colaborar para análises do processo de SI. Segundo a OECD (1993), os indicadores de fluxo de materiais são ferramentas importantes para descrever o uso de recursos de materiais da economia e para informar sobre a eficiência econômica e eficácia ambiental com que estes materiais são utilizados na produção e no consumo até a disposição final. Eles informam sobre:

- O nível e as características base dos recursos físicos de uma economia ou uma atividade.

- As consequências ambientais da utilização de recursos materiais em nível nacional e internacional.

- Os efeitos do ambiente e as políticas econômicas sobre o uso de materiais, e as implicações de comércio e da globalização sobre os fluxos de materiais nacionais e internacionais.

A organização considera os indicadores de fluxo de materiais a partir de uma visão mais abrangente. No guia, estes indicadores informam sobre o nível e as características dos fluxos de materiais e utilização dos recursos, que vão desde medidas agregadas a fluxo de materiais individuais.

De acordo com Eurostat (2001), um grande número de indicadores pode ser derivado de uma análise econômica baseada no balanço de materiais. $E$ estes podem ser agrupados em indicadores de entrada, indicadores de saída, 
indicadores de consumo, indicadores de comércio e indicadores de eficiência ambiental. Os indicadores mais utilizados em estudos de AFM na Europa são:

1. Indicadores de entrada:

a. Entrada direta de material (DMI): compreende todo material com valor econômico e que é diretamente usado nas atividades de produção e consumo. DMI equivale à soma de extrações domésticas e importações.

b. Total requerido de material (TMR): inclui adicionalmente ao DMI extrações domesticas não usadas e os fluxos indiretos associados com importações e economia.

2. Indicadores de saída:

a. Saídas domésticas de processo (DPO): equaliza os fluxos de saída em direção à natureza e compreende todos os fluxos de materiais usados de origem doméstica ou externa. DPO inclui emissões para água, ar, aterros sanitários e fluxos dissipativos.

3. Indicadores de consumo:

a. Consumo doméstico de material (DMC): estima a quantidade total de materiais usados em um sistema econômico, excluindo fluxos indiretos. O seu cálculo é feito extraindo do DMI das exportações.

b. Consumo total de material (TMC): inclui adicionalmente ao DMC, os fluxos indiretos associados à importação e exportação. TMC é equivalente ao TMR menos exportações e seus fluxos indiretos.

4. Indicadores de comércio:

a. Balanço físico de comércio (PTB): indica quando as importações de recursos excedem as exportações de um país ou uma região e mostra o quanto o consumo doméstico de material está baseado em extração de recursos domésticos ou importados. O PTB pode ser baseado em fluxos de materiais diretos (importações menos exportações) ou adicionalmente incluir fluxos indiretos associados com importações e exportações.

5. Indicadores de eficiência ambiental:

a. A compatibilidade da análise de fluxo de materiais com dados do Sistema Nacional de Contabilidade (SNA), permite uma relação direta entre os indicadores baseados em balanço de materiais com indicadores de performance econômica como o "Produto Interno Bruto - PIB". Esses 
indicadores de ligação quantificam a eficiência ambiental (ou rendimento em produção) de um sistema econômico através do cálculo das saídas geradas (estimadas em unidades monetárias) por unidade produzida (estimada em unidades físicas), como exemplo PIB / DMI. Indicadores de eficiência ambiental são ferramentas úteis para monitorar processos acoplados ao uso de recursos em uma economia crescente. E servem como ferramentas estratégicas na busca de uma maior sustentabilidade no uso de recursos naturais. Esses indicadores econômicos e ambientais podem ser usados também para testar a hipótese da curva de Kuznets (EKC) em relação à entrada de materiais e para definir a melhor escolha entre diferentes possibilidades de crescimento econômico ambientalmente sustentável.

Exemplos de utilização de indicadores baseados em balanço de materiais em escala industrial podem ser encontrados nos trabalhos de Sendra, Gabarrell e Vicent (2007) e Geng et al. (2012).

\subsubsection{Método de análise hierárquica (AHP)}

O Método de Análise Hierárquica (Analytic Hierarchy Process - AHP) foi criado em 1971 por Thomas L. Saaty, mas só atingiu a maturidade em 1973 com o estudo dos transportes do Sudão que ele dirigia (SAATY, 1991). O método é útil na tomada de decisões envolvendo multicritérios para identificar e selecionar o melhor caminho que envolve um problema de decisão complexo com diversas variáveis.

O Método AHP é uma teoria geral de medida, usada para derivar escalas de prioridade através de comparações par a par realizadas em matrizes. A comparação par a par é feita a partir de atribuições de pesos que refletem a força relativa de preferências e sentimentos (SAATY, 1987).

O AHP é caracterizado por sua simplicidade e robustez, sendo considerado um método multicritério que permite a análise de variáveis qualitativas e quantitativas em um processo de decisão. Assim, o método é aplicado para que todos os fatores importantes sejam considerados e medidos, sendo visto como um modo eficiente de criar medidas para entidades subjetivas, podendo usá-las em um processo decisório (GRANEMANN; GARTNER, 1998; SAATY, 1991). 
Para Shimizu (2001), o AHP é aplicado para situações de definição de prioridades, avaliação de custos e benefícios, alocação de recursos, medida de desempenho (benchmarking), pesquisa de mercado, determinação de requisitos, decisões estratégicas, planejamento e sequencia de atividades, previsão de cenários, negociação e resolução de conflitos, decisões e previsões políticas ou sociais.

Para que o processo de tomada de decisão usando o método de análise hierárquica seja feito é necessário realizar as seguintes etapas (SAATY, 2008):

- Definir o problema e determinar o objetivo a ser alcançado;

- Estruturar uma hierarquia em níveis, com o objetivo no topo, os critérios no nível intermediário e as alternativas de decisão fechando a estrutura;

- Construir um conjunto de matrizes através da comparação par a par, sendo que cada elemento em um nível superior é usado para comparar os elementos do nível inferior;

- Encontrar a escala de prioridades de cada matriz. A partir de todas as escalas uma análise conjunta ou global deve ser obtida.

O método tem início com a estruturação de um problema, definindo o objetivo almejado. A partir deste objetivo ou meta principal, é elaborada a estrutura hierárquica. Os níveis hierárquicos são compostos por um objetivo principal, pelos critérios, subcritérios (se houver) e pelas alternativas que envolvem a decisão (SAATY, 1990; SHIMIZU, 2001).

Um modelo de estrutura hierárquica contendo três níveis é apresentado na Figura 6:

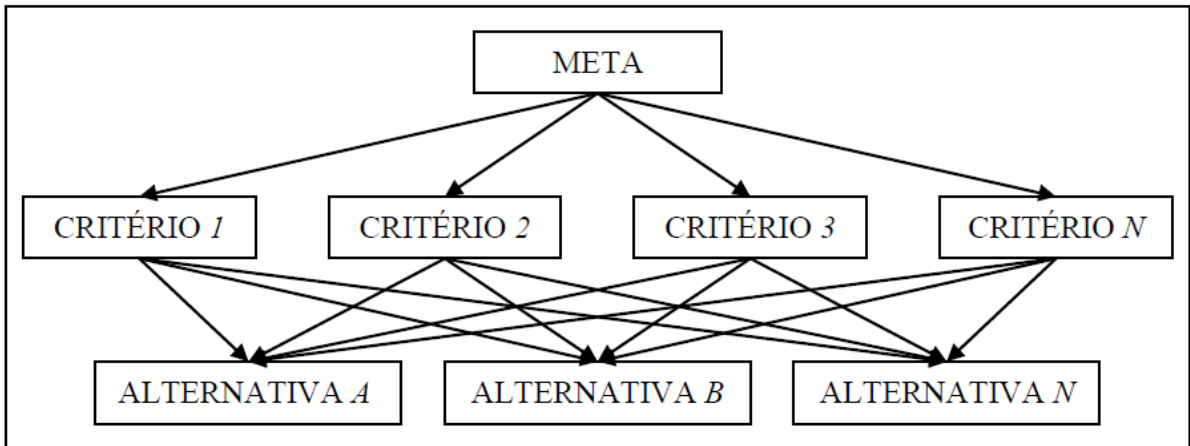

Figura 6. Decomposição de um problema em uma estrutura hierárquica. Fonte: Magalhães, 2011. 
Em seguida, inicia-se a fase de avaliação (GRANEMANN; GARTNER, 1998), que compreende a formação das matrizes através das comparações par a par entre os critérios, os subcritérios (se houver) e as alternativas de decisão. Através da comparação par a par serão determinadas as importâncias relativas a cada critério, subcritério e alternativa de decisão.

Para cada grupo de alternativas ou critérios comparados, que possui um mesmo elemento pertencente ao nível superior à qual a comparação está sendo relacionada, será gerada uma matriz com pesos atribuídos conforme julgamento de comparação (SHIMIZU, 2001). A intensidade das comparações é feita utilizando-se a escala fundamental de 1 a 9 proposta por Saaty e Vargas (2006), como indica a Tabela 1.

Tabela 1. Escala fundamental de julgamento em grau de importância.

\begin{tabular}{|c|c|c|}
\hline $\begin{array}{l}\text { Intensidade } \\
\text { de } \\
\text { importância }\end{array}$ & Definição & Explicação \\
\hline 1 & Igual & $\begin{array}{c}\text { As duas atividades contribuem igualmente para o } \\
\text { objetivo. }\end{array}$ \\
\hline 2 & Entre igual e moderada & - \\
\hline 3 & Moderada & $\begin{array}{l}\text { A experiência e o julgamento favorecem } \\
\text { ligeiramente uma atividade sobre a outra. }\end{array}$ \\
\hline 4 & Entre moderada e forte & - \\
\hline 5 & Forte & $\begin{array}{l}\text { A experiência e o julgamento favorecem } \\
\text { fortemente uma atividade sobre a outra. }\end{array}$ \\
\hline 6 & Entre forte e muito forte & - \\
\hline 7 & $\begin{array}{l}\text { Muito forte ou } \\
\text { importância } \\
\text { demonstrada }\end{array}$ & $\begin{array}{c}\text { Uma atividade é favorecida muito fortemente } \\
\text { sobre a outra; sua dominância é demonstrada na } \\
\text { prática. }\end{array}$ \\
\hline 8 & Entre forte e extrema & - \\
\hline 9 & Extrema & $\begin{array}{c}\text { As evidências favorecendo uma atividade sobre a } \\
\text { outra são da ordem de afirmação das mais altas } \\
\text { possíveis. }\end{array}$ \\
\hline Recíprocos & \multicolumn{2}{|c|}{$\begin{array}{l}\text { Se a atividade i tem um dos números acima quando comparada com a } \\
\text { atividade } j \text {, então } j \text { tem o valor recíproco quando comparada com } i \text {. }\end{array}$} \\
\hline $\begin{array}{l}\text { Números } \\
\text { Racionais }\end{array}$ & \multicolumn{2}{|c|}{ Se houver necessidade de forçar a consistência da matriz. } \\
\hline
\end{tabular}

Então, cria-se a matriz a partir das comparações par a par. 
O peso de um critério é a sua importância no modelo, ou de forma mais simples, a sua taxa de substituição no modelo. Numa definição mais formal, peso é um fator de escalar (Bana;Costa,1993).

Magalhães (2011) aplicou o método AHP para identificar a melhor alternativa dentre os eletrodomésticos de linha branca que pudesse sofrer reprocesso na perspectiva da logística reversa quando o produto atinge seu efetivo fim do ciclo de vida útil.

Ruy (2011) utilizou o método AHP, juntamente com a ACV, para propor um método de apoio para analisar e selecionar conceitos de produto envolvendo critérios ambientais.

Zhu et al. (2010) desenvolveram um sistema de indicadores para controlar a entrada de empresas no EIP. O método AHP foi aplicado para gerar pesos aos indicadores do sistema.

Portanto, nota-se que as decisões ambientais são complexas e o método AHP é uma ferramenta que vem sendo muito utilizada na área da El e sustentabilidade para dar conta da complexidade dos critérios envolvidos na decisão. 


\section{A SIMBIOSE EM DOIS PARQUES INDUSTRIAIS BRASILEIROS}

Foram realizados dois estudos de caso em parques que se autodenominavam EIPs, chamados aqui de casos I e II, para analisar se os mesmos apresentavam as características constituintes de um EIP encontradas na literatura e para compreender seus principais problemas e desafios. Foram selecionados parques em estágio inicial de construção para analisar os elementos considerados no planejamento e as ferramentas utilizadas para selecionar as empresas interessadas no Parque. Foi elaborado um questionário com o objetivo de descrever o perfil de cada parque, o processo de atração e inclusão das empresas, o papel do agenciador, a motivação e critérios utilizados para se autodenominar EIP e as principais dificuldades. Os objetivos centrais do questionário foram desdobrados em uma série de catorze perguntas (Apêndice $B$ ).

Os questionários foram respondidos pelo responsável do parque após visitas guiadas, onde o pesquisador conhecia as instalações. As principais características dos dois casos foram descritas e por fim, os resultados comparados com os elementos constituintes de um EIP.

Por meio da revisão bibliográfica inicial, foi possível levantar na literatura os principais elementos de um EIP. Lowe (2001, 2005), Chertow (2000), Schlarb (2001) e outros autores apontam que um dos elementos que caracteriza um EIP é a adoção de um sistema de gestão ambiental (SGA). O SGA é uma ferramenta que vem sendo implementada por organizações, empresas, indústrias e distritos industriais ao redor do mundo, inclusive no Brasil por meio da norma ISO 14001, que auxilia as empresas na sua implantação. Para Geng et al. (2009), a implantação de um SGA num EIP não é o grande desafio encontrado pelos agenciadores. A falta de colaboração e parceria entre as indústrias pode reduzir as oportunidades e, consequentemente, os ganhos ambientais, econômicos e sociais. Outro elemento importante para o desenvolvimento de um EIP é a arquitetura e construção sustentável, uma vez que suas medidas reduzem potencialmente os impactos ambientais. Para Lowe (2001), um EIP pode proporcionar uma importante oportunidade para o campo da instalação industrial no desenvolvimento de inovações arquitetônicas e paisagísticas. 
Além desses elementos, Kincaid e Overcash (2001) expõem sobre a necessidade de um agenciador em seus estudos sobre o projeto da Carolina do Norte - EUA de implantação da SI. Os autores apontaram como principal falha nas comunidades a ausência de um agente para promover a visão de teia de materiais, água e energia que flui entre os vizinhos.

Assim, um EIP deveria: 1) apresentar simbiose entre os seus membros; 2) possuir um sistema de gestão ambiental que garanta a melhoria contínua, impedindo a saída de resíduos e de impactos ambientais do parque como um todo; 3) possuir empresas com tecnologias ambientais; 4) estimular a cooperação entre os membros para melhoria do desempenho ambiental; 5) ter parceria entre o setor público e privado; 6) apresentar arquitetura e construção sustentável, e 7) apresentar um agenciador.

No caso I, o parque foi idealizado sobre o conceito de um parque de inovação para a promoção do desenvolvimento não só tecnológico, mas também econômico, social e ambiental de toda a região. Eles definem parque de inovação como um ambiente dotado de infraestrutura e sistemas para atrair/formar talentos e empreendimentos capazes de gerar ideias e conhecimentos e transformá-los em novos produtos e serviços para a sociedade, promovendo o desenvolvimento sustentável sócio-econômico-ambiental da região. O parque conta com quatro módulos (comunidade e sociedade, ciência e tecnologia, meio ambiente e, arte e cultura) que darão suporte aos clusters (cluster de serviço, cluster de turismo, cluster de tecnologia e cluster público), envolvendo assim, governo, empresas, sociedade e academia.

O parque encontra-se no início de suas atividades, sua infraestrutura conta com o chamado "marco zero", composta pelas primeiras obras. Atualmente possui em uma das instalações, a primeira incubadora de clusters, que está em fase final de construção e deve acolher empresas das áreas de mídias interativas assim como pequenas empresas, formada por pesquisadores e pequenos empresários. Abriga também empresas de alta tecnologia na área de hardware e software. Existem mais dois prédios em construção, o prédio do Instituto do Petróleo Gás e Energia (INPETRO), uma iniciativa conjunta entre empresa e Universidade, que reunirá centenas de pesquisadores e a implantação do prédio do Centro de Referência em Farmacologia Pré-Clínica (FARMACOS), o qual se encontra em 
fase de construção. Além das empresas citadas, o parque possui uma trilha ecológica, uma biblioteca para a população, um local onde são realizadas algumas atividades interativas com visitantes do parque e uma arena, reservada para eventos culturais, lazer e esporte. A ideia é atrair primeiro as empresas âncoras que darão suporte a outras empresas para juntas, desenvolverem a cooperação entre elas.

As empresas participantes possuem um perfil mais voltado para ciência, serviços, tecnologia e saúde. O processo de inclusão e atração das empresas é realizado por meio de editais, que são lançados pelo parque com todos os requisitos e especificações necessárias.

No Caso II, o parque é um projeto de uma empresa privada e faz parte do sistema paulista de parques tecnológicos, programa lançado pela secretaria de desenvolvimento do governo do Estado de São Paulo e viabilizado por meio de parcerias público-privadas e recursos de órgãos e agências de fomento do governo estadual, federal, da prefeitura e de diversas universidades e institutos de pesquisa. Quanto à estrutura, o parque prevê a implantação de um núcleo de inovação, com uma incubadora de empresas e um centro de serviços, com laboratórios, escritórios de administração, consultoria e comunicação.

A gestão do parque é realizada por um instituto, que funciona como entidade jurídica responsável por ele. São papéis do instituto a intermediação entre empresas e universidades parceiras, auxílio à captação de recursos para projetos e empresas e, articulação de parcerias com parques tecnológicos nacionais e internacionais.

As empresas participantes também possuem um perfil mais voltado para ciência, serviços, tecnologia e saúde. Neste caso, qualquer empresa pode garantir seu terreno por meio da compra, não existindo uma seleção do tipo de empresa que irá operar no parque, sendo suficiente o cumprimento dos requisitos de construção contido nas normas construtivas do projeto urbanístico. Segundo os responsáveis pelo parque, os projetos deverão apresentar em sua arquitetura no mínimo nove elementos de sustentabilidade, sendo sete obrigatórios e dois opcionais. Assim, as empresas candidatas aos terrenos têm seus projetos avaliados por bancas, que verificam o cumprimento dos requisitos presentes nas normas construtivas. 
O Quadro 1 mostra o resultado das análises dos estudos de caso apresentado, traçando um paralelo comparativo entre os dois casos.

Quadro 1. Resultado da avaliação dos elementos de um EIP nos casos I e II

\begin{tabular}{llll}
\hline Elementos do EIP & Caso I & Caso II \\
\hline $\begin{array}{l}\text { Presença de Simbiose entre seus } \\
\text { membros }\end{array}$ & ausente & ausente \\
\hline $\begin{array}{l}\text { Sistema de Gestão Ambiental } \\
\text { Tecnologias Ambientais }\end{array}$ & presente & presente \\
\hline $\begin{array}{l}\text { Estímulo à cooperação para melhoria do } \\
\text { desempenho industrial }\end{array}$ & presente & presente \\
\hline Parceria setor Público e Privado & & ausente \\
\hline Arquitetura e Construção Sustentável & presente & presente \\
\hline
\end{tabular}

Para o caso I, notou-se que o parque se autodenominava EIP principalmente por incluir uma trilha ecológica e a coleta seletiva. O conceito de simbiose industrial não foi mencionado pelo agenciador ou observado durante visitas às empresas. Também não foram observados indícios de incentivos para a cooperação na área ambiental, isto é, para a melhoria de desempenho ambiental. A cooperação citada durante as entrevistas versavam sempre sobre questões específicas de negócio, como novos produtos e competitividade.

Por estar num estágio inicial de implantação, a principal preocupação observada nos gestores era a infraestrutura e atração de empresas. Logo, aspectos ambientais não eram tratados como prioridade. Além disso, não foram encontradas ferramentas para o gerenciamento dos aspectos ambientais do parque e a escolha das empresas não incluía critérios específicos para aspecto ambiental ou que incentivasse a simbiose. Foi mencionada a existência de um edital com critérios focados na construção sustentável. 
No caso 2, o parque se considerava ecológico por incorporar as questões de sustentabilidade às edificações industriais. Além disso, o parque visava priorizar empresas que fizessem uso do desenvolvimento de pesquisas, de apoio, de serviços e de produção, que se enquadrassem nas categorias: sem risco ambiental, ou empresas de risco ambiental leve, de baixo grau de nocividade e médio grau de incomodidade, conforme definido na lei 5.597/87 do Estado de São Paulo e demais disposições legais. São, portanto, duas iniciativas.

Quanto à relação de cooperação entre os componentes do parque, o instituto responsável pelo gerenciamento visava inicialmente, focar em estruturas de uso comum, como transporte, por exemplo. Entretanto, nenhuma relação de cooperação entre as empresas estava prevista e o desenvolvimento da relação simbiótica não era tratada como prioridade.

Os dados levantados diante dos estudos de caso permitem concluir que nenhum dos parques analisados apresenta o elemento simbiótico presente na definição de EIP proposto pelo instituto Indigo Development (2005), conforme as características apontadas na revisão bibliográfica.

Os dois casos consideram o impacto ambiental, mas de maneira restrita ao problema das edificações e na preocupação de evitar empresas com alto impacto ambiental.

É notável a ausência de visão sistêmica para coordenar as atividades de fechamento do ciclo produtivo nos parques. Há uma preocupação dos gestores em administrar os aspectos ambientais decorrentes da instalação das empresas e em promover a colaboração, mas faltam instrumentos e visão de como implementá-las.

Assim, há poucos elementos que possam caracterizá-los como EIPs. Uma das razões para isso pode ser o fato de ambos os parques encontrarem-se em estágio inicial de implantação. Em tal circunstância, é natural que a preocupação principal dos responsáveis pela gestão dos parques concentre-se no investimento da infraestrutura, considerando as questões ambientais somente na fase de construção das edificações, fator importante, mas não o suficiente para a denominação EIP.

A pesquisa revela, porém, aspectos importantes para os pesquisadores da área. Em primeiro lugar, o desconhecimento por parte dos profissionais que gerem estes parques sobre o conceito e características de um EIP. O primeiro passo para 
a implantação deste conceito deve ser, portanto, a difusão. Um dos desafios é a própria existência de critérios e características bem definidas.

O segundo aspecto importante é a constatação de que faltam instrumentos e ferramentas aos gestores sobre como implementar este conceito de EIP. Vê-se que há sensibilização sobre a importância de ser um EIP e há o desejo por parte dos gestores em utilizar tal rótulo. Mas, é preciso que os pesquisadores se dediquem a criar instrumentos e ferramentas que possam ajudar. Em especial, quanto ao conceito de simbiose industrial, que não foi detectado nos parques analisados. Os gestores também não possuem hoje, instrumentos para o incentivo da simbiose.

Este trabalho ajudou na identificação de oportunidades para o presente estudo. Os editais apresentados no caso I mostraram que podem existir elementos de apoio ao organismo gerenciador, que controlam e selecionam, de alguma forma, a entrada das empresas no parque. Além disso, ficou claro a ausência de metodologias e ferramentas de incentivo das relações simbióticas em tais parques. 


\section{INDICADORES AMBIENTAIS}

Neste capítulo são apresentadas as definições, bem como os diversos tipos de indicadores ambientais. Em seguida, é apresentado o processo de desenvolvimento de indicadores e por fim, tem-se o resultado da revisão bibliográfica sistemática, com os indicadores ambientais utilizados em EIPs.

\subsection{O QUE DEFINE UM INDICADOR?}

Os indicadores são elementos centrais no processo de tomada de decisão. Segundo Magalhães (2004), eles são os principais elementos de informação e é sobre eles que o conhecimento sobre diversos temas é construído pelos tomadores de decisão. Eles determinam, portanto, o que e como se percebe determinado objeto, afetando diretamente as decisões.

De acordo com Veleva e Ellenbecker (2001), os indicadores fornecem informações sobre sistemas físicos, sociais e econômicos, permitindo analisar tendências e relações causa-efeito. Estes indicadores podem ser utilizados para avaliar o desempenho e o gerenciamento dos negócios, para verificar se a empresa está realizando os objetivos e metas estabelecidos e/ou para estabelecer comparações dentro do mesmo setor.

No âmbito das normas de referência ISO 14.001, os indicadores devem ser capazes de mostrar a situação da organização sobre os seus principais aspectos ambientais e também de mostrar o desempenho em relação aos objetivos e metas definidos. Santos (2004) concorda que os indicadores fornecem conhecimento sobre questões e/ou fenômenos considerados importantes para os seus diversos usuários, subsidiam os processos de planejamento e gestão ambiental, favorecendo o controle e monitoramento do meio ambiente, bem como o aumento da participação da sociedade na gestão pública.

Para Sustainable measure (2008) um indicador ajuda a compreender a situação atual (onde se está), qual o caminho a ser seguido (como chegar) e qual a distância a ser percorrida para atingir a meta estabelecida (onde se deseja chegar). Um bom indicador ajuda a identificar os problemas antes que eles ocorram e auxiliam na sua solução. Para que um indicador seja efetivo é necessário que seja 
relevante, reflita o sistema que precisa ser conhecido, fácil de ser entendido e baseado em dados acessíveis.

Segundo Tocchetto et al. (2003) a avaliação dos indicadores ambientais fornece informações para retroalimentar o sistema de gestão ambiental na busca da melhoria continua do sistema. Para os autores, os indicadores ambientais devem ilustrar as melhorias ambientais ao longo do tempo em determinadas avaliações.

O tema "indicador" aborda sobre alguns termos que podem dar margem à existência de equívocos na definição e no uso de indicadores que muitas vezes são utilizados como sinônimos "dados, informação, parâmetro e índice". Por isso, é interessante recorrer à etimologia destes termos e da definição empregada na pesquisa.

O termo dado é o mais básico componente de um indicador (SEGNESTAM, 2002). Faz-se referência a uma medida, quantidade, ou observação de uma propriedade (parâmetro), que pode ser apresentado de diversas formas, tais como números, descrições, caracteres ou mesmo símbolos (SANTOS, 2004). Segundo Winograd e Farrow (2009), os dados são a base para indicadores, índices, informações e por si só não podem ser usados para interpretar mudanças ou condições. Um dado torna-se um indicador quando for capaz de transmitir conhecimento, ou seja, quando sua compreensão ultrapassar o número ou mensuração, no sentido de adquirir significado através da informação interpretada, possibilitando avaliar a situação e as tendências do ambiente.

Para Gallopín (1997), indicador é uma variável, a qual é uma representação operacional de um atributo (característica, propriedade do sistema), sendo que esta variável transmite informação da condição e/ou tendência do atributo. Ainda segundo o autor, a variável indica o atributo, não sendo o atributo em si, mas a imagem do atributo (mensuração específica ou processo de observação).

Não se considera como indicador a simples mensuração de um parâmetro (valor), mas sim a informação que provém do significado desta mensuração, possibilitando, portanto avaliar a situação e as tendências do ambiente (no caso do indicador ambiental).

A análise do indicador sob determinado contexto gera a informação que, segundo Segnestam (2002), é a base do processo de tomada de decisão. A 
informação é, portanto, o resultado da análise de indicadores e índices, sendo politicamente relevante.

Alguns indicadores podem, ainda, ser combinados originando um índice, que é também um indicador, geralmente usado em níveis mais agregados de análise (nacional, regional, internacional). Khanna (2000) coloca que um índice é composto de indicadores (suas variáveis) e resulta em um valor agregado final baseado em todo um procedimento de cálculo. De uma forma mais simples, a autora expressa que um índice é um indicador de alta categoria.

Um número índice, segundo Spiegel (1972), é uma medida estatística idealizada para mostrar as variações de uma variável, ou de um grupo de variáveis, correlacionados ao tempo, à localização geográfica, ou a outras características. Segundo Medeiros e Medeiros (1999), por meio do emprego de números-índices é possível estabelecer comparações entre:

- variações ocorridas no tempo;

- diferenças entre variáveis tomadas em lugares diversos;

- diferenças entre categorias semelhantes, tais como produtos, pessoas, organizações, etc.

Segundo Barboza (2007), a utilização dos números-índices é tão importante dentro das empresas como fora delas, numa visão micro ou macroeconômica. As constantes mudanças da economia, as inovações tecnológicas acarretam mudanças contínuas nos hábitos da população. Com o auxílio de números-índices é bem mais fácil mensurar essas mudanças.

Assim, para Gomes (2011), as principais vantagens do índice são a facilidade de comunicação com o público que não se interessa por detalhes e prefere quadros resumidos dos principais fatos, além do fato de representar diversas variáveis em um único número. Quanto as desvantagens, a autora destaca a perda de informações das variáveis individuais, não substituindo uma avaliação detalhada de um construto.

Gomes (2011) alerta sobre a construção de indicadores "pobres", que fornecem informações inadequadas e imprecisas sobre o que está sendo mensurado, e indicadores com baixa capacidade de informação para tomada de decisão adequada, que ignora, por exemplo, a participação de seus usuários na discussão de sua relevância. 
O principal determinante de um bom indicador segundo World Bank (1997) é a ligação da medição das condições ambientais com as opções políticas concretas, as quais implicam na relação entre as questões ambientais e sociais. Ainda segundo o autor, os indicadores devem ser apropriados e influenciar na tomada de decisão. Os indicadores ambientais consistem basicamente no levantamento e transformações de dados em informações de maneira sistemática para informar a situação do objeto de estudo. Por meio deles, é possível interpretar e esclarecer as situações ambientais aos interessados, tomar decisões cabíveis frente às constantes mudanças e inovações que ocorrem no desenvolvimento mundial, e analisar tendências do ambiente. Para Tocchetto et al.(2003) os indicadores de controle são expressões quantitativas que representam uma informação gerada, a partir da medição e avaliação de uma estrutura de produção, dos processos que a compõem e/ou dos produtos resultantes. A autora conclui que os indicadores/parâmetros de controle são instrumentos de apoio à tomada de decisão em relação a uma determinada estrutura, processo ou produto. Para EEA (2003) a comunicação da informação é a principal função dos indicadores ambientais.

Ainda de acordo com CSIRO (1999), um bom indicador ambiental deve possuir os seguintes requisitos:

a) Ter um significativo e legítimo valor científico;

b) Representar um aspecto ambiental de importância para a sociedade;

c) Demonstrar algo de importância e de entendimento imediato;

d) Ter um processo de mensuração legítimo e prático;

e) Ajudar a focar informações para responder questões importantes; e

f) Ser eficiente e efetivo no apoio ao processo de tomada de decisão.

Gomes (2011), baseado em Santos (2004), APHO - The Association Of Public Health Observatorie (2008), ACOS - Advisory Committee on Official Statistics (2009), Martínez (2009), SIBIS - Statistical Indicators Benchmarking the Information Society (2003) e CSO (Central Statistical Office - Ireland (2008), elaborou o Quadro 2 com os requisitos para a obtenção de um indicador ideal de forma resumida, explicando a definição de cada um deles. 
Quadro 2. Condições para um indicador ideal.

\begin{tabular}{cl}
\hline Requisitos & Explicação \\
\hline Representatividade & $\begin{array}{l}\text { Refere-se à capacidade de retratar os problemas da área de } \\
\text { estudo. }\end{array}$ \\
Validade científica & $\begin{array}{l}\text { Em suma, tem relação à forma de coleta e elaboração do dado. } \\
\text { Deve-se observar a confiabilidade da sua origem (se de órgão } \\
\text { oficial, instituição creditada, organização não governamental, } \\
\text { jornal,etc.). } \\
\text { O indicador deve possuir concordância com o quadro legislativo } \\
\text { do governo local para possibilitar a avaliação e monitoramento do } \\
\text { progresso no sentido de alcançar resultados para sociedade. }\end{array}$
\end{tabular}

Valores de referência

Conformidade temporal

Redundância

Sensibilidade às
mudanças

Séries temporais

Abrangência

Conectividade

Integração

Tipo de Informação

Disponibilidade e

Acesso

Comunicação/

divulgação dos
Para que o usuário possa estabelecer comparações e julgar a relevância do seu valor.

Deve-se averiguar o tempo decorrido entre a coleta do dado e a realidade que se deseja representar. Neste aspecto, é evidente que para cada temática, há um intervalo de tempo aceitável, que deve ser julgado pelo seu especialista.

Deve se tomar cuidado para que o indicador não a apresente, ou seja, que diferentes dados coletados não expressem a mesma informação.

À medida que ocorrem as alterações no ambiente, mesmo que pequenas, a resposta do dado é imediata, mudando o seu valor; e se for de natureza preventiva que seja capaz de sinalizar a degradação antes da ocorrência de sérios danos.

Se a sensibilidade às mudanças ao longo do tempo, pode-se gerar séries temporais de dados(lineares, cíclicos ou sazonais), entendidas como ótimos tradutoras dos fenômenos de diferentes dinâmicas em um determinado tempo. Quando for importante a analise da evolução, os indicadores devem ter a capacidade de expressar as mudanças em uma escala de tempo compatível com os problemas.

No que se refere a dados espaciais, o indicador deve apresentar limites bem definidos no espaço, de forma a facilitar, geográfica e operacionalmente, o gerenciamento das propostas do planejamento.

Conectividade do indicador com outros do meio, ou seja, os elos entre as diversas informações e as respostas integradas às suas mudanças.

É importante se o indicador é integrador, se tem a capacidade de sintetizar informações de vários outros indicadores.

Informação prescritiva: deve-se considerar se a informação é prescritiva - aquela que é analítica e apresenta recomendações ao desenvolvimento de alternativas, constituindo um bom indicador.

Informação descritiva: deve-se considerar se a informação descritiva - restringe-se à descrição das propriedades do meio, sem a pretensão de fornecer subsídios diretos à tomada de decisão.

Informação sobre o indicador, sem perda de tempo que impeça ou dificulte o planejamento.

Comunicados de forma que envolva o público, por gráficos e informações contextuais, auxiliando na compreensão e 


\begin{tabular}{|c|c|}
\hline Requisitos & Explicação \\
\hline indicadores & interpretação da medição. \\
\hline Custo razoável & $\begin{array}{l}\text { Corresponde ao valor ideal para obtenção da informação em } \\
\text { função da quantidade de dados, da unidade de área e da escala } \\
\text { de trabalho. Em suma, pretende-se que haja uma relação } \\
\text { custo/benefício. }\end{array}$ \\
\hline Participação popular & $\begin{array}{l}\text { Em algum momento, ou na elaboração ou revisão dos } \\
\text { indicadores. }\end{array}$ \\
\hline $\begin{array}{l}\text { Atualização e } \\
\text { Divulgação }\end{array}$ & $\begin{array}{l}\text { Os dados precisam ser coletados e reportados regularmente, } \\
\text { devendo haver um tempo mínimo entre a coleta e a reportagem, } \\
\text { para garantir a atualidade e utilidade para o usuário. }\end{array}$ \\
\hline Fácil compreensão & $\begin{array}{l}\text { Indicadores devem ser simples e fáceis de compreender para } \\
\text { informar o grupo de pessoas que tomará as decisões quantos aos } \\
\text { rumos do planejamento. }\end{array}$ \\
\hline $\begin{array}{l}\text { Modelo conceitual } \\
\text { estrutural }\end{array}$ & $\begin{array}{l}\text { Usado como guia para o desenvolvimento e estruturação de um } \\
\text { conjunto de indicadores, de uma forma coerente. Sem ele, o } \\
\text { conjunto se torna uma mistura eclética de indicadores sem } \\
\text { qualquer justificação clara para a sua seleção. }\end{array}$ \\
\hline
\end{tabular}

Fonte: Gomes, 2011.

Além disso, segundo Gallopín (1997), Gomes, Marcelino, Espada (2000) e Santos (2004), os indicadores devem refletir as diversas perspectivas que envolvem os múltiplos grupos de interesse, ou seja, os cidadãos, setor público e privado, e os próprios tomadores de decisão.

\subsubsection{Tipos de indicadores}

Tocchetto et al. (2003) classificam os indicadores ambientais em três tipos:

- Indicadores absolutos e relativos: são os focos primários de qualquer avaliação ambiental, pois representam o consumo de materiais, energia, água e outros insumos da empresa (consumo de energia em kW/h ou de geração de resíduos em t). Podem ser entendidos com a compreensão dos impactos ambientais. Indicadores relativos demonstram medidas de melhoria da performance ambiental ou geral da empresa;

- Indicadores corporativos e de processos: estes indicadores determinam, em nível de chão-de-fábrica da empresa, se as ações planejadas e medidas estão de acordo ou se devem dar lugar a novos planos de ação ou planos de correção. Também determinam em que intervalos de tempo devem ser revistos e/ou monitorados. Indicadores de processo são especialmente importantes para se verificar níveis de consumo de recursos (matérias primas e demais 
insumos) e de emissões (resíduos, efluentes e emissões) relacionados às etapas do processo. São importantes para determinar a real fonte de consumo de insumos e as causas da geração de emissões;

- Indicadores quantitativos e de custo: são indicadores que utilizam uma linguagem de gerência, ao invés de medidas físicas como $\mathrm{Kg}, \mathrm{t}$, unidades, peças, $\mathrm{m}^{3}$, entre outros. Estes itens passam a ser associados a valores em moeda corrente, para verificar a relevância de cada item abordado na matriz de custos globais e nos valores de investimentos ambientais implementados ou a serem implementados na empresa.

Além desta classificação, os indicadores ambientais são definidos em três categorias:

- Indicadores de comportamento ou rendimento ambiental: permitem avaliar e controlar os impactos ambientais.

- Indicadores de gestão ambiental: referem-se às ações da organização que a direção está empreendendo para minimizar o impacto ambiental da empresa.

- Indicadores de situação ou estado ambiental: proporcionam informações sobre a qualidade do entorno de uma empresa, o estado do meio local, regional e mundial. Estas informações servem para obtenção de sistemas de indicadores de comportamento ambiental específicos relativos aos principais problemas do meio ambiente.

\subsubsection{Indicadores de desempenho ambiental}

Historicamente as empresas e organizações focavam a avaliação do seu desempenho unicamente pelo resultado financeiro com indicadores do tipo: lucro líquido, rentabilidade e faturamento.

Atualmente as novas condições conduzem as empresas a avaliar seu desempenho frente a outras exigências. A medição é feita sobre todas as partes interessadas que são: processos, clientes, fornecedores, acionistas, funcionários e sociedade (TOCCHETTO et al., 2003).

Os indicadores de desempenho ambiental sintetizam as informações quantitativas e qualitativas que permitem a determinação da eficiência e efetividade da empresa, de um ponto de vista ambiental, em utilizar os recursos disponíveis. 
São úteis para orientar, gerir e comunicar o desempenho ambiental. Segundo Oliveira (2011) os indicadores de desempenho, como medidas quantitativas, podem e devem ser acompanhados de avaliações qualitativas, tais como a satisfação de usuários, por intermédio de pesquisas efetuadas a intervalos regulares de tempo.

São informações simples e instrumentos orientadores para o objetivo de melhoria contínua, pois permitem aumentar a clareza, transparência e comparabilidade da informação fornecida pela organização.

Segundo Diógenes (2004), os indicadores de desempenho podem ser agrupados de forma a compor um indicador global, referenciado por um índice, que é uma medida de alto nível de agregação combinando indicadores importantes para descrever o desempenho de uma organização, região ou setor econômico, e são úteis quando há a possibilidade de comparar realidades de distintos locais em diferentes períodos de tempo, pois apontam tendências e relações de maneira concisa.

A norma ISO 14.031 define a avaliação de desempenho ambiental como um processo para facilitar as decisões gerenciais com relação ao desempenho ambiental de uma organização e que compreende a seleção de indicadores, a coleta e análise de dados. Nota-se no conceito apresentado o papel fundamental dos indicadores, servindo como instrumento da avaliação de desempenho.

A necessidade de informar o desempenho das organizações tem ocorrido por várias razões: o atendimento a legislação e a redução de custos de exigências futuras; a adoção de códigos voluntários ambientais; a diminuição de custos operacionais; a melhoria das relações com as partes interessadas; além da percepção da visibilidade ambiental da empresa como uma vantagem competitiva (MORHARDT; BAIRD; FREEMAN, 2002). Os indicadores podem ser utilizados como importante ferramenta de medida para expressar as informações, de forma clara e objetiva, e para auxiliar no atendimento aos interessados.

\subsection{Processo de desenvolvimento de Indicadores ambientais}


A literatura existente sobre metodologia de desenvolvimento de indicadores tende a um ponto comum no que diz respeito às etapas do processo de montagem de um sistema de indicadores. Apesar de uma tendência ao consenso, são poucas as experiências que apresentam uma sistematização metodológica.

Para Cardoso (2004) e Martínez (2009), o desenvolvimento de um indicador envolve alguns estágios, representados na Figura 7 , onde inicialmente, são utilizados dados primários (de medição ou observação). O tratamento estatístico dos dados primários é transformado em uma série sistemática e estatística. Esta combinação gera um indicador. Os autores, no entanto, não propõem uma metodologia especifica para o desenvolvimento de um indicador.

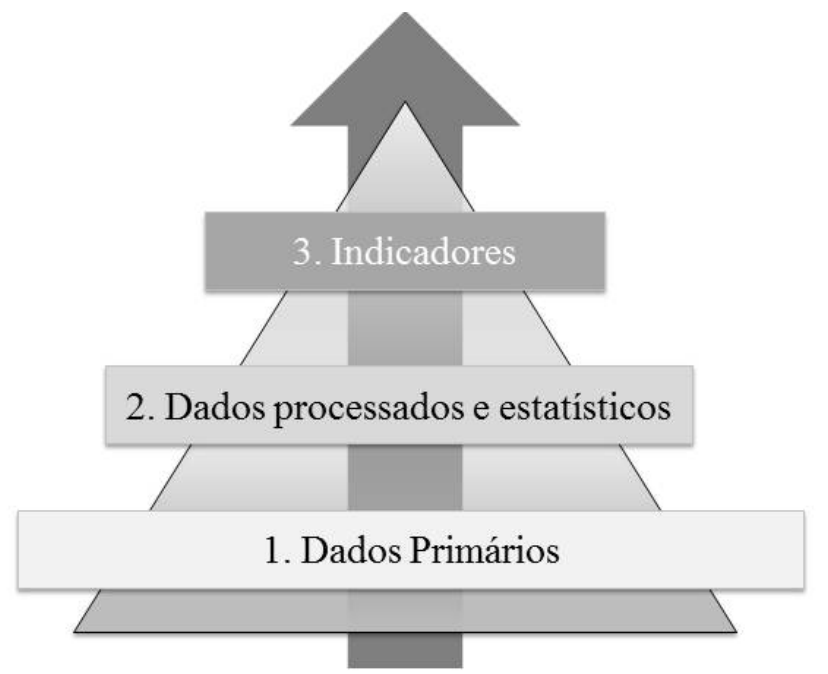

Figura 7. Construção do Indicador.

Fonte: Adaptado de Martínez, 2009.

Numa visão mais abrangente que considera o funcionamento de um indicador e analisa todos os aspectos que compõem a sua formação, a Figura 8 mostra a relação entre os dados primários, que são as entradas dos processos ocorridos no sistema, formado por uma estrutura organizacional, com os agenciadores e instituições, que irão utilizar esses dados para alimentar o indicador. O sistema estatístico é concebido para processar as informações necessárias de acordo com os objetivos pré-definidos. Segundo Martínez (2009), o processo de produção da informação é construída sob critérios, ferramentas e métodos para garantir o rigor e qualidade dos produtos resultantes. A partir disso, pode-se produzir indicadores, que por sua vez, são tratados como insumos para formulação de políticas e relatórios sobre o estado do ambiente analisado. 


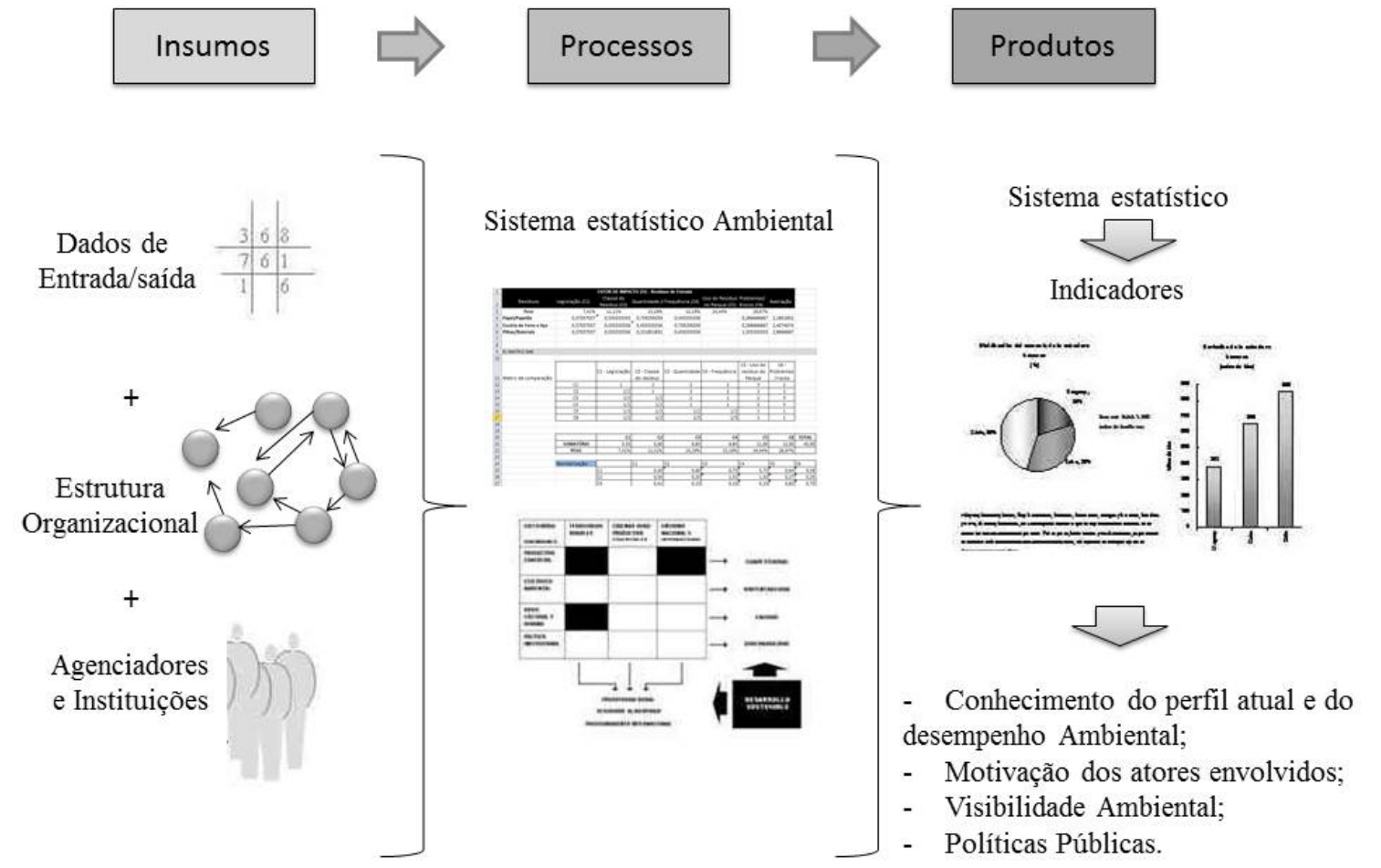

Figura 8. Integração dos resultados e resultados.

Fonte: Adaptado de Martínez, 2009.

O desenvolvimento de bons indicadores exige o cumprimento de alguns requisitos. Segundo The World Bank (1997) e o OECD (1993) os indicadores devem estar de acordo com os seguintes critérios:

a) Ser construído dentro de um modelo conceitual aceito;

b) Ser claramente definido (fácil de entender e interpretar);

c) Mostrar tendências ao longo do tempo;

d) Ser cientificamente credível e com base em dados de alta qualidade;

e) Ser politicamente relevantes.

f) Ser relevantes para os usuários, politicamente aceitável e uma base para ação;

g) Ser sensível às mudanças ambientais e atividades humanas;

h) Fornecer base de comparação internacional provendo um limiar/valor de referência;

i) Ser objeto de agregação (de uso doméstico à comunidade e da comunidade à nação);

j) Ser objetivo (independente da coleta dos dados);

k) Ter exigências razoáveis em relação aos dados (ou dados que estão disponíveis ou dados que podem ser coletados a baixo custo); e 
I) Ser limitados em números.

\subsection{INDICADORES AMBIENTAIS NA REALIDADE DOS EIPS}

Alguns trabalhos abordam sobre a utilização de indicadores ambientais em EIPs. Os indicadores são aplicados na avaliação das empresas de maneira individual, ou mesmo na avaliação do parque como um sistema.

Sendra, Gabarrell e Vicent (2007), na tentativa de converter uma área industrial existentes na Espanha em EIPs, adaptaram a metodologia MFA proposta pela Eurostat (2001), muito utilizada para analisar o metabolismo social, para avaliar um parque industrial e as empresas localizadas em seu interior. Os autores, por meio de um estudo de caso, utilizaram os indicadores do MFA para avaliar a eficiência de algumas estratégias na conversão da área industrial de Santa Perpétua de Mogoda em um EIP. No estudo, o fluxo de materiais de reuso e de reciclagem interna do sistema não foram considerados e os fluxos analisados foram contabilizados separadamente.

Segundo os autores, é um processo lento e progressivo, exigindo o alinhamento das empresas individuais com os objetivos coletivos do sistema e a utilização de indicadores para medir esta evolução.

Geng et al. (2009) apresentam o modelo de economia circular implantado na China e discutem sobre desempenho ambiental dos projetos nas áreas industriais. A implantação de EIPs surgiu como um projeto de apoio à política da economia circular chinesa, tendo atualmente mais de cinquenta projetos pilotos em andamento. Os autores apresentaram quatro grupos de indicadores aplicáveis nos parques industriais chineses para medir sua eco-eficiência: indicadores de desenvolvimento econômico, indicadores de redução de materiais e reciclagem, indicadores de controle de poluição e indicadores relacionados à gestão do parque.

Mais tarde, Geng et al. (2012) propuseram um sistema de doze indicadores, categorizados em quatro grupos. Quatro indicadores para a saída de recursos e quatro para categoria de consumo, dois indicadores para a utilização de recursos integrados e dois para a eliminação de resíduos e emissão de poluentes. O MFA foi selecionado como principal método para desenvolver tais indicadores, e outras ferramentas, como indicadores de eco eficiência, também foram adotadas para medir o desempenho ambiental relacionado com o desempenho econômico, 
especialmente para o uso de água, energia e geração de resíduos. Os autores concluem que a aplicação desse sistema pode colaborar para maior atenção dos governos locais quanto às questões ambientais e para atingir benefícios econômicos, ambientais e sociais. Entretanto, existem barreiras significativas, como a forma de implementação deste sistema, a falta de indicadores específicos de SI e indicadores sociais, e a ausência de estudos que apresentam resultados significativos da implantação deste sistema de indicadores.

Kurup e Stehlik (2009) aplicaram um modelo de avaliação em EIPs para medir os benefícios da simbiose industrial nas dimensões ambientais, sociais e econômicas. Para avaliar a eficiência do método, os autores desenvolveram indicadores para medir alguns aspectos de cada dimensão. Os autores destacaram a falta de estudos para medir as relações entre os stakeholders e estudar as regras comuns que ajudam as organizações e comunidades a trabalharem de forma mais eficiente. O Quadro 3 mostra os indicadores utilizados.

Quadro 3. Indicadores utilizados para avaliar os benefícios da SI em cada dimensão de análise segundo Kurup e Stehlik (2009).

\begin{tabular}{|c|c|c|}
\hline Dimensions & Capitals & Indicators \\
\hline \multirow[t]{5}{*}{ Environmental benefits } & Natural & Resource conservation \\
\hline & & Resource security \\
\hline & Eco-system & Water contamination \\
\hline & & Dust emission \\
\hline & & Noise impact \\
\hline \multirow[t]{10}{*}{ Social benefits } & Human & Productivity \\
\hline & & Retention of employees \\
\hline & & Job security/creation \\
\hline & & $\begin{array}{l}\text { Sharing occupational health } \\
\text { and safety programmes }\end{array}$ \\
\hline & & $\begin{array}{l}\text { Investment in research and } \\
\text { development }\end{array}$ \\
\hline & & $\begin{array}{l}\text { Sharing of infrastructure and } \\
\text { technology }\end{array}$ \\
\hline & & Sharing of human resources \\
\hline & & management \\
\hline & & $\begin{array}{l}\text { Information sharing between } \\
\text { companies }\end{array}$ \\
\hline & Community & $\begin{array}{l}\text { Perception of communities in } \\
\text { regards to environmental }\end{array}$ \\
\hline
\end{tabular}




\begin{tabular}{|c|c|c|}
\hline Dimensions & Capitals & Indicators \\
\hline & & health \\
\hline & & $\begin{array}{l}\text { Communication about the } \\
\text { project in the community }\end{array}$ \\
\hline & & $\begin{array}{l}\text { Opportunities of educational } \\
\text { partnership for school children }\end{array}$ \\
\hline & & Employment opportunities \\
\hline & & Complaints from community \\
\hline & & $\begin{array}{l}\text { Sharing of information between } \\
\text { community and industries }\end{array}$ \\
\hline & & $\begin{array}{l}\text { Level of understanding about } \\
\text { IS projects among the } \\
\text { community }\end{array}$ \\
\hline & & Opportunities of public relations \\
\hline & & $\begin{array}{l}\text { Networking between industries } \\
\text { and communities }\end{array}$ \\
\hline \multirow[t]{10}{*}{ Economic benefits } & Manufactured & Business opportunities \\
\hline & & Infrastructure for industries \\
\hline & & Infrastructure for public \\
\hline & Financial & Labour costs \\
\hline & & Equipment costs \\
\hline & & Raw material costs \\
\hline & & Compliance costs \\
\hline & & Permit costs \\
\hline & & Cost of penalties/fines \\
\hline & & Cost of future liabilities \\
\hline
\end{tabular}

Fonte: Kurup e Stehlik (2009).

Pakarinen et al. (2010) utilizaram indicadores ambientais para avaliar a sustentabilidade em quatro diferentes condições de simbiose industrial. Para cada condição, os autores escolheram temas como, recursos não renováveis, emissões para a natureza, uso de terra, impactos sobre a saúde humana e sobre a sociedade para então, selecionar os indicadores específicos dentro destas condições para avaliar os impactos causados pela evolução da SI. O Quadro 4 apresenta os indicadores selecionados.

Quadro 4. Indicadores usados para analisar a sustentabilidade do sistema.

\begin{tabular}{cccc}
\hline $\begin{array}{c}\text { System Condition 1: } \\
\text { non-renewable } \\
\text { resources }\end{array}$ & $\begin{array}{c}\text { System Condition 2: } \\
\text { emissions } \\
\text { to nature }\end{array}$ & $\begin{array}{c}\text { System Condition 3: } \\
\text { land use }\end{array}$ & $\begin{array}{c}\text { System Condition 4: } \\
\text { impacts } \\
\text { on human health and } \\
\text { society }\end{array}$ \\
\hline
\end{tabular}




\begin{tabular}{llll}
\hline \multicolumn{1}{c}{ Indicators } & & & \\
Recycling of metals & $\begin{array}{l}\text { Recovery of process } \\
\text { chemicals }\end{array}$ & $\begin{array}{l}\text { Extraction of wood } \\
\text { and other resources }\end{array}$ & $\begin{array}{l}\text { Health risks of the } \\
\text { pollution }\end{array}$ \\
$\begin{array}{l}\text { Waste and by-product } \\
\text { utilization }\end{array}$ & $\begin{array}{l}\text { Hazardous emissions } \\
\text { to water } \\
\text { Fuel use }\end{array}$ & $\begin{array}{l}\text { Other area-consuming } \\
\text { activities } \\
\text { Other emissions to } \\
\text { water } \\
\text { Emissions to air } \\
\text { Recycling and waste } \\
\text { treatment }\end{array}$ \\
\hline Fonte: Pakarinen et al. (2010).
\end{tabular}

Segundo os autores, os indicadores apresentados no estudo de caso podem ser um ponto de partida para a análise dos aspectos que envolvem o processo de simbiose industrial.

Zhu et al. (2010) desenvolveram um método de seleção de empresas interessadas em participar de um EIP que incluía a aplicação de um sistema de indicadores, fornecendo um método quantitativo para avaliar a adequação da empresa em um EIP para aumentar a eficiência e estabilidade sistêmica. O sistema é composto por sete indicadores primários e vinte e sete secundários, os quais constituem uma estrutura hierárquica. $O$ quadro 5 mostra os indicadores componentes do sistema:

Quadro 5. Sistema de indicadores aplicados em EIPs.

\begin{tabular}{ll}
\hline PRIMARY INDICATOR (NO) & SECONDARY INDICATOR (NO) \\
\hline Park-based indicators & \\
Matching with existing industrial chains (F1) & Industrial chain extension (M1) \\
& Industrial chain coupling (M2) \\
& Industrial chain adjustability (M3) \\
& Land carrying capacity (M4) \\
Park carrying capacity (F2) & Water carrying capacity (M5) \\
& Energy carrying capacity (M6) \\
& Wastewater collection and treatment capacity \\
& $($ M7) \\
& Wastes collection and central treatment capacity \\
& (M8) \\
& COD $^{\text {a }}$ environmental capacity (M9) \\
& SO2 environmental capacity (M10) \\
& Park COD emission change rate (M11) \\
Park environment performance improvement & \\
(F3) &
\end{tabular}




\begin{tabular}{ll}
\hline PRIMARY INDICATOR (NO) & SECONDARY INDICATOR (NO) \\
\hline & Park SO2 emission change rate (M12) \\
& Percent-added of park water productivity (M13) \\
Enterprise-based indicators & Percent-added of park energy productivity (M14) \\
Eco-design (F4) & \\
& Sustainable architecture design (M15) \\
& Product eco-design (M16) \\
& Green packing (M17) \\
Economic benefit (F5) & Green transportation design (M18) \\
& Industrial value-added per unit area (M19) \\
Resources utilization (F6) & Industrial value-added per capita (M20) \\
& Energy consumption per IVA (M21) \\
& Fresh water consumption per IVA (M22) \\
& Recycling rate of industrial water (M23) \\
& Recycling rate of industrial solid wastes(M24) \\
Pollutants production (F7) & Wastewater production per unit IVA (M25) \\
& CoD production per unit IVA (M26) \\
& Production of wastes per unit IVA (M27) \\
&
\end{tabular}

${ }^{\mathrm{a}} \mathrm{COD}=$ chemical oxygen demand

IVA= industrial value-added

Fonte: Adaptada de Zhu et al. (2010).

Por meio do estudo de caso em um EIP chinês, os autores aplicaram o sistema de indicadores em cinco empresas candidatas para avaliar sua funcionalidade para triagem dessas empresas. O método AHP foi utilizado para gerar pesos aos sete indicadores primários. Os autores concluíram que o sistema fornece uma avaliação direta para os desenvolvedores e administradores de EIP.

Os trabalhos apresentam a aplicação de indicadores ambientais sob uma perspectiva estática, não consideram o dinamismo do sistema. 


\section{PROPOSTA DO INDICADOR DE SIMBIOSE - ISI}

Neste capítulo é apresentada a proposta do indicador, cujo objetivo é apontar a evolução do desempenho das relações simbióticas entre as empresas de um EIP, de forma que possa ser utilizado como instrumento de gestão para o incentivo na ampliação desse tipo de relacionamento.

Inicialmente discutem-se as características do indicador por meio da elaboração de princípios e requisitos. Em seguida é apresentado o papel fundamental do indicador, bem como sua forma de utilização por todos os atores envolvidos.

Por fim, apresenta-se o processo de desenvolvimento do indicador de simbiose, incluindo os elementos participantes, sua avaliação e análise.

\subsection{PRINCÍPIOS E REQUISITOS PARA UM INDICADOR DE SIMBIOSE PARA EIP}

As pesquisas que analisaram EIPs sustentam que os indicadores são um instrumento importante, tal qual apresentado na seção 4.3. Para tanto, é de extrema importância caracterizá-los por meio de princípios específicos e limitar as fronteiras que o abrangem utilizando certos requisitos.

A partir da análise dos casos apresentados e dos requisitos apontados por Gomes (2011), foi possível adaptar e elaborar princípios que o indicador deve obedecer segundo a realidade do processo de SI:

a) $O$ indicador deve levar em consideração se os requisitos do ponto de vista do usuário foram respeitados;

b) $O$ indicador deve ser a medida do desempenho atual e passível de alteração por intervenção gerencial no futuro;

c) Deve encorajar comportamentos e decisões de curto e longo prazo que tragam significativas melhorias continuamente;

d) Deve também ser capaz de avaliar se o planejamento atual permite atingir níveis de desempenho determinados e sirvam de base para a tomada de decisões gerenciais; 
e) O indicador deve ser definido de modo que as principais ações relativas ao fluxo de resíduos afetem o processo de simbiose industrial e em consequência ser objeto de medições e ajustes;

f) Deve ser passível de comparação em uma escala temporal.

Esses princípios harmonizam-se com as características que devem ser atendidas por um indicador, segundo o estudo de Gomes (2011).

O indicador em estudo deve retratar o nível de simbiose entre as empresas de um EIP. Sua composição deve contar com dados identificados regularmente resultantes do fluxo de resíduos do sistema, podendo variar de acordo com as mudanças do ambiente, limitando-se às fronteiras do EIP. Estas mudanças precisam refletir diretamente nas variáveis utilizadas. A variação do indicador deve ser influenciada apenas pela variação de parâmetros fundamentais do processo de simbiose, garantindo sua relevância.

O indicador deve formar uma série histórica e necessita de uma referência. O primeiro mês de aplicação do indicador seria a escolha indicada como referência inicial. A fim de garantir a conformidade temporal, o valor do indicador deve corresponder ao mês analisado anteriormente, fornecendo uma informação prescritiva, ou seja, é analítica e apresenta recomendações ao desenvolvimento de alternativas, fundamental para tomada de decisão. O indicador deve ser acessível e disponível a todos os atores envolvidos, sendo comunicado de forma gráfica, mostrando seu desempenho durante o período de interesse. Na fase de construção da variável grau do resíduo (circulante ou saída), os pesos dados aos critérios na classificação dos resíduos devem ser fornecidos pelos agenciadores do EIP, priorizando cada critério de acordo com seus interesses.

Este indicador não visa substituir outros indicadores importantes, por exemplo, o próprio indicador de impacto ambiental. Ao contrário, seu objetivo seria complementar o uso de outros indicadores. Por exemplo, o gestor do parque poderia monitorar ao mesmo tempo a simbiose e o impacto ambiental do EIP. O seu objetivo seria aumentar a simbiose e diminuir o impacto do parque como um todo. Assim, o objetivo é que este indicador possa ser integrado a um sistema de indicadores de desempenho maior, contendo outras medidas.

O Quadro 5 sumariza os atributos do indicador que foram propostos para este trabalho, baseado na proposta de Gomes (2011), adaptada para o contexto de um EIP, entendido como um sistema complexo. 
Quadro 6. Paralelo entre as características ideais de um indicador com os atributos do indicador de simbiose industrial proposto.

\begin{tabular}{|c|c|}
\hline Requisitos & Atributos do Indicador de Simbiose \\
\hline Representatividade & $\begin{array}{l}\text { Deve ter capacidade de retratar o nível simbiótico numa } \\
\text { série temporal. }\end{array}$ \\
\hline Fonte de informação & $\begin{array}{l}\text { Deve considerar dados confiáveis e ao mesmo tempo } \\
\text { passíveis de serem obtidos com custos e tempo } \\
\text { compatíveis. }\end{array}$ \\
\hline Relevância & $\begin{array}{l}\text { Sua variação deve ser influenciada apenas pela } \\
\text { variação de parâmetros fundamentais do processo de } \\
\text { simbiose. }\end{array}$ \\
\hline Valores de referência & $\begin{array}{l}\text { A primeira medição deve ser a referência inicial para } \\
\text { análise do próximo valor, pois o objetivo é mostrar a } \\
\text { evolução. }\end{array}$ \\
\hline Conformidade temporal & $\begin{array}{l}\text { O valor do indicador deve corresponder ao período de } \\
\text { tempo analisado. }\end{array}$ \\
\hline Sensibilidade às mudanças & $\begin{array}{l}\text { Qualquer alteração nos dados de resíduos circulante e } \\
\text { saída deverá afetar diretamente no valor do indicador. }\end{array}$ \\
\hline Séries temporais & Os dados devem ser coletados mensalmente. \\
\hline Abrangência & Deve-se limitar às fronteiras geográficas de um EIP. \\
\hline Integração & $\begin{array}{l}\text { Este indicador deve ser capaz de se integrar a um } \\
\text { sistema de indicadores de desempenho contendo outras } \\
\text { medidas. }\end{array}$ \\
\hline Tipo de Informação & O indicador deve fornecer uma informação prescritiva. \\
\hline Disponibilidade e Acesso & $\begin{array}{l}\text { O indicador necessita estar disponível ao agenciador e } \\
\text { às empresas participantes. }\end{array}$ \\
\hline $\begin{array}{l}\text { Comunicação/divulgação dos } \\
\text { indicadores }\end{array}$ & $\begin{array}{l}\text { O nível de simbiose deve ser divulgado de maneira } \\
\text { gráfica para avaliar o desempenho numa escala } \\
\text { temporal. }\end{array}$ \\
\hline Participação dos usuários & $\begin{array}{l}\text { A classificação dos resíduos na elaboração do grau do } \\
\text { resíduo deverá ser priorizada e/ou selecionada de } \\
\text { acordo com o interesse dos gerenciadores do EIP. }\end{array}$ \\
\hline Atualização e Divulgação & Os dados devem ser coletados regularmente. \\
\hline Fácil compreensão & $\begin{array}{l}\text { O indicador deve ser o resultado da divisão do fluxo } \\
\text { interno de resíduos circulantes sobre o fluxo de resíduos } \\
\text { de saída. }\end{array}$ \\
\hline Modelo conceitual estrutural & $\begin{array}{l}\text { O indicador deve possui uma estrutura coerente de } \\
\text { desenvolvimento baseado em Cardoso (2004). }\end{array}$ \\
\hline
\end{tabular}

Os requisitos "validação científica" e "custo" não serão considerados nesta pesquisa. O requisito "redundância" não se aplica ao caso, pois a ideia é que seja o indicador mais simples possível, uma vez que sua utilização não é realizada por especialistas em sustentabilidade, mas por gestores e profissionais, atores do 
parque. Quanto mais simples e menos redundante, mais facilmente influenciaria nas decisões dos atores. O requisito "conectividade" não se aplica.

\subsection{Papel do indicador de simbiose e a dinÂmica do EIP.}

O indicador de simbiose proposto tem como papel fundamental a avaliação da evolução do nível de simbiose do EIP ao longo do tempo. Deve-se fazer isso de forma que esses resultados possam ser utilizados por diferentes usuários, conforme a Figura 9.

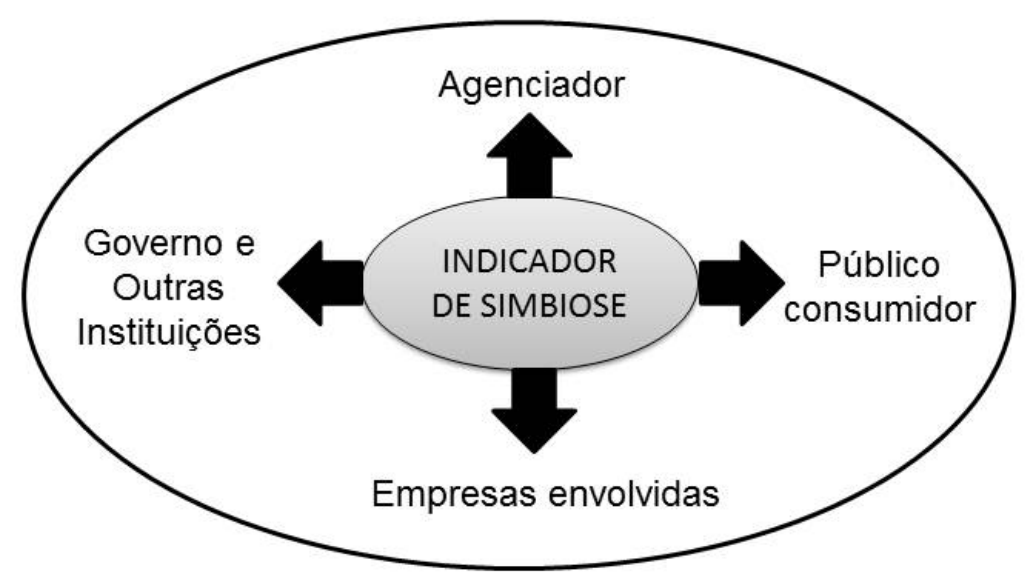

Figura 9. Usuários do Indicador de Simbiose.

Os usuários podem alinhar as suas estratégias individuais às estratégias dos negócios integrados numa abordagem middle out, proposta por Costa e Ferrão (2010), cujo objetivo é criar um contexto favorável para o desenvolvimento de SI através de um processo de feedback que possa orientar os envolvidos em suas ações.

Assim, à medida que decisões são tomadas, os efeitos são observados e geram-se informações que são enviadas de volta para os agentes, que podem introduzir ou reajustar suas intervenções.

O indicador poderia fornecer ao agenciador um retrato momentâneo e um histórico da situação do EIP quanto ao processo de SI, possibilitando na escolha de futuras empresas, controlando e gerenciando sua interatividade de forma a aumentar o nível simbiótico do parque.

Dessa forma, o agenciador por meio do indicador, pode: 
- priorizar a entrada de empresas que contribuam para o aumento do nível do indicador e, consequentemente, da SI;

- monitorar e avaliar o desempenho simbiótico das empresas participantes e do EIP como um todo, comparando com períodos de referência anteriores;

- identificar resíduos que possam ser alvo de estratégias de estímulo ao aumento de consumo entre as empresas por meio da cooperação entre as empresas;

- oferecer medidas de incentivo como isenções em taxas de transporte, tratamento e descarte, incentivando que as empresas desenvolvam processos de produção que reutilizem resíduos gerados dentro do parque, incentivando a simbiose;

- comunicar o desempenho ambiental do EIP aos stakeholders;

- promover o chamado "marketing verde" do EIP;

- estimular potenciais parcerias com outros EIPs; e

- identificar resíduos e emissões mais prejudiciais.

Além do agenciador, as empresas envolvidas podem utilizar o indicador para verificar o impacto de suas ações e reportar os avanços. O indicador serviria para sinalizar aos diretores que os demais agentes estão avaliando-os nesta dimensão. Isso incentivaria a busca de melhor desempenho e demonstraria a contribuição no nível simbiótico gerado pelo indicador. Por fim, os profissionais teriam uma forma de identificar ações e poderiam passar a considerar esta questão de maneira mais objetiva, durante o planejamento de novos produtos, plantas industriais ou substituições de equipamentos e matérias-primas. Contudo, as empresas podem:

- realizar novas trocas de resíduos industriais;

- analisar oportunidades para inovações tecnológicas e melhorias de eficiência; e

- identificar novas oportunidades de mercado.

O resultado final seria um processo que incentivaria o alinhamento das ações dos atores do EIP, de maneira dinâmica. Este processo participativo é essencial, pois atende ao conceito de parque industrial como um ambiente complexo e dinâmico. Os atores podem utilizá-lo, então, como parte de seu processo decisório e definir as metas e prioridades para o indicador e, no seu 
processo de comunicação, buscar a efetiva compreensão e interpretação dos resultados em relação aos valores e visões destes atores.

A Figura 10 ilustra esquematicamente o papel do indicador no fluxo de atividades e decisão. O agenciador do parque, como principal usuário do indicador, seria responsável pelo levantamento dos dados relacionados com todos os resíduos circulantes e de saída do EIP. O objetivo é alimentar o banco de dados com os tipos e quantidades dos resíduos, que são cadastrados, codificados e utilizados na construção do indicador.

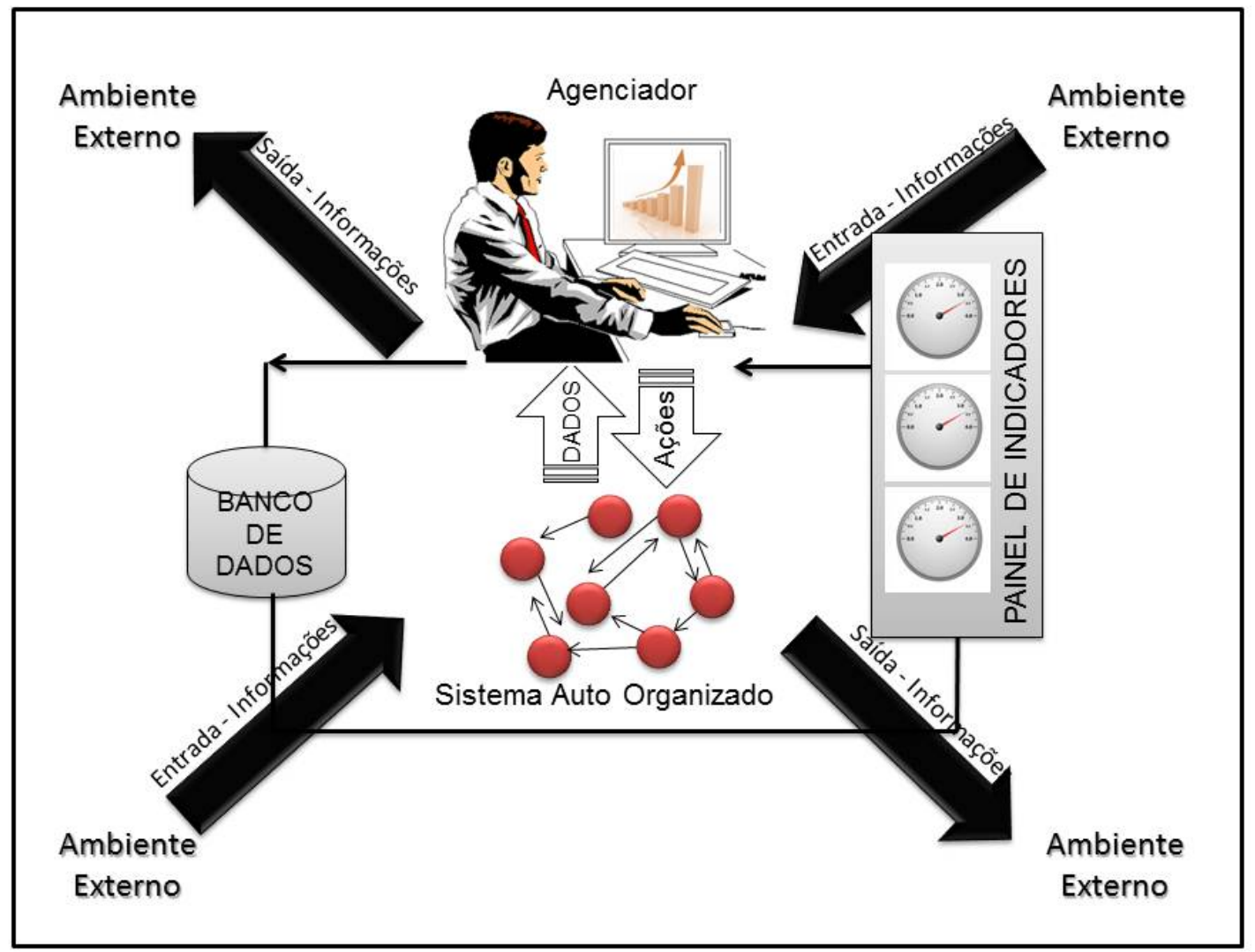

Figura 10. Esquema do funcionamento do indicador.

Isto é possível na medida que o agenciador comumente se responsabiliza por ações de infraestrutura do parque, como a de transporte de resíduos. Isto é, ele poderia oferecer os serviços como a coleta e transporte de resíduos internamente e fora do parque e, ao fazê-lo, poderia coletar os dados de fluxo de materiais interno e externo.

Os valores são armazenados no banco de dados e utilizados no cálculo do indicador. Então, eles poderiam ser comparados mensalmente a fim de avaliar o desempenho simbiótico do EIP ao longo do tempo. Além disso, o agenciador pode avaliar a entrada de novas empresas no parque por meio de simulações com o 
indicador, averiguando a contribuição da potencial empresa no valor do nível simbiótico.

O agenciador pode, ainda, estimular a permanência ou até mesmo atrair novas empresas no parque por meio de descontos sobre a taxa de condomínio ou outros serviços, caso a empresa tenha uma alta contribuição no valor do indicador simbiótico. Assim, os atores, gestores e técnicos das empresas que fazem parte do parque passariam a contabilizar este aspecto nas suas decisões. O resultado seriam organizações estimuladas a permanecerem no EIP e a aumentarem sua contribuição para a simbiose do parque, mesmo com as possíveis mudanças de mercado geradas pelo ambiente externo.

\subsection{Desenvolvimento do IndiCAdor DE SIMBIOSE}

O indicador desenvolvido é específico para o contexto organizacional de um EIP e, segundo requisitos dos usuários. O processo de desenvolvimento do indicador acompanhou os elementos fundamentais apontados por Cardoso (2004) e Martínez (2009), e a metodologia adaptada de Magalhães (2004).

Primeiramente, foi selecionado o processo considerado relevante para compor o indicador e, consequentemente, a determinação das variáveis que pudessem caracterizar o processo escolhido.

Em seguida, foi possível desdobrar e consolidar as variáveis selecionadas em uma fórmula matemática para então, calcular o indicador.

Por fim, foram construídas diferentes situações para averiguar a aplicabilidade do indicador proposto com dados reais de resíduos.

\subsubsection{Conceito geral do indicador}

O ponto de partida para a escolha das variáveis foi selecionar os principais processos dentro do EIP que o caracterizasse como tal.

Como dito na revisão, a simbiose, em seu sentido específico, como sistema fechado, mostra uma situação em que um indivíduo gera resíduos de seu funcionamento vital, os quais são totalmente aproveitados por outro indivíduo, e 
vice-versa, de forma que ambos tornam-se auto-suficientes, deixando de necessitar do ambiente.

O paralelo na simbiose industrial é o resíduo industrial. Em um cenário de simbiose industrial perfeita, portanto, os resíduos industriais de uma empresa do parque seriam utilizados pelas demais e assim sucessivamente, tal que, nenhuma delas dependesse mais do ambiente, como num ciclo fechado. Faz-se necessário medir, portanto, a quantidade de resíduos que é absorvida por cada empresa do parque.

Um indicador de simbiose poderia espelhar a relação entre a quantidade de resíduo que circula dentro do parque (resíduos circulantes) e a quantidade de resíduos que sai do parque, ou do sistema industrial, somado a 1. Em uma simbiose perfeita haveria uma quantidade grande de resíduos circulando e nenhum saindo do parque, tal que o resultado da conta será sempre a quantidade de resíduo circulando. E também, quanto maior o resíduo circulando, sem saída de resíduo, maior a simbiose. Colocando a série em uma base de referência, por exemplo, o período inicial 1 , teríamos uma forma de avaliar a evolução. Portanto, partiu-se da quantidade de resíduos.

Além disso, as variáveis "Grau do resíduo" (circulante e saída) foram criadas para representar o aspecto ambiental sugerido por Olsthoonr et al. (2001) e CSIRO (1999). Para os autores, os dados mensuráveis dos principais aspectos ambientais das empresas devem ser transformados e citados na composição do indicador.

Assim, para cada quantidade de diferentes resíduos foi multiplicado o seu respectivo "Grau do resíduo" (circulante e saída). O resultado deste cálculo gerou duas novas variáveis chamadas de Quantidade de Impacto Circulante (QIC), englobando a quantidade de resíduo circulante, e a Quantidade de Impacto de Saída (QIS), considerando a quantidade de resíduo de saída.

As equações resultantes das construções das variáveis foram detalhadas na seção 5.3 .3 e 5.3.5. 


\subsubsection{Quantidade de resíduos}

A quantidade de resíduos é representada por duas variáveis: Quantidade de Resíduo Circulante (QRC) e Quantidade de Resíduo de Saída (QRS). Os valores apresentados são absolutos e as unidades de medidas são dadas em tonelada/mês.

A QRC é a quantidade de materiais trocados entres as empresas de um EIP e a QRS é a quantidade de materiais que não são reutilizados pelas empresas e saem do parque.

Um problema nestas variáveis é que elas levam em conta apenas a quantidade de resíduos e não consideram a diferença que há na natureza do impacto ambiental gerado. Por exemplo, $100 \mathrm{Kg}$ de papelão não podem ser contabilizados igualmente a $100 \mathrm{Kg}$ de bateria, pelos níveis de toxidade e comprometimento ao meio ambiente dos dois resíduos.

A maneira utilizada para contornar este problema foi a inclusão de uma variável que avaliasse cada resíduo de acordo com alguns critérios, de forma a considerar esta questão.

Assim, foram introduzidas novas variáveis, chamadas de Grau do resíduo circulante (GRC) e Grau do resíduo de saída (GRS).

\subsubsection{Grau do resíduo}

As variáveis "Grau de resíduo circulante" (GRC) e "Grau de resíduo de saída" (GRS) foram criadas para mostrar o grau de importância do resíduo, baseado em critérios da avaliação qualitativa de impacto ambiental.

O Grau do resíduo (circulante e saída) é resultado de uma avaliação dos resíduos, que considera quatro critérios para resíduos circulantes (legislação, classe do resíduo, uso do resíduo no parque e problemas/riscos) e quatro critérios para resíduos de saída (legislação, classe do resíduo, destinação do resíduo e problemas/riscos). Para cada critério, foram estipulados três níveis de pontuação, conforme proposta de Gossen (2008). O objetivo desta etapa é registrar e caracterizar os resíduos industriais. A elaboração das variáveis GRC e GRS é de 
fundamental importância, uma vez que ela diferencia os resíduos e seus potenciais impactos no processo de SI.

Quanto aos critérios utilizados nas variáveis, foi necessário gerar pesos para cada um deles, já que alguns tinham maior importância que outros. Neste trabalho, a atribuição dos pesos aos critérios baseou-se no método de análise hierárquica. Conforme apresentado na seção 2.4.3, a ferramenta AHP permite avaliar variáveis qualitativas em um processo de tomada de decisão gerando parte do resultado que esta pesquisa objetiva. Demonstrou-se também que ela vem sendo empregada com frequência em estudos da área ambiental para solucionar problemas semelhantes a este, quando há muitos critérios para a tomada de decisão.

Sabe-se que o método AHP é utilizado para escolher o melhor caminho em meio a várias opções. No presente trabalho, o método foi escolhido somente para gerar pesos aos critérios das variáveis GRC e GRS de maneira consistente e não para escolher um critério específico. Mesmo assim, foi possível construir a estrutura hierárquica que o método propõe, mas de forma adaptada.

As etapas para a construção dos pesos das variáveis foram aplicadas utilizando o método AHP de acordo com a proposta de Saaty (2008) e são descritas a seguir.

\subsubsection{Definição do problema e objetivo}

Nesta etapa, o objetivo foi gerar diferentes pesos para os critérios que caracterizam os resíduos circulantes e de saída do EIP de forma consistente. A ideia foi atribuir valores de acordo com a importância de cada critério comparados entre si, par a par.

\subsubsection{Estruturação do problema}

A estrutura hierárquica foi elaborada a partir da definição do problema e objetivo. A estrutura para o objetivo em questão foi composta por dois níveis hierárquicos que são apresentados na sequência.

Como mostrado na Figura 11, o primeiro nível compreendeu o próprio objetivo. O objetivo é a raiz da estrutura hierárquica e a partir dele a árvore invertida é formada. Já o segundo nível foi composto pelos seguintes critérios: Legislação, Classe do Resíduo, Uso/Destinação do resíduo e Problemas/Riscos. 


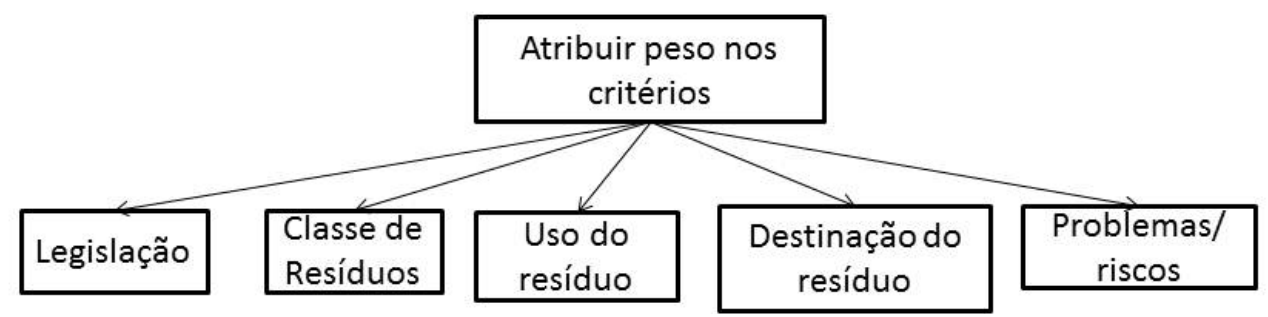

Figura 11. Decomposição de um problema em uma estrutura hierárquica.

A seguir, são apresentados no Quadro 7, os critérios escolhidos na composição do grau do resíduo (circulante e saída) e suas respectivas categorias. A explicação referente a cada categoria encontra-se no anexo A.

Quadro 7. Critérios utilizados na variável "Grau do resíduo (circulante e saída)".

\begin{tabular}{|c|c|}
\hline CRITÉRIOS & AVALIAÇÃO \\
\hline \multirow{3}{*}{ Legislação } & 1.Boas Práticas \\
\hline & 3.Requisito Geral \\
\hline & 5.Requisito Legal Específico \\
\hline \multirow{3}{*}{ Classe de resíduos } & 1.Não perigoso-Inertes \\
\hline & 3.Não perigoso-Não inertes \\
\hline & 5.Perigosos \\
\hline \multirow{3}{*}{ Uso de resíduos } & $\begin{array}{l}\text { 1. Existe tratamento do resíduo na empresa } \\
\text { doadora e receptora }\end{array}$ \\
\hline & $\begin{array}{l}\text { 3. Existe tratamento na empresa receptora do } \\
\text { resíduo }\end{array}$ \\
\hline & $\begin{array}{l}\text { 5.Não é necessário tratamento em nenhuma } \\
\text { das empresas }\end{array}$ \\
\hline \multirow{3}{*}{ Destinação dos resíduos } & 1.Outro EIP com pré-tratamento \\
\hline & 3.Outro EIP sem pré-tratamento \\
\hline & 5.Aterro Industrial (Classe I e II) \\
\hline \multirow{3}{*}{ Problemas/riscos } & 1.Inexistente \\
\hline & 3.Eventuais/isolados \\
\hline & 5.Frequentes \\
\hline
\end{tabular}

\subsubsection{Avaliação dos critérios}

A matriz de comparação par a par foi construída utilizando os cinco critérios e atribuindo valores de acordo com a escala fundamental de julgamento em grau de importância. Os critérios "uso" e "destinação" dos resíduos foram considerados 
como o mesmo critério na matriz, pois a sua importância é igual na análise dos resíduos. As Tabelas 2 e 3 mostram os resultados da avaliação. 
Tabela 2. Matriz de comparação.

\begin{tabular}{ccccc}
\hline & $\begin{array}{c}\text { Critério 1 } \\
\text { Legislação }\end{array}$ & $\begin{array}{c}\text { Critério 2 } \\
\text { Classe do } \\
\text { resíduo }\end{array}$ & $\begin{array}{c}\text { Critério 3 } \\
\text { Uso/Destinação do } \\
\text { resíduo no parque }\end{array}$ & $\begin{array}{c}\text { Critério 4 } \\
\text { Problemas/ } \\
\text { riscos }\end{array}$ \\
\hline $\begin{array}{c}\text { Critério 1 } \\
\text { Legislação } \\
\text { Critério 2 }\end{array}$ & 1 & 2 & 3 & 3 \\
$\begin{array}{c}\text { Classe do resíduo } \\
\text { Critério 3 }\end{array}$ & $1 / 2$ & 1 & 3 & 1 \\
$\begin{array}{c}\text { Uso/Destinação do } \\
\text { resíduo no parque } \\
\text { Critério 4 }\end{array}$ & $1 / 3$ & $1 / 3$ & 1 & 1 \\
Problemas/riscos & $1 / 3$ & $1 / 2$ & $1 / 2$ & 1 \\
\hline
\end{tabular}

Tabela 3. Resultado da avaliação.

\begin{tabular}{lccccc}
\hline & Critério & Critério & Critério & Critério & TOTAL \\
& $\mathbf{1}$ & $\mathbf{2}$ & $\mathbf{3}$ & $\mathbf{4}$ & \\
\hline Somatório & 2,17 & 4,33 & 8 & 6 & 20,5 \\
Peso & $10,57 \%$ & $21,14 \%$ & $39,02 \%$ & $29,27 \%$ & \\
\hline
\end{tabular}

O resultado do cálculo da razão de consistência após a avaliação foi de $\mathrm{RC}=0,043$ obedecendo ao limite proposto por Saaty $(1987,1991)$ de 0,08 para uma comparação de quatro elementos. Assim, a matriz com os julgamentos revela-se consistente.

Logo, de acordo com a Tabela 3 , o critério com maior peso é o uso/destinação do resíduo com $39,02 \%$, seguido do critério problemas/riscos com peso $29,27 \%$, o critérios classe do resíduo com $21,14 \%$ e por último, com o menor peso, a legislação com $10,57 \%$.

Note que esta avaliação foi realizada pela pesquisadora. Em uma aplicação real do indicador seria possível obter um conjunto de pesos que fosse consenso entre os atores do parque ou condomínio industrial. Isto é, cada ator, agenciador, empresas ou representantes dos stakeholders, como o poder público, dariam notas semelhantes e seria obtido um valor que seria consenso.

Assim, o cálculo do grau do resíduo (circulante e saída) pode ser expresso na Equação 1.

$$
\text { GR = avaliação do critério } \times \text { peso do critério }
$$


Onde,

GR: Grau do resíduo (circulante e saída)

Avaliação do critério: valores que podem ser 1, 3 ou 5

Peso do critério: calculado pelo método AHP, podendo ser 10,57\%, 21,14\%, $39,02 \%$ e $29,27 \%$.

\subsubsection{Quantidade de Impacto Circulante (QIC) e Quantidade de Impacto de Saída (QIS)}

O desenvolvimento do indicador de simbiose inclui, basicamente, comparar o fluxo interno de resíduos circulantes no EIP, chamado aqui de quantidade de impacto circulante, com o fluxo externo de resíduos, denominado de quantidade de impacto de saída, tentando a partir daí, chegar numa relação de simbiose com o aumento do número do indicador.

A variável QIC é resultado da soma das quantidades de resíduos circulantes, multiplicados pelos seus respectivos GRC, e a variável QIS é o resultado da soma das quantidades de resíduos de saída, multiplicados com seus respectivos GRS.

\subsubsection{Formulação matemática do indicador}

A lógica da comparação de fluxos de resíduos é a seguinte: quanto maior for o fluxo interno de resíduos circulantes e menor o fluxo externo de resíduos, maior será o valor do indicador de simbiose, ou seja, a maior parte dos resíduos gerados no EIP estão sendo reutilizados dentro do próprio parque e poucos resíduos estão saindo, como mostrado na Equação 2. Caso contrário, se o fluxo externo de resíduos for alto, o nível de simbiose certamente será menor.

$$
\mathrm{ISI}=\frac{\mathrm{QIC}}{(1+\mathrm{QIS})}
$$

Onde,

ISI: Indicador de Simbiose Industrial

QIC: Quantidade de Impacto Circulante

QIS: Quantidade de Impacto de Saída

Cada resíduo possui particularidades e características que necessitam ser consideradas. Assim, todos os resíduos cadastrados no banco de dados do 
agenciador do parque são avaliados por meio de quatro critérios, tendo cada um, pontuações e pesos diferentes. O resultado desta avaliação é considerado na formulação do indicador por meio do grau do resíduo (circulante e saída). Cada quantidade de resíduo, seja ele QRC ou QRS, é multiplicado pelo seu grau do resíduo (circulante e saída). O valor resultante dado pela fórmula será um valor adimensional. O resultado é a fórmula expressa na Equação 3.

$$
\mathbf{I S I}=\frac{\mathrm{QIC}}{1+\mathrm{QIS}}=\frac{\sum(\mathrm{QRC} \times \mathrm{GRC})}{1+\sum(\mathrm{QRS} \times \mathrm{GRS})}
$$

Onde,

QRC: Quantidade de resíduo circulante

GRI: Grau do resíduo circulante

QRS: Quantidade de resíduo de saída

GRS: Grau do resíduo de saída

\subsection{AvaliaçÃo E ANÁLISE do INDICADOR}

O propósito desta fase foi averiguar a aplicabilidade do indicador proposto diante de diferentes situações, com dados reais de quantidade de resíduos. A avaliação do indicador seguiu dois objetivos: avaliar sua coerência em situações de simbiose e não simbiose (seção 5.4.1) e avaliar seu comportamento diante de diferentes variações (seção 5.4.2).

\subsubsection{Análise do ISI em três situações}

Para exemplificar a aplicação da fórmula e avaliar sua coerência em algumas situações, foram criadas três delas: parque industrial sem simbiose, parque industrial com simbiose, parque industrial com simbiose perfeita.

Para avaliar o comportamento do ISI, deve-se, primeiramente, definir as variáveis GRC e GRS, e assim torná-las constantes para a aplicação das três situações. A avaliação do uso e destinação do resíduo são os únicos critérios que dependem da atuação das empresas quanto ao tratamento dos resíduos. A avaliação dos outros critérios é determinada pela própria característica do resíduo, sendo um valor absoluto e independente. 
Optou-se por gerar uma situação otimista na realidade do GRC e GRS. Portanto, no caso do "grau dos resíduos circulantes", foi adotado para o critério "uso do resíduo" o valor 5, retratando uma situação ótima, onde não há a necessidade de tratamento do resíduo em nenhumas das empresas. E no "grau dos resíduos de saída", foi adotado 1 para o critério "destinação do resíduo", retratando uma situação ótima, onde o resíduo é enviado para outro EIP com prétratamento.

Considere um parque industrial com um sistema de informações capaz de coletar dados de resíduos internos e externos.

Os dados sobre a quantidade de resíduos para a construção das situações foram cedidos pela administração de um dos parques industriais analisados nos estudos de caso. Foi disponibilizada uma lista com a quantidade de resíduos de duas empresas. Foram escolhidos três resíduos que se enquadrassem nos diferentes critérios na avaliação do grau do resíduo, colaborando assim, para melhor visualização e análise final do indicador.

Considere três tipos de resíduos nos limites de um parque industrial: Papel/Papelão, Escória de ferro/aço e Pilhas/Baterias. A construção do GRC e GRS para cada um destes resíduos, utilizando a avaliação por critérios e considerando os resíduos circulantes e de saída, respectivamente, é dada nas Tabelas 4 e 6 a seguir. Os pesos utilizados foram gerados pelo método AHP e seu desenvolvimento pode ser averiguado nas Tabelas 2 e 3.

As Tabelas 4 e 5 mostram a avaliação dos critérios para cada resíduo e o resultado do cálculo do GRC, respectivamente. As Tabelas 6 e 7 mostram a avaliação dos critérios para cada resíduo e o resultado do cálculo do GRS, respectivamente.

Tabela 4. Avaliação dos critérios para cada resíduo - GRC.

\begin{tabular}{|c|c|c|c|c|c|}
\hline & \multicolumn{5}{|c|}{ Critérios } \\
\hline \multirow{4}{*}{ 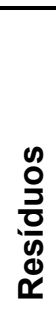 } & & Legislação & $\begin{array}{l}\text { Classe do } \\
\text { Resíduo }\end{array}$ & $\begin{array}{l}\text { Uso do } \\
\text { resíduo }\end{array}$ & $\begin{array}{l}\text { Problemas } \\
\text { /riscos }\end{array}$ \\
\hline & Papel/Papelão & 5 & 3 & 5 & 1 \\
\hline & $\begin{array}{l}\text { Escória de Ferro } \\
\text { e Aço }\end{array}$ & 5 & 5 & 5 & 1 \\
\hline & Pilhas/Baterias & 5 & 5 & 5 & 5 \\
\hline
\end{tabular}


Tabela 5. Valores do cálculo do grau do resíduo circulante.

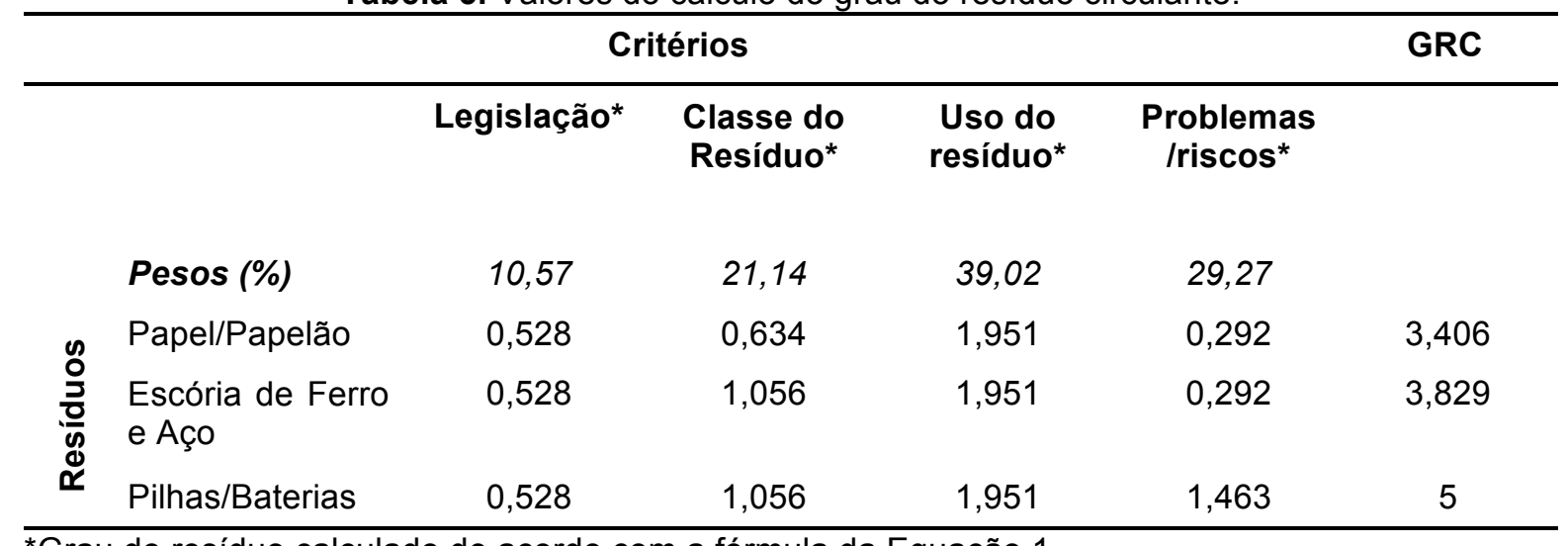

${ }^{*}$ Grau do resíduo calculado de acordo com a fórmula da Equação 1.

Tabela 6. Avaliação dos critérios para cada resíduo - GRS.

\begin{tabular}{|c|c|c|c|c|c|}
\hline & \multicolumn{5}{|c|}{ Critérios } \\
\hline \multirow{4}{*}{ 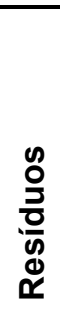 } & & Legislação & $\begin{array}{l}\text { Classe do } \\
\text { Resíduo }\end{array}$ & $\begin{array}{l}\text { Destinação } \\
\text { do resíduo }\end{array}$ & $\begin{array}{l}\text { Problemas } \\
\text { /riscos }\end{array}$ \\
\hline & Papel/Papelão & 5 & 3 & 1 & 1 \\
\hline & $\begin{array}{l}\text { Escória de Ferro } \\
\text { e Aço }\end{array}$ & 5 & 5 & 1 & 1 \\
\hline & Pilhas/Baterias & 5 & 5 & 1 & 5 \\
\hline
\end{tabular}

Tabela 7. Valores do cálculo do grau do resíduo de saída.

\begin{tabular}{|c|c|c|c|c|c|c|}
\hline & \multicolumn{5}{|c|}{ Critérios } & \multirow[t]{2}{*}{ GRS } \\
\hline & & Legislação* & $\begin{array}{l}\text { Classe do } \\
\text { Resíduo** }\end{array}$ & $\begin{array}{l}\text { Destinação } \\
\text { do resíduo* }\end{array}$ & $\begin{array}{l}\text { Problemas } \\
\text { / riscos* }\end{array}$ & \\
\hline \multirow{4}{*}{ 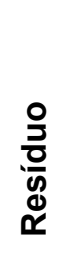 } & Pesos (\%) & 10,57 & 21,14 & 39,02 & 29,27 & \\
\hline & Papel/Papelão & 0,528 & 0,634 & 0,390 & 0,292 & 1,845 \\
\hline & $\begin{array}{l}\text { Escória de Ferro } \\
\text { e Aço }\end{array}$ & 0,528 & 1,056 & 0,390 & 0,292 & 2,268 \\
\hline & Pilhas/Baterias & 0,528 & 1,056 & 0,390 & 1,463 & 3,439 \\
\hline
\end{tabular}

*Grau do resíduo calculado de acordo com a fórmula da Equação 1.

Uma vez calculados e definidos os GRC e GRS, considerando as melhores situações, partiu-se para criar uma situação inicial de um parque com nenhuma simbiose.

Considere então, um parque que tenha mais de duas empresas produtoras de produtos que gerem como resíduo papel/papelão, escória de ferro e aço e pilha/bateria conforme a Tabela 8 , e que toda a quantidade de resíduos seja descartada para fora do parque. Poderíamos calcular o ISI, conforme a Tabela 9 e 
o resultado será um indicador de simbiose no valor zero, indicando nenhuma simbiose.

Tabela 8. Quantidade de resíduos.

\begin{tabular}{cc}
\hline RESíDUos & $\begin{array}{c}\text { QUANTIDADES } \\
\text { TOTAIS } \\
\text { (ton/ano) }\end{array}$ \\
\hline Papel/papelão & 0,82 \\
Escória de ferro e aço & 0,36 \\
Pilha/bateria & 0,05 \\
\hline
\end{tabular}

Tabela 9. Situação 1 - Nenhuma simbiose.

\begin{tabular}{cccccccc}
\hline $\begin{array}{c}\text { Cód. } \\
\text { Resíduo }\end{array}$ & $\begin{array}{c}\text { Nome do } \\
\text { Resíduo }\end{array}$ & QRC & GRC* $^{*}$ & QRCxGRC & QRS $^{* * *}$ & GRS $^{* *}$ & QRSxGRS \\
\hline PP & Papel/Papelão & 0,00 & 3,406 & 0,000 & 0,82 & 1,845 & 1,513 \\
EFA & $\begin{array}{c}\text { Escória de ferro e } \\
\text { aço }\end{array}$ & 0,00 & 3,829 & 0,000 & 0,36 & 2,268 & 0,817 \\
& Pilha/Bateria & 0,00 & 5 & 0,000 & 0,05 & 3,439 & 0,172 \\
PB & & QIC & 0,000 & & QIS & 2,502 \\
& & & & & & ISI & 0,000 \\
\hline
\end{tabular}

*Valores calculados na Tabela 5.

**Valores calculados na Tabela 7.

***Valores fornecidos pela Tabela 8.

Pode-se agora, criar duas variações desta situação. A situação 2 considera que existe uma quantidade de resíduo circulante dentro do parque e uma quantidade de resíduo de saída sendo descartado para fora do parque, conforme a Tabela 10. Os valores de QRC e QRS para cada resíduo, se somados, resultam na quantidade de resíduos totais. As quantidades totais de resíduos foram divididas entre os QRC e QRS de maneira equilibrada.

Tabela 10. Quantidade de resíduos circulantes e de saída.

\begin{tabular}{cccc}
\hline RESíDuos & $\begin{array}{c}\text { QUANTIDADES } \\
\text { TOTAIS } \\
\text { (ton/ano) }\end{array}$ & QRC & QRS \\
\hline Papel/papelão & 0,82 & 0,40 & 0,42 \\
Escória de ferro e aço & 0,36 & 0,15 & 0,21 \\
Pilha/bateria & 0,05 & 0,03 & 0,02 \\
\hline
\end{tabular}


Conforme a Tabela 11 , o resultado final foi um ISI de 0,899 , indicando a existência de simbiose no parque.

Tabela 11. Situação 2 - Situação equilibrada.

\begin{tabular}{cccccccc}
\hline $\begin{array}{c}\text { Cód. } \\
\text { Resíduo }\end{array}$ & $\begin{array}{c}\text { Nome do } \\
\text { Resíduo }\end{array}$ & QRC* $^{*}$ & GRC** $^{*}$ & QRCxGRC & QRS $^{*}$ & GRS $^{* * *}$ & QRSxGRS \\
\hline PP & Papel/Papelão & 0,40 & 3,407 & 1,363 & 0,42 & 1,845 & 0,775 \\
EFA & $\begin{array}{c}\text { Escória de ferro e } \\
\text { aço }\end{array}$ & 0,15 & 3,829 & 0,574 & 0,21 & 2,268 & 0,476 \\
& Pilha/Bateria & 0,03 & 5 & 0,150 & 0,02 & 3,439 & 0,069 \\
PB & & QIC & 2,087 & & QIS & 1,320 \\
& & & & & & ISI & 0,899 \\
\hline
\end{tabular}

*Valores fornecidos pela Tabela 10

**Valores calculados na Tabela 5.

***Valores calculados na Tabela 7.

Por fim, pode-se gerar uma situação 3, considerando que todo o resíduo produzido pelo parque é consumido pelas empresas envolvidas, ou seja, ocorre a simbiose perfeita. Neste caso assume-se que toda a quantidade de resíduo apresentado na Tabela 8 é consumida pelas empresas participantes. O resultado do cálculo do indicador é apresentado na Tabela 12, gerando um valor de 4,422.

Tabela 12. Situação 3 - Simbiose perfeita.

\begin{tabular}{cccccccc}
\hline $\begin{array}{c}\text { Cód. } \\
\text { Resíduo }\end{array}$ & $\begin{array}{c}\text { Nome do } \\
\text { Resíduo }\end{array}$ & QRC* $^{*}$ & GRC** $^{*}$ & QRCxGRC & QRS & GRS*** & QRSxGRS \\
\hline PP & Papel/Papelão & 0,82 & 3,407 & 2,793 & 0,0 & 1,845 & 0,0 \\
EFA & $\begin{array}{c}\text { Escória de ferro e } \\
\text { aço }\end{array}$ & 0,36 & 3,829 & 1,379 & 0,0 & 2,268 & 0,0 \\
& Pilha/Bateria & 0,05 & 5 & 0,250 & 0,0 & 3,439 & 0,0 \\
PB & & QIC & 4,422 & & QIS & 0,0 \\
& & & & & & ISI & 4,422 \\
\hline
\end{tabular}

*Valores fornecidos pela Tabela 8

**Valores calculados na Tabela 5.

${ }^{* * *}$ Valores calculados na Tabela 7.

Deve-se observar que o valor de simbiose para a situação 1 tem um significado real, físico. O ISI foi calculado como zero, o que significa que não há simbiose neste parque, tal qual proposto na situação.

Nas outras duas situações, o ISI igual a 0,899 e igual a 4,422, o mesmo não se verifica. Tais valores não possuem um significado físico, preciso no mundo real. Porém, eles permitem uma indicação de diferença ou de evolução. Isto é, indicam 
que na situação 3 , ISI igual a 4,422, há uma situação de simbiose mais intensa que na situação 2, ISI igual a 0,899. Assim, se essas três situações distintas acontecessem neste mesmo parque ao longo do tempo, o indicador teria sido capaz de mostrar a evolução do parque em termos de simbiose industrial, de uma situação moderada $(0,899)$ para outra mais avançada $(4,422)$.

\subsubsection{Análise do comportamento do ISI}

Um aspecto importante para garantir a validade do indicador é a possibilidade dele variar de maneira apropriada, indicando acréscimos ou decréscimos em simbiose se, e apenas se, a situação do parque em relação ao nível simbiótico seja positiva ou negativa, respectivamente.

Inicia-se com o estudo do parâmetro quantidade de resíduos circulantes (seção 5.4.2.1), seguido do estudo do parâmetro grau do resíduo (seção 5.4.2.2) e por fim, estudo do parâmetro quantidade de resíduos de saída (seção 5.4.2.3).

\subsubsection{Variação do ISI frente à variação na quantidade de resíduos circulante}

Considere como referência inicial o mês de janeiro da Tabela 11, da seção anterior 5.4.1. Suponha agora o aumento do QRC para os três resíduos em $10 \%$ do valor do mês base de janeiro. Se houver aumento de resíduo circulante, sem respectivo aumento de resíduo de saída, tem-se uma situação favorável, isto é, de incremento da simbiose industrial.

Realizando os cálculos dos novos valores do indicador, tem-se o resultado calculado na Tabela 13. O ISI passaria então de 0,899, calculado na Tabela 11 , para ISI igual a 0,989, calculado na Tabela 13. O ISI aumentou, portanto, 10\%. A variação do ISI indicou que houve um aumento da simbiose na mesma proporção do aumento da quantidade de resíduo circulante. 
Tabela 13. Cálculo do valor do ISI frente ao aumento em $10 \%$ da QRC.

\begin{tabular}{cccccccc}
\hline \multicolumn{7}{c}{ Fevereiro } \\
\hline $\begin{array}{c}\text { Cod } \\
\text { Resíduo }\end{array}$ & $\begin{array}{c}\text { Nome do } \\
\text { Resíduo }\end{array}$ & QRC & GRC & QRCxGRC & QRS & GRS & QRSxGRS \\
PP & $\begin{array}{c}\text { Papel/Papelão } \\
\text { EFA }\end{array}$ & 0,44 & 3,407 & 1,499 & 0,42 & 1,846 & 0,775 \\
Escória de ferro & 0,165 & 3,829 & 0,632 & 0,21 & 2,268 & 0,476 \\
PB & $\begin{array}{c}\text { e aço } \\
\text { Pilhas/Baterias }\end{array}$ & 0,033 & 5,000 & 0,165 & 0,02 & 3,439 & 0,069 \\
& & & QIC & 2,296 & & QIS & 1,320 \\
& & & & & & ISI & 0,989 \\
\hline
\end{tabular}

Suponha agora a diminuição do QRC para os três resíduos em 10\% do valor do mês base de janeiro da Tabela 11. Se houver a diminuição de resíduo circulante, sem respectivo aumento de resíduo de saída, tem-se uma situação desfavorável, isto é, a diminuição da simbiose industrial.

Realizando os cálculos dos novos valores do indicador, tem-se o resultado calculado na Tabela 14. O ISI passaria então de 0,899, calculado na Tabela 11 , para ISI igual a 0,810, calculado na Tabela 14 . O ISI diminuiu, portanto, 10\%. A variação do ISI indicou, portanto, que houve a diminuição da simbiose na mesma proporção da diminuição da quantidade de resíduo circulante.

Tabela 14. Cálculo do valor do ISI frente à diminuição em 10\% da QRC.

\begin{tabular}{cccccccc}
\hline \multicolumn{7}{c}{ Março } \\
\hline $\begin{array}{c}\text { Cod } \\
\text { Resíduo } \\
\text { PP }\end{array}$ & $\begin{array}{c}\text { Nome do } \\
\text { Resíduo } \\
\text { Papel/Papelão }\end{array}$ & QRC & GRC & QRCxGRC & QRS & GRS & QRSxGRS \\
EFA & $\begin{array}{l}\text { Escória de } \\
\text { ferro e aço }\end{array}$ & 0,14 & 3,407 & 1,226 & 0,42 & 1,846 & 0,775 \\
& Pilhas/Baterias & 0,03 & 5,000 & 0,517 & 0,21 & 2,268 & 0,476 \\
& & & QIC & 1,878 & & QIS & 1,320 \\
& & & & & & ISI & 0,810 \\
\hline
\end{tabular}

A Tabela 15 mostra de forma resumida o resultado desta avaliação. Neste tópico, os valores das variáveis GRC, QRS e GRS mantiveram-se constantes, e a QRC sofreu variações. No mês de fevereiro, a quantidade de resíduo circulante aumentou em 10\% comparado ao mês de janeiro. No mês de março, a quantidade de resíduo circulante diminuiu em 10\% comparado ao mês de janeiro. 
Tabela 15. Avaliação do comportamento do indicador - Variação da QRC.

\begin{tabular}{cccccc}
\hline MÊS & $\mathbf{\Delta Q R C}$ & GRC & QRS & GRS & ISI \\
\hline JAN & 0,40 & 3,407 & 0,42 & 1,846 & \\
JAN & 0,15 & 3,829 & 0,21 & 2,268 & \\
JAN & 0,03 & 5,000 & 0,02 & 3,439 & $\mathbf{0 , 8 9 9}$ \\
& & & & & \\
FEV & 0,44 & 3,407 & 0,42 & 1,846 & \\
FEV & 0,165 & 3,829 & 0,21 & 2,268 & \\
FEV & 0,033 & 5,000 & 0,02 & 3,439 & $\mathbf{0 , 9 8 9}$ \\
& & & & & \\
MAR & 0,36 & 3,407 & 0,42 & 1,846 & \\
MAR & 0,14 & 3,829 & 0,21 & 2,268 & \\
MAR & 0,03 & 5,000 & 0,02 & 3,439 & $\mathbf{0 , 8 1 0}$ \\
\hline
\end{tabular}

Analisando os valores do ISI comparado ao mês de janeiro, nota-se que o aumento em 10\% (fevereiro) e a diminuição em 10\% (março) da quantidade de resíduo circulante refletiu em variações do ISI na mesma proporção. Isso está coerente com a própria fórmula do indicador, expressa na equação 3. Há uma relação diretamente proporcional entre a quantidade de resíduos circulantes e o resultado do indicador. Em um caso real, em que possa haver variação de apenas um ou parte dos resíduos, esta variação dependerá também de qual resíduo permanecerá estável e qual irá mudar, visto que existe um peso para os resíduos, representado pelo grau de cada um deles.

\subsubsection{Variação do ISI frente à variação da natureza ou grau de resíduos}

Outro aspecto que precisa ser estudado é a variação no indicador, conforme a mudança da natureza dos resíduos em si, circulantes ou de saída, ou mesmo na variação derivada de alguma alteração na avaliação do grau do resíduo, determinada pelos agentes segundo um conjunto de critérios. A mudança do próprio resíduo pode ocorrer quando uma empresa altera seu processo produtivo passando a gerar ou consumir resíduo distinto.

A variação do grau pode acontecer no critério uso ou destinação do resíduo, componentes do grau do resíduo circulante e de saída, respectivamente. Estes critérios (Quadro 3) são os únicos que dependem da atuação das empresas quanto ao tratamento dos resíduos. A avaliação dos outros critérios é determinada pela característica do resíduo, sendo um valor absoluto e independente. 
O primeiro passo para a análise dessa situação seria fixar os três resíduos, mantendo a natureza dos resíduos constante. Sendo resíduos iguais, que circulam e saem do parque, e por terem os mesmos pesos, os valores da avaliação dos resíduos no grau do resíduo circulante e de saída são os mesmos, respectivamente.

Entretanto, vale lembrar que, os valores 1, 3 e 5 na avaliação dos critérios uso e destinação dos resíduos apresentam diferentes significados (Anexo A).

Considere o critério uso do resíduo igual a 1, onde há tratamento do resíduo na empresa doadora e receptora, e o critério destinação igual 1, onde o resíduo vai para outro EIP com pré-tratamento, conforme o resultado da Tabela 16.

Tabela 16. Grau do resíduo para uso/destinação=1.

\begin{tabular}{cccc}
\hline Critério & Papel/Papelão & $\begin{array}{l}\text { Escória de } \\
\text { Ferro e Aço }\end{array}$ & Pilhas/Baterias \\
\hline $\begin{array}{c}\text { *Uso/Destinação } \\
\text { do resíduo }=\mathbf{1}\end{array}$ & 1,845 & 2,268 & 3,439 \\
\hline
\end{tabular}

Considere agora o critério uso do resíduo igual a 3 , onde há tratamento do resíduo na empresa receptora, e o critério destinação igual 3, onde o resíduo vai para outro EIP sem pré-tratamento, conforme a Tabela 17 e 18.

Tabela 17. Avaliação dos critérios para cada resíduo.

\begin{tabular}{|c|c|c|c|c|c|}
\hline & & & Critérios & & \\
\hline \multirow{4}{*}{$\begin{array}{l}\text { 옹 } \\
\frac{0}{2} \\
\frac{0}{y} \\
d \\
\alpha\end{array}$} & & Legislação & $\begin{array}{l}\text { Classe do } \\
\text { Resíduo }\end{array}$ & $\begin{array}{l}\text { Uso/Destinação } \\
\text { do resíduo }\end{array}$ & $\begin{array}{c}\text { Problemas } \\
\text { /riscos }\end{array}$ \\
\hline & Papel/Papelão & 5 & 3 & 3 & 1 \\
\hline & $\begin{array}{l}\text { Escória de Ferro } \\
\text { e Aço }\end{array}$ & 5 & 5 & 3 & 1 \\
\hline & Pilhas/Baterias & 5 & 5 & 3 & 5 \\
\hline
\end{tabular}

Tabela 18. Valores do cálculo do grau do resíduo (circulante e saída).

\section{Critérios}

\begin{tabular}{|c|c|c|c|c|c|}
\hline & *Legislação & $\begin{array}{c}{ }^{*} \text { Classe } \\
\text { do } \\
\text { Resíduo }\end{array}$ & $\begin{array}{l}\text { *Uso ou } \\
\text { Destinação do } \\
\text { resíduo }\end{array}$ & $\begin{array}{l}\text { *Problemas } \\
\text { /riscos }\end{array}$ & \\
\hline Peso(\%) & 10,57 & 21,14 & 39,02 & 29,27 & \\
\hline $\boldsymbol{\propto}$ @ Papel/Papelão & 0,528 & 0,634 & 1,170 & 0,292 & 2,626 \\
\hline
\end{tabular}




\begin{tabular}{lccccc}
\hline & & Critérios & & $\begin{array}{c}\text { GRC e } \\
\text { GRS }\end{array}$ \\
\hline $\begin{array}{l}\text { Escória de } \\
\text { Ferro e Aço } \\
\text { Pilhas/Baterias }\end{array}$ & 0,528 & 1,056 & 1,170 & 0,292 & 3,048 \\
\hline Grau do resín & 0,528 & 1,056 & 1,170 & 1,463 & 4,219 \\
\hline
\end{tabular}

*Grau do resíduo calculado de acordo com a fórmula da Equação 1

A Tabela 19 mostra de maneira resumida, os valores finais do grau do resíduo quando o critério uso ou destinação são iguais a 3.

Tabela 19. Grau do resíduo para uso/destinação=3.

\begin{tabular}{cccc}
\hline Critério & Papel/Papelão & $\begin{array}{c}\text { Escória de } \\
\text { Ferro e Aço }\end{array}$ & Pilhas/Baterias \\
\hline $\begin{array}{c}\text { *Uso/Destinação } \\
\text { do resíduo }=\mathbf{3}\end{array}$ & 2,626 & 3,048 & 4,219 \\
\hline *Valores calculados na Tabela 18. & &
\end{tabular}

Considere o critério uso do resíduo igual a 5 , onde não há necessidade de tratamento do resíduo em nenhuma das empresas, e o critério destinação igual 5, onde o resíduo vai para um aterro industrial.

Tabela 20. Grau do resíduo para uso/destinação=5.

\begin{tabular}{cccc}
\hline Critério & Papel/Papelão & $\begin{array}{l}\text { Escória de } \\
\text { Ferro e Aço }\end{array}$ & Pilhas/Baterias \\
\hline $\begin{array}{c}\text { *Uso/Destinação } \\
\text { do resíduo = 5 }\end{array}$ & 3,406 & 3,829 & 5 \\
\hline
\end{tabular}

*Valores calculados na Tabela 5.

Uma vez calculados e definidos os GRC e GRS, considerando as três possibilidades de uso e destinação (1, 3 ou 5), partiu-se para criar variações do grau do resíduo (circulante e saída).

Considere primeiramente, a variação da variável GRC por meio das alterações dos valores do critério uso do resíduo.

Adote como referência inicial o mês de janeiro, que neste caso, foi construído com as quantidades de resíduos circulantes e de saída da Tabela 10, e com o grau do resíduo para uso e destinação igual 1 da Tabela 7 , com os valores de $1,845,2,268$ e 3,439 . 
Realizando os cálculos do valor do indicador, tem-se o resultado na Tabela 21. O valor do ISI resultante é de 0,509 , e servirá como referência para as próximas análises.

Tabela 21. Cálculo do valor do ISI com o GRC=GRS=1 como mês referência.

\begin{tabular}{cccccccc}
\hline \multicolumn{7}{c}{ Janeiro } \\
\hline $\begin{array}{c}\text { Cód. } \\
\text { Resíduo }\end{array}$ & $\begin{array}{c}\text { Nome do } \\
\text { Resíduo }\end{array}$ & ${ }^{*}$ QRC & ${ }^{* *}$ GRC & QRCxGRC & ${ }^{*}$ QRS & ${ }^{* *}$ GRS & QRSxGRS \\
\hline PP & Papel/Papelão & 0,40 & 1,845 & 0,738 & 0,42 & 1,845 & 0,775 \\
EFA & $\begin{array}{c}\text { Escória de ferro } \\
\text { e aço }\end{array}$ & 0,15 & 2,268 & 0,340 & 0,21 & 2,268 & 0,476 \\
PB & Pilha/Bateria & 0,03 & 3,439 & 0,103 & 0,02 & 3,439 & 0,069 \\
& & & QIC & 1,181 & & QIS & 1,320 \\
& & & & & & ISI & 0,509 \\
\hline
\end{tabular}

*Valores fornecidos pela Tabela 10.

**Valores fornecidos pela Tabela 16.

Suponha agora o critério uso do resíduo do GRC igual a 3 em que há tratamento do resíduo somente na empresa receptora. Se houver tratamento do resíduo na empresa receptora, sem a respectiva mudança na destinação do resíduo, tem-se uma situação favorável, isto é, o aumento da simbiose industrial.

Realizando os cálculos dos novos valores do indicador, tem-se o resultado calculado na Tabela 22. O ISI passaria então de 0,509, calculado na Tabela 21, para ISI igual a 0,703, calculado na Tabela 22. A variação do ISI indicou, portanto, que houve o aumento da simbiose quando o resíduo do parque passou a ser tratado somente pela empresa receptora, e não pela doadora e receptora ao mesmo tempo como no mês de janeiro.

Tabela 22. Cálculo do valor do ISI com uso do resíduo= 3 do GRC.

\begin{tabular}{|c|c|c|c|c|c|c|c|}
\hline \multicolumn{8}{|c|}{ Fevereiro } \\
\hline $\begin{array}{c}\text { Cód. } \\
\text { Resíduo }\end{array}$ & $\begin{array}{l}\text { Nome do } \\
\text { Resíduo }\end{array}$ & ${ }^{*} \mathrm{QRC}$ & ${ }^{* *} \mathrm{GRC}$ & QRCxGRC & ${ }^{*} \mathrm{QRS}$ & ${ }^{* * *}$ GRS & QRSxGRS \\
\hline PP & Papel/Papelão & 0,40 & 2,626 & 1,050 & 0,42 & 1,845 & 0,775 \\
\hline EFA & $\begin{array}{c}\text { Escória de ferro } \\
\text { e aço }\end{array}$ & 0,15 & 3,048 & 0,457 & 0,21 & 2,268 & 0,476 \\
\hline \multirow[t]{3}{*}{ PB } & Pilha/Bateria & 0,03 & 4,219 & 0,126 & 0,02 & 3,439 & 0,069 \\
\hline & & & QIC & 1,633 & & QIS & 1,320 \\
\hline & & & & & & ISI & 0,703 \\
\hline
\end{tabular}

*Valores fornecidos pela Tabela 10.

**Valores fornecidos pela Tabela 19.

***Valores fornecidos pela Tabela 16. 
Suponha agora o critério uso do resíduo do GRC igual a 5 , em que não há necessidade do tratamento do resíduo. Se não houver a necessidade de tratamento do resíduo na empresa, sem a respectiva mudança na destinação do resíduo, tem-se uma situação favorável, isto é, o aumento da simbiose industrial.

Realizando os cálculos dos novos valores do indicador, tem-se o resultado calculado na Tabela 23. O ISI passaria então de 0,509, calculado na Tabela 21, para ISI igual a 0,9, calculado na Tabela 23. A variação do ISI indicou, portanto, que houve o aumento da simbiose quando o resíduo não precisou ser tratado por nenhuma empresa.

Tabela 23. Cálculo do valor do ISI com uso do resíduo= 5 do GRC.

\begin{tabular}{|c|c|c|c|c|c|c|c|}
\hline \multicolumn{8}{|c|}{ Março } \\
\hline $\begin{array}{c}\text { Cód. } \\
\text { Resíduo }\end{array}$ & $\begin{array}{l}\text { Nome do } \\
\text { Resíduo }\end{array}$ & ${ }^{*} \mathrm{QRC}$ & ${ }^{* *} \mathrm{GRC}$ & QRCxGRC & ${ }^{*} \mathrm{QRS}$ & ***GRS & QRSxGRS \\
\hline PP & Papel/Papelão & 0,40 & 3,406 & 1,362 & 0,42 & 1,845 & 0,775 \\
\hline EFA & $\begin{array}{c}\text { Escória de ferro } \\
\text { e aço }\end{array}$ & 0,15 & 3,829 & 0,574 & 0,21 & 2,268 & 0,476 \\
\hline \multirow[t]{3}{*}{ PB } & Pilha/Bateria & 0,03 & 5 & 0,15 & 0,02 & 3,439 & 0,069 \\
\hline & & & QIC & 2,086 & & QIS & 1,320 \\
\hline & & & & & & ISI & 0,9 \\
\hline
\end{tabular}

*Valores fornecidos pela Tabela 10.

${ }^{* *}$ Valores fornecidos pela Tabela 20.

${ }^{* * *}$ Valores fornecidos pela Tabela 16.

A Tabela 24 mostra de forma resumida o resultado desta avaliação. Aqui, os valores das variáveis $Q R C$, QRS e GRS mantiveram-se constantes, e o GRC sofreu variações. No mês de fevereiro, a mudança positiva do critério uso do resíduo do GRC aumentou o valor do ISI comparado ao mês de janeiro. No mês de março, a mudança do critério uso do resíduo do GRC sem a necessidade de seu tratamento fez o ISI alcançar seu maior valor desta série temporal.

Tabela 24. Avaliação do comportamento do indicador - Variação da GRC.

\begin{tabular}{cccccc}
\hline MÊS & $\mathbf{\Delta G R C}$ & QRC & QRS & GRS & ISI \\
\hline JAN & 1,845 & 0,4 & 0,42 & 1,846 & \\
JAN & 2,268 & 0,15 & 0,21 & 2,268 & \\
JAN & 3,439 & 0,03 & 0,02 & 3,439 & $\mathbf{0 , 5 0 9}$ \\
& & & & & \\
FEV & 2,626 & 0,4 & 0,42 & 1,846 & \\
\hline
\end{tabular}




\begin{tabular}{cccccc}
\hline MÊS & DGRC & QRC & QRS & GRS & ISI \\
\hline FEV & 3,048 & 0,15 & 0,21 & 2,268 & \\
FEV & 4,219 & 0,03 & 0,02 & 3,439 & $\mathbf{0 , 7 0 3}$ \\
& & & & & \\
MAR & 3,406 & 0,4 & 0,42 & 1,846 & \\
MAR & 3,829 & 0,15 & 0,21 & 2,268 & \\
MAR & 5 & 0,03 & 0,02 & 3,439 & $\mathbf{0 , 9}$ \\
\hline
\end{tabular}

Analisando os valores do ISI comparado ao mês de janeiro, nota-se que a alteração dos valores no critério uso do resíduo na composição do GRC refletiu em variações do ISI. Isso está coerente com a própria fórmula do indicador, expressa na equação 3. O resultado mostra que, as empresas do parque que utilizam resíduos sem a necessidade de tratamento, influenciam positivamente no valor final do ISI.

Nesta próxima análise, considere agora, a variação da variável GRS por meio das alterações dos valores do critério destinação do resíduo.

Adote como referência inicial o mês de janeiro da Tabela 21. Suponha o critério destinação do resíduo do GRS igual a 3 em que o resíduo destina-se para outro EIP sem pré-tratamento. Se houver destinação do resíduo sem prétratamento, sem a respectiva mudança no uso do resíduo, tem-se uma situação desfavorável, isto é, a diminuição da simbiose industrial.

Realizando os cálculos dos novos valores do indicador, tem-se o resultado calculado na Tabela 25. O ISI passaria então de 0,509, calculado na Tabela 21, para ISI igual a 0,417, calculado na Tabela 25. A variação do ISI indicou, portanto, que houve a diminuição da simbiose quando o resíduo do parque passou a ser destinado para outro EIP sem pré-tratamento, diferentemente do mês de janeiro, em que o resíduo sofreu pré-tratamento antes de ser destinado a outro EIP.

Tabela 25. Cálculo do valor do ISI com destinação do resíduo= 3 do GRS.

\begin{tabular}{|c|c|c|c|c|c|c|c|}
\hline \multicolumn{8}{|c|}{ Fevereiro } \\
\hline $\begin{array}{c}\text { Cód. } \\
\text { Resíduo }\end{array}$ & $\begin{array}{l}\text { Nome do } \\
\text { Resíduo }\end{array}$ & QRC & GRC & QRCxGRC & QRS & GRS & QRSxGRS \\
\hline PP & Papel/Papelão & 0,40 & 1,845 & 0,738 & 0,42 & 2,626 & 1,102 \\
\hline EFA & $\begin{array}{c}\text { Escória de ferro e } \\
\text { aço }\end{array}$ & 0,15 & 2,268 & 0,340 & 0,21 & 3,048 & 0,640 \\
\hline \multirow[t]{3}{*}{ PB } & Pilha/Bateria & 0,03 & 3,439 & 0,103 & 0,02 & 4,219 & 0,084 \\
\hline & & & QIC & 1,181 & & QIS & 1,826 \\
\hline & & & & & & ISI & 0,417 \\
\hline
\end{tabular}


Suponha agora o critério destinação do resíduo do GRS igual a 5, em que o resíduo é destinado a um aterro industrial. Se o resíduo for direcionado a um aterro industrial tem-se uma situação desfavorável, isto é, a diminuição da simbiose industrial.

Realizando os cálculos dos novos valores do indicador, tem-se o resultado calculado na Tabela 26. O ISI passaria então de 0,509, calculado na Tabela 21, para ISI igual a 0,354, calculado na Tabela 26. A variação do ISI indicou, portanto, que houve a diminuição da simbiose quando o resíduo foi direcionado para um aterro industrial.

Tabela 26. Cálculo do valor do ISI com destinação do resíduo= 5 do GRS.

\begin{tabular}{|c|c|c|c|c|c|c|c|}
\hline \multicolumn{8}{|c|}{ Março } \\
\hline $\begin{array}{l}\text { Cód. } \\
\text { Resíduo }\end{array}$ & $\begin{array}{l}\text { Nome do } \\
\text { Resíduo }\end{array}$ & QRC & GRC & QRCxGRC & QRS & GRS & QRSxGRS \\
\hline $\mathrm{PP}$ & Papel/Papelão & 0,40 & 1,845 & 0,738 & 0,42 & 3,406 & 1,430 \\
\hline EFA & $\begin{array}{c}\text { Escória de ferro e } \\
\text { aço }\end{array}$ & 0,15 & 2,268 & 0,340 & 0,21 & 3,829 & 0,804 \\
\hline \multirow[t]{3}{*}{ PB } & Pilha/Bateria & 0,03 & 3,439 & 0,103 & 0,02 & 5 & 0,1 \\
\hline & & & QIC & 1,181 & & QIS & 2,334 \\
\hline & & & & & & ISI & 0,354 \\
\hline
\end{tabular}

A Tabela 27 mostra de forma resumida o resultado desta avaliação. Aqui, os valores das variáveis QRC, GRC e QRS mantiveram-se constantes, e o GRS sofreu variações. No mês de fevereiro, o envio do resíduo sem pré-tratamento para outro EIP no critério destinação do resíduo do GRS diminuiu o valor do ISI comparado ao mês de janeiro. No mês de março, o envio do resíduo par um aterro industrial fez o ISI alcançar seu menor valor desta série temporal.

Tabela 27. Avaliação do comportamento do indicador - Variação da GRS.

\begin{tabular}{cccccc}
\hline MÊS & DGRS & QRC & GRC & QRS & ISI \\
\hline JAN & 1,845 & 0,4 & 1,846 & 0,42 & \\
JAN & 2,268 & 0,15 & 2,268 & 0,21 & \\
JAN & 3,439 & 0,03 & 3,439 & 0,02 & $\mathbf{0 , 5 0 9}$ \\
& & & & & \\
FEV & 2,626 & 0,4 & 1,846 & 0,42 & \\
FEV & 3,048 & 0,15 & 2,268 & 0,21 & \\
FEV & 4,219 & 0,03 & 3,439 & 0,02 & $\mathbf{0 , 4 1 7}$ \\
& & & & & \\
\hline
\end{tabular}




\begin{tabular}{cccccc}
\hline MÊS & DGRS & QRC & GRC & QRS & ISI \\
\hline MAR & 3,406 & 0,4 & 1,846 & 0,42 & \\
MAR & 3,829 & 0,15 & 2,268 & 0,21 & \\
MAR & 5 & 0,03 & 3,439 & 0,02 & $\mathbf{0 , 3 5 4}$ \\
\hline
\end{tabular}

Analisando os valores do ISI comparado ao mês de janeiro, nota-se que a alteração dos valores no critério destinação do resíduo na composição do GRS, refletiram em variações do ISI. Isso está coerente com a própria fórmula do indicador, expressa na equação 3. O resultado mostra que, as empresas que enviam seus resíduos para um aterro industrial influenciam negativamente no valor final do ISI.

\subsubsection{Variação do ISI frente à variação na quantidade de resíduos de saída}

Considere como referência inicial o mês de janeiro da Tabela 11, da seção anterior 5.4.1. Suponha agora o aumento do QRS para os três resíduos em $10 \%$ do valor do mês base de janeiro. Se houver aumento de resíduo de saída, sem respectivo aumento de resíduo circulante, tem-se uma situação desfavorável, isto é, de diminuição da simbiose industrial.

Realizando os cálculos dos novos valores do indicador, tem-se o resultado calculado na Tabela 28. O ISI passaria então de 0,899, calculado na Tabela 11, para ISI igual a 0,851, calculado na Tabela 28. O ISI diminuiu, portanto, aproximadamente 5\%. A variação do ISI indicou, portanto, que houve uma diminuição da simbiose inversamente proporcional ao aumento da quantidade de resíduo de saída.

Tabela 28. Cálculo do valor do ISI frente ao aumento em $10 \%$ da QRS.

\begin{tabular}{cccccccc}
\hline \multicolumn{7}{c}{ Fevereiro } \\
\hline $\begin{array}{c}\text { Cod } \\
\text { Resíduo }\end{array}$ & $\begin{array}{c}\text { Nome do } \\
\text { Resíduo } \\
\text { PP }\end{array}$ & QRC & GRC & QRCxGRC & QRS & GRS & QRSxGRS \\
Papel/Papelão & 0,40 & 3,407 & 1,363 & 0,46 & 1,846 & 0,853 \\
EFA & $\begin{array}{c}\text { Escória de ferro } \\
\text { e aço }\end{array}$ & 0,150 & 3,829 & 0,574 & 0,23 & 2,268 & 0,524 \\
PB & Pilhas/Baterias & 0,030 & 5,000 & 0,150 & 0,02 & 3,439 & 0,076 \\
& & & QIC & 2,087 & & QIS & 1,452 \\
& & & & & & ISI & 0,851 \\
\hline
\end{tabular}


Suponha agora a diminuição da QRS para os três resíduos em $10 \%$ do valor do mês base de janeiro da Tabela 11. Se houver a diminuição de resíduo de saída, sem respectivo aumento de resíduo circulante, tem-se uma situação favorável, isto é, o aumento da simbiose industrial.

Realizando os cálculos dos novos valores do indicador, tem-se o resultado calculado na Tabela 29. O ISI passaria então de 0,899, calculado na Tabela 11, para ISI igual a 0,954, calculado na Tabela 29. O ISI aumentou, portanto, aproximadamente 6\%. A variação do ISI indicou, portanto, que houve o aumento da simbiose inversamente proporcional a diminuição da quantidade de resíduo de saída.

Tabela 29. Cálculo do valor do ISI frente a diminuição em 10\% da QRS.

\begin{tabular}{|c|c|c|c|c|c|c|c|}
\hline \multicolumn{8}{|c|}{ Março } \\
\hline $\begin{array}{c}\text { Cod } \\
\text { Resíduo }\end{array}$ & $\begin{array}{c}\text { Nome do } \\
\text { Resíduo }\end{array}$ & QRC & GRC & QRCxGRC & QRS & GRS & QRSxGRS \\
\hline PP & Papel/Papelão & 0,40 & 3,407 & 1,363 & 0,38 & 1,846 & 0,698 \\
\hline EFA & $\begin{array}{l}\text { Escória de } \\
\text { ferro e aço }\end{array}$ & 0,15 & 3,829 & 0,574 & 0,19 & 2,268 & 0,429 \\
\hline \multirow[t]{3}{*}{ PB } & Pilhas/Baterias & 0,03 & 5,000 & 0,150 & 0,02 & 3,439 & 0,062 \\
\hline & & & QIC & 2,087 & & QIS & 1,188 \\
\hline & & & & & & ISI & 0,954 \\
\hline
\end{tabular}

A Tabela 30 mostra de forma resumida o resultado desta avaliação. Neste tópico, os valores das variáveis GRC, GRC e QRC mantiveram-se constantes, e a QRS sofreu variações. No mês de fevereiro, a quantidade de resíduo de saída aumentou em 10\% comparado ao mês de janeiro. No mês de março, a quantidade de resíduo de saída diminuiu em 10\% comparado ao mês de janeiro.

Tabela 30. Avaliação do comportamento do indicador - Variação da QRS.

\begin{tabular}{cccccc}
\hline MÊS & DQRS & GRS & QRC & GRC & ISI \\
\hline JAN & 0,42 & 1,846 & 0,40 & 3,407 & \\
JAN & 0,21 & 2,268 & 0,15 & 3,829 & \\
JAN & 0,02 & 3,439 & 0,03 & 5,000 & $\mathbf{0 , 8 9 9}$ \\
& & & & & \\
FEV & 0,46 & 1,846 & 0,40 & 3,407 & \\
FEV & 0,231 & 2,268 & 0,15 & 3,829 & \\
FEV & 0,022 & 3,439 & 0,03 & 5,000 & $\mathbf{0 , 8 5 1}$ \\
& & & & & \\
\hline
\end{tabular}




\begin{tabular}{llllll}
\hline MAR & 0,38 & 1,846 & 0,40 & 3,407 & \\
MAR & 0,19 & 2,268 & 0,15 & 3,829 & \\
MAR & 0,02 & 3,439 & 0,03 & 5,000 & $\mathbf{0 , 9 5 4}$ \\
\hline
\end{tabular}

Analisando os valores do ISI comparado ao mês de janeiro, nota-se que o aumento em $10 \%$ (fevereiro) e a diminuição em 10\% (março) da quantidade de resíduo de saída refletiu em variações do ISI de forma inversamente proporcional. Isso está coerente com a própria fórmula do indicador, expressa na equação 3 . Há uma relação inversamente proporcional entre a quantidade de resíduos de saída e o resultado do indicador. Em um caso real, em que possa haver variação de apenas um ou parte dos resíduos, esta variação dependerá também de qual resíduo permanecerá estável e qual irá mudar, visto que existe um peso para os resíduos, representado pelo grau de cada um deles.

\subsubsection{Análise dos resultados}

A construção das situações e das possibilidades de variações do ISI permitiu avaliar a coerência do indicador quanto à presença do processo de simbiose num parque e o seu comportamento diante de diferentes variações dos elementos que o compõem.

A situação 1 permitiu demonstrar a capacidade do indicador em captar a ausência total de simbiose. Juntas, as situações 1,2 e 3 demonstram que o indicador poderia identificar níveis de simbiose distintos para um mesmo parque, conforme sua evolução em direção a uma simbiose perfeita.

A primeira variação realizada com a variável QRC mostrou que o ISI indica uma variação direta no nível de simbiose, conforme o aumento da quantidade dos resíduos circulantes, sendo lógico ao conceito de simbiose industrial.

A segunda variação realizada com as variáveis "grau do resíduo"(circulante e saída) mostrou que o indicador pode continuar comparando a simbiose nas duas situações (resíduos circulantes e de saída) de um mesmo parque, mesmo havendo mudança na natureza dos resíduos gerados ou consumidos. $A$ análise também mostrou que o ISI pode continuar comparando os níveis de simbiose mesmo que, em um dado momento, os agenciadores mudem a forma de avaliação dos critérios 
do grau de cada resíduo. Além disso, as diferentes formas de uso e destinação dos resíduos mostraram-se como critérios de grande influência nas variações do ISI.

A terceira variação realizada com a variável QRS indicou uma variação indireta no nível de simbiose, quando a quantidade de resíduo de saída aumentava, o nível de simbiose diminuía.

O ISI não possui um valor teto, ou seja, um valor máximo de simbiose. Este indicador é um escalar real e infinito, podendo sempre aumentar, conforme o aumento do nível de simbiose. Esta análise estaria coerente com o conceito de que a simbiose perfeita não pode ser atingida, mas ela poderia ser sempre incrementada. Pode-se conjecturar que, se o resíduo circulante aumenta, estaria sendo ampliada a produção e, portanto, o impacto ambiental do parque aumentaria. Neste caso, o ideal seria utilizar um indicador de impacto ambiental, tal que o agenciador, analisando-os conjuntamente, poderia verificar a situação do parque, uma vez que o ISI, por si só, não mede impacto ambiental. 


\section{CONCLUSÃO E CONSIDERAÇÕES FINAIS}

O desenvolvimento de EIPs e de ferramentas de apoio para os organismos agenciadores de parques industriais é ainda um tema emergente. Neste sentido, o trabalho fornece duas principais contribuições ao tema: (1) identificação dos indicadores ambientais que colaboram para a gestão de um EIP; (2) proposição e teste do indicador de simbiose - ISI como ferramenta de gestão.

O levantamento dos métodos e indicadores utilizados em EIPs na revisão bibliográfica permitiu identificar uma lacuna teórica importante. Os resultados indicaram que os autores encaram EIPs sob uma perspectiva estática, prejudicando a análise do desempenho desses parques a longo prazo. A revisão mostrou que poucos têm investido em métodos e ferramentas sob a perspectiva de um ambiente industrial dinâmico.

Outra contribuição do trabalho foi o desenvolvimento do ISI, que representa o nível de desenvolvimento do processo de simbiose industrial ao longo de uma escala temporal. A ferramenta foi proposta a fim de suprir as carências identificadas na literatura: ausência de elementos que caracterizam o EIP e ausência de métodos e ferramentas de apoio ao organismo gestor para avaliar e analisar o EIP sob uma perspectiva dinâmica.

No desenvolvimento do indicador de simbiose industrial - ISI foram: definidos seus usuários, elaborado os requisitos e princípios, determinado as variáveis envolvidas, formulado a expressão matemática e por fim, avaliado e analisado seus resultados. A proposta teórica conceitual do ISI baseou-se nos requisitos de um indicador ideal adaptada a realidade de EIPs, delimitando sua abrangência, caracterizando seus elementos e fornecendo informações aos diferentes usuários.

Ao final, averiguou-se a aplicabilidade do indicador proposto diante de diferentes situações, com dados reais de quantidade de resíduos. A avaliação da coerência do ISI permitiu demonstrar sua capacidade em captar a ausência e a presença do processo de simbiose, atendendo as expectativas iniciais da construção do indicador. A avaliação do comportamento do ISI por meio da variação dos seus elementos, permitiu analisar o indicador sob diferentes possibilidades, correspondendo positivamente às expectativas da pesquisa. 
Por ser original, a investigação apresentada na pesquisa permite um conjunto de considerações iniciais (seção 6.1) e proposta de trabalhos futuros (seção 6.2) para que esse uso possa ser validado e verificado quanto à sua efetividade prática.

\subsection{CONSIDERAÇÕES SOBRE O INDICADOR PROPOSTO}

Após a investigação apresentada na pesquisa foi possível realizar algumas considerações e limitações do ISI.

$\mathrm{Na}$ apresentação das situações, nota-se que na simbiose perfeita não existe um teto, ou seja, um limite máximo para o valor do indicador. O aumento da quantidade do resíduo circulante garante o aumento do nível do ISI. Esta análise mostra-se coerente com o conceito de que a simbiose perfeita não pode ser atingida, podendo ser sempre incrementada.

Um ponto que merece destaque diz respeito à avaliação dos critérios dos resíduos, que utiliza o método AHP para gerar os pesos. Esta avaliação pode ser realizada pelos agenciadores, podendo variar os valores dos pesos de acordo com o interesse dos envolvidos, mas sempre obedecendo ao limite da razão de consistência proposto por Saaty(1987,1991).

O trabalho apresenta algumas limitações. O desenvolvimento do indicador de simbiose incluiu, basicamente, comparar o fluxo interno de resíduos circulantes no EIP, chamado de QIC, com o fluxo externo de resíduos, denominado de QIS. A quantidade de resíduo de entrada não foi considerada na análise de fluxo dos materiais. Além disso, o estudo limitou-se as fronteiras do EIP, não considerando também uma possível relação de simbiose com outros parques.

O indicador por si só, não mediu o impacto ambiental do parque, por isso a necessidade complementá-lo com outros indicadores capazes de fornecer informações importantes para o gerenciamento do parque como um todo. É sabido que, apresentar um alto nível de evolução do processo de SI não significa, necessariamente, menos impacto ambiental.

É possível considerar como principais vantagens do uso do indicador: o monitoramento periódico do desempenho ambiental do EIP, permitindo maior conhecimento do perfil atual, ilustrando as melhorias ambientais ao longo do tempo, promovendo a motivação de todos os atores envolvidos e maior visibilidade 
ambiental das empresas do EIP como uma vantagem competitiva; e a possibilidade de ser usado como ferramenta de gerenciamento flexível num sistema dinâmico, podendo oferecer medidas de incentivo como isenções em taxas de transporte, tratamento e descarte, incentivando as empresas a desenvolverem processos de produção que reutilizem resíduos gerados dentro do parque, promovendo a simbiose.

Diante disso, nota-se o indicador como uma ferramenta útil durante a fase do planejamento de um EIP, podendo ajudar na formação e definição da visão e metas para a comunidade; e na fase de operação, onde há a identificação e levantamento dos dados coletados na elaboração do banco de dados, alimentando o indicador, ajudando o parque a manter seu desempenho ao longo do tempo, avaliando seu progresso e determinando novos programas para a comunidade.

\subsection{SUGESTÕES PARA FUTURAS PESQUISAS}

Para o complemento do conhecimento obtido com este trabalho na busca por uma ferramenta de apoio ao gerenciamento do EIP que promovesse o processo de SI, sugerem-se como trabalhos futuros:

- Avaliar em EIPs consolidados a aplicação do ISI;

- Desenvolvimento de um sistema de indicadores para avaliar o desempenho ambiental, os componentes e estruturas do EIP; 


\section{REFERÊNCIAS BIBLIOGRÁFICAS}

ABNT - ASSOCIAÇÃO BRASILEIRA DE NORMAS TÉCNICAS. NBR ISO 14040: Gestão ambiental - avaliação do ciclo de vida - princípios e estrutura. Rio de Janeiro, p. 10, 2001.

ABREU, M. C. S.; FIGUEIREDO JUNIOR, H. S.; VARVAKIS, G. Modelo de avaliação da estratégia ambiental: os perfis de conduta estratégica. REAd - Edição Especial 30, v. 8, n. 6, nov-dez 2002.

ACOS - Advisory Committee on Official Statistics. (2009). Good practice guidelines for the development and reporting of indicators. Wellington: Statistics New Zealand. Disponível em: <http://www.statisticsnz.govt.nz/>. Acesso em: 09 set. 2012.

AGARWAL, A.; STRACHAN, P. Literature review on eco-industrial development initiatives around the world and the methods employed to evaluate their performance $I$ effectiveness. The Robert Gordon University. Report, 2006.

APHO - The Association of Public Health Observatorie. The good indicators guide: understanding how to use and choose indicators, 2008. Disponível em: <http://www.apho.org.uk/resource/item.aspx?RID=44584>. Acesso em: 15 nov. 2012.

ARDENTE, F.; CELLURA M.; BRANO, V. L.; MISTRETTA M. Life cycle assessment - driven selection of industrial ecology strategies. Integrated Environmental Assessment and Management, v. 6, n. 1, 2010.

AYRES, R. Industrial metabolism: theory and policy. In: Industrial Metabolism - Restructuring for Sustainable Development, R. Ayres, U. Simonis (eds.), United Nations University Press, Tóquio, p. 3-20, 1994.

BAAS, L. Cleaner production and industrial ecosystems: a dutch experience. J Cleaner Prod 6, 189-197, 1998.

BANA \& COSTA. Processo de apoio à decisão: actores e acções; estruturação e avaliação material de apoio - IST, 1993.

BARBOZA, M. P. B. Proposta para desenvolvimento de um indicador de custos proporcionais de logística para a indústria de transformação do estado de São Paulo. Dissertação (Mestrado). Escola Politécnica. Universidade de São Paulo, São Paulo, 2007.

BESSERMANN, S. Indicadores. In: Meio ambiente no século XXI. Rio de Janeiro: Sextante, 2003.

BIOLCHINI, J.; MIAN, P. G.; NATALI, A. C. C.;TRAVASSOS, G. H. Systematic review in software engineering. Rio de Janeiro, 2005.

BIOLCHINI, J. C. A.; MIAN, P. G.; NATALI, A. C. C.; CONTE, T. U.; TRAVASSOS, G. H.. Scientific research ontology to support systematic review in software engineering. Advanced Engineering Informatics, v. 21, n. 2, p. 133-151, 2007.

BOERI, A.; LONGO, D. Eco-Industrial Parks: Technologies and procedures for low environmental impacts. In: $5^{\text {th }}$ International Conference on Sustainable Development and Planning, SDP 2011. New Forest, v. 150, p. 177-188, 2011. Disponível em <http://books.google.com.br/books?hl=pt-BR\&lr=\&id=uojOg7iXZZAC\&oi=fnd\&pg=PA177\&dq=E co-industrial+parks:+technologies+and+procedures+for+low+environmental+impacts\&ots $=\mathrm{GAz}$ ULy1vr6\&sig=fnQHkMAGNA00090Oh_2CDDSTuq4>. Acesso em: 15 dez. 2012. 
BOONS, F.; SPEKKINK, W.; MOUZAKITIS, Y. The dynamics of industrial symbiosis: a proposal for a conceptual framework based upon a comprehensive literature review. Journal of Cleaner Production 19, 905e911, 2011.

BOSSEL, H. Indicators for sustainable development: theory, methods, applications: a report to balaton group. Internacional Institute for Sustainable Development. Winnipeg, Manitoba, Canada, IISD,124P, 1999.

BROWN, S.; K. EISENHARDT. The art of continuous change: Linking complexity theory and time-paced evolution in relentlessly shifting organizations. Administrative Science Quarterly 42(1): 1-34, 1997.

CARDOSO, L. M. F. Indicadores de produção limpa: uma proposta para análise de relatórios ambientais de empresas. Salvador, BA, 2004.

CHERTOW, M. R. The eco-industrial park model reconsidered. Journal of Industrial Ecology, v. 2(3), p. 8-10, 1999.

CHERTOW, M. R. Industrial symbiosis: literature and taxonomy. Annual Review of Energy and Environment, v. 25, p. 313-337, 2000.

CHERTOW, M. R. Industrial symbiosis. In: Encyclopedia of Energy, edited by C. J. Cleveland. San Diego: Elsevier, 2004.

CHERTOW, M. R. Dynamics of geographically based industrial ecosystems. In: The dynamics of regions and networks in industrial ecosystems, edited by M. Ruth and B. Davidsdottir. Cheltenham, UK: Edward Elgar, 2009.

CHERTOW, M.; LOMBARDI, D. R. Quantifying economic and environmental benefits of colocated firms. Environmental Science \& Technology, v. 39(17), p. 6535-6541, 2005.

CHERTOW, M.; EHRENFELD, J. Organizing self-organizing systems - toward a theory of industrial symbiosis. Journal of industrial ecology, v.16(1), 2012.

CHIU, A. S. F.; YONG, G. On the industrial ecology potential in Asian developing countries. J. Cleaner Prod 2004; 12(8-10): p. 1037-45, 2004.

CHRISTENSEN, J. Personal communication with J. Christensen, member, Kalundborg Industrial Development Council. Kalundborg, Denmark, November, 1998.

COHEN-ROSENTHAL, E. A walk on the human side of industrial ecology. American Behavioral Scientist 44(2): 245-264, 2000.

COSTA, I.; FERRÃO, P. A case study of industrial symbiosis development using a middle-out approach. Journal of Cleaner Production 18 (10e11), 984e992, 2010.

COSTA, I.; MASSARD, G.; AGARWAL, A. Waste management policies for industrial symbiosis development: case studies in European countries. Journal of Cleaner Production 18 (8), 815e822, 2010.

COSTA, M. M. Princípios da ecologia industrial aplicados à sustentabilidade ambiental e aos sistemas de produção do aço. Tese (Doutorado). Ciências do Planejamento Estratégico. Universidade Federal do Rio de Janeiro. Rio de Janeiro, 2002.

CÔTÉ, R. P. HALL J. Designing eco-industrial parks: a synthesis of some experiences. Journal of Cleaner Production, 1998. 
CSIRO - Commonwealth Scientific and Industrial Research Organization. A guidebook to environmental indicators. 1999. Disponível em: <http://www.csiro.au/csiro/envind/code/pages/ menu.htm>. Acesso em: 15 out. 2012.

CSO - Central Statistical Office. Measuring Ireland's Progress 2007. Dublin: Stationary Office, 2008. Disponível em: <http://www.cso.ie/releasespublications/documents/other_releases/2007/ progress2007/measuringirelandsprogress.pdf>. Acesso em: 23 set. 2012.

DIÓGENES, Mara Chagas. Indicadores de desempenho no gerenciamento da segurança viária. 2004. Dissertação (Mestrado em Engenharia de Produção) - Programa de PósGraduação em Engenharia de Produção, Universidade Federal do Rio Grande do Sul, Porto Alegre, abril de 2004

ECKELMAN, M.I., CHERTOW, M.R. Quantifying life cycle environmental benefits from the reuse of industrial materials in Pennsylvania. Environmental Science \& Technology 43 (7), 2550e2556, 2009.

EEA - European Environment Agency. Environmental Indicators: Typology and Use in Reporting. EEA, Copenhagen, p.20, 2003.

EHRENFELD, J.; N. GERTLER. Industrial ecology in practice: the evolution of interdependence at Kalundborg. Journal of Industrial Ecology 1(1): 67-79, 1997.

ESPEY HUSTON \& ASSOCIATES, et al. Port of cape Charles sustainable technologies industrial park comprehensive master plan report. Prepared for the Joint Industrial Development Authority of Northampton County and its Incorporated Towns with funding from the National Oceanic and Atmospheric Administration, 1995.

EUROSTAT - European Statistic. Economy-wide material flow accounts and derived indicators. A methodological guide. Luxembourg: Office for Official Publications of the European Communities; 2001.

FROSCH, R. A.; GALLOPOULOS, N. E. Strategies for Manufacturing. Scientific American, 189(3), p. 1-7, 1989.

FOREST SUSTAINABILITY INDICATOR TOOLS FOR COMMUNITIES. Indicator toolKit development. 2003. Disponível em: <www.communitiescommittee.org/fsitool/index.html>. Acesso em: 01 dez. 2012.

GALLOPÍN, G. Indicators and their use: information for decision making. In: MOLDAN, B.; BILHARZ, S. Sustainability Indicators. Chichester: Scientific Committee on Problems of the Environment - SCOPE (Report on the project on Indicators of Sustainable Development), 1997.

GENG, Y.; ZHANG, P.; CÔTÉ, R.; FUJITA, T. Assessment of the national eco-industrial park standard for promoting industrial symbiosis in China. Journal of Industrial Ecology, v.13(1), p. 15-26, 2009.

GENG, Y.; FU, J.; SARKIS, J.; XUE, B. Towards a national circular economy indicator system in China: an evaluation and critical analysis. Journal of Cleaner Production, v. 23, p. 216-224, 2012.

GENG Y., TSUYOSHI F., CHEN X. Evaluation of innovative municipal solid waste management through urban symbiosis: a case study of Kawasaki. Journal of Cleaner Production 18 (1011), p. 993-1000, 2010.

GERTLER, N. Industrial ecosystems: developing sustainable industrial structures. Unpublished master's thesis, Massachusetts Institute of Technology, Cambridge, MA, USA, 1995. 
GIBBS, D. E.; DEUTZ, P. Implementing industrial ecology? Planning for eco-industrial parks in the USA. Geoforum, p. 452-464, 2005.

GIL, A. C. Como elaborar projetos de pesquisa. São Paulo: Atlas, 2010.

GRANEMANN, S. R.; GARTNER, I. R. Seleção de financiamento para aquisição de aeronaves: Uma aplicação do método de análise hierárquica (AHP). Revista Transportes, Rio de Janeiro, v. 6, n. 1, p. 18-40, 1998.

GOMES, P. R. Indicadores ambientais na discussão da sustentabilidade: uma proposta de análise estratégica no contexto do etanol de cana de açúcar no estado de São Paulo. Dissertação (Mestrado). Escola de Engenharia de São Carlos. Universidade de São Paulo, São Carlos, 2011.

GOMES, M. L.; MARCELINO, M. M; ESPADA, M. Proposta para um sistema de indicadores de desenvolvimento sustentável. Portugal: Direção de Serviços de Informação e Acreditação/Direção Geral do Ambiente. 228p., 2000. Disponível em: <http://www.iambiente.pt/ sids/sids.pdf>. Acesso em: 01 nov. 2012.

GOSSEN, M. A. Programa de gerenciamento de resíduos sólidos industriais: proposta de um procedimento e aplicação. Revista acadêmica, Ciências Agrárias Ambientais, v. 6(2), p. 149167, Curitiba, 2008.

HARRIS, S.; PRITCHARD, C. Industrial ecology as a learning process in business strategy. Prog Indust Ecol 1 (2004), 89-111, 2004.

HEWES, A. K.; LYONS, D. I. The humanistic side of ecoindustrial parks: champions and the role of trust. Regional Studies 42(10): 1329-1342, 2008.

INDIGO DEVELOPMENT. Eco-industrial parks (EIP). 2005. Disponível em: <http://www.indigodev.com/Ecoparks.html>. Acesso em: 10 abr. 2011.

JACOBSEN, N. B. Industrial symbiosis in Kalundborg, Denmark - a quantitative assessment of economic and environmental aspects. Journal of Industrial Ecology 10(1-2): 239-255, 2006.

KHANNA, N. Measuring environmental quality: an index of pollution. Ecological Economics, [S. I.]: Elsevier, v. 35, n. 2, 2000.

KAZEMERSKY, P. D.; WINTERS, K. H. Chattanooga SMART park education of graduate students through the use of real world projects. ASEE Southeastern Section Conference, 1999.

KINCAID, J.; OVERCASH, M. Industrial Ecosystem development at metropolitan level. Journal of Cleaner Production, v. 5, n. x, p. 117-126, 2001.

KURUP, B.; STEHLIK, D. Towards a model to assess the sustainability implications of industrial symbiosis in eco-industrial parks. Progress in Industrial Ecology - An International Journal, v. 6(2), p. 103-119, 2009.

LIFSET, R.; GRAEDEL, T. E. Industrial ecology: goals and definitions. In: A handbook of industrial ecology, 2002.

LIU, Q.; JIANG, P.; ZHAO, J.; ZHANG, B.; BIAN, H.; QIAN, G. Life cycle assessment of an industrial symbiosis based on energy recovery from dried sludge and used oil. Journal of Cleaner Production 19 (15), p. 1700-1708, 2011.

LOWE, E. A. Eco-industrial park handbook for Asian developing countries. A Report to Asian Development Bank, Environment Department, Indigo Development, Oakland, CA, 2001. 
LOWE, E. An eco-industrial park definition for the circular economy. Indigo Development, 2005. Disponível em: <http://indigodev.com/Defining_EIP.html>. Acesso em: 15 mar. 2011.

MAGALHÃES, A. P. S. Logística reversa de eletrodomésticos da linha branca: processo de escolha pelo método de análise hierárquica (AHP). Dissertação (Mestrado). Escola de Engenharia de São Carlos. Universidade de São Carlos, São Carlos, 2011.

MAGALHÃES, M. T. Q. Metodologia para desenvolvimento de sistemas de Indicadores: uma aplicação no planejamento e gestão da política nacional de transportes. Dissertação (Mestrado). Universidade de Brasília, Brasília, 2004.

MARTIN, S. A.; WEITZ, K. A.; CUSHMAN, R. A.; SHARMA A.; LINDROOTH, R. C.; MORAN, S. R. Eco-industrial parks: a case study and analysis of economic, environmental, technical, and regulatory issues: final report. Research Triangle Park, NC: Research Triangle Institute. 1996.

MARTIN, S. A.; CUSHMAN, R. A.; WEITZ, K. A.; SHARMA, A.; LINDROOTH, R. Applying industrial ecology to industrial parks: An economic and environmental analysis. Research Triangle Institute, Research Triangle Park, NC, 1996.

MARTÍNEZ, R. Q. Guía metodológica para desarrollar indicadores ambientales y de desarrollo sostenible en países de América Latina y el Caribe. Nações Unidas, Chile. 2009.

MASSARD, G.; ERKMAN, S. A regional industrial symbiosis methodology and its implementation in Geneva, Switzerland. In: Conference proceeding for the 3rd international conference on life cycle management, University of Zurich, Irchel, Zurich, p. 27-29, 2007.

MATTILA, T. J.; PAKARINEN, S.; SOKKA, L. Quantifying the total environmental impacts of an industrial symbiosis - a comparison of process -, hybrid and input-output life cycle assessment. Environmental Science and Technology44 (11), p. 4309-4314, 2010.

MEDEIROS, E. S.; MEDEIROS, E. S. Matemática e Estatística Aplicada. Editora Atlas s/a, São Paulo, 1999.

MIRATA, M. Experiences from early stages of national industrial symbiosis programme in the UK: determinants and coordination challenges. Journal of Cleaner Production, v.12 (8-10), p. 967-983, 2004.

MORHARDT, J. E.; BAIRD, S.; FREEMAN, K. Scoring corporate environmental and sustainability reports using GRI 2000, ISO 14031 and other criteria. Corporate Social Responsibility and Environmental Manegement, n. 9, p. 215-233, 2002.

OECD - Organization for Economic Co-operation and Development. Core set of indicators for environmental performance reviews. Environment Monographs $\mathrm{n}^{\circ}$ 83. OECD. 1993. Disponível em: <http://www.nssd.net/pdf/gd93179.pdf>. Acesso em: 03 dez. 2012.

OH, D. S.; KIM, K. B.; JEONG, S. Y. Eco-industrial park design: a daedeok technovalley case study. Habitat International, v. 29 (2), p. 269-284, 2005.

OLIVEIRA, J. A. L. Indicadores de desempenho no setor de aviação civil. Monografia (Especialização). Instituto Serzedello Corrêa - ISC/TCU. Brasília - DF, 2011.

OLSTHOONR, X.; TYTECA, D.; WEHRMEYER, W.; WAGNER, M. Environmental indicators for business: a review of the literature and standardization methods. Journal of Cleaner Production 2001; 9:453e63, 2001.

PAKARINEN, S.; MATTILA, T.; MELANEN, M.; NISSINEN, A.; SOKKA, L. Sustainability and industrial symbiosis - the evolution of a finnish forest industry complex. Resources, Conservation and Recycling, p. 1393-1404, 2010. 
PECK, S. When is an eco-industrial park not an eco- industrial park. Journal of Industrial Ecology, v. 5, n. 3, p. 3-5, 2002.

PEREIRA, A. S.; LIMA, J. C. F.; RUTKOWSKI, W. Ecologia industrial, produção e ambiente: uma discussão sobre as abordagens de inter-conectividade produtiva. In: Anais $1^{\text {st }}$ International Workshop Advances in Cleaner Production, v. 1, São Paulo, 2007.

RUY, M. Método de avaliação ambiental de conceitos de produtos baseado nas estratégias do DFE e no AHP. Tese (Doutorado). Universidade Federal de São Carlos, São Carlos, 2011.

SAATY, T. L.; VARGAS, L. G. Decision making with the analytic network process: economic, political, social and technological applications with benefits, opportunities, costs and risks. New York: Springer, 2006.

SAATY, R. W. The analytic hierarchy process: what it is and how it is used? Mathematical Modelling, Great Britain, v. 9, n. 3-5, p. 161-176, 1987.

SAATY, T. L. Decision making with the Analytic Hierarchy Process. Int. J. Services Sciences, Pittsburgh, v. 1, n. 1, p. 83-98, 2008.

How to make a decision: The Analytic Hierarchy Process. European Journal of Operational Research, North Holland, v. 48, n. 1, p. 9-26, 1990.

Método de Análise Hierárquica. São Paulo: Makron, 1991.

SABLOWSKI, A. R. M. Balanço de materiais na gestão ambiental da cadeia produtiva do carvão vegetal para a produção de ferro gusa em Minas Gerais. Tese (Doutorado). Universidade de Brasília, Brasília, 2008.

SANTOS, R. F. Planejamento ambiental: teoria e prática. São Paulo: Oficina de Textos, 2004.

SCHLARB, M. Eco industrial development: a strategy for building sustainable communities. $U$. S. Economic Development Administration, Work and Environment Initiative, Cornell University, 2001.

SEGNESTAM, L. Indicators of environmental and sustainable development: theories and practical experiences. World Bank, Washington DC, 2002.

SENDRA, C.; GABARRELL, X.; VICENT, T. Material flow analysis adapted to an industrial area. Journal of Cleaner Production, v.15, p. 1706-1715, 2007.

SEURING, S. A. A framework for green supply chain costing: a fashion industry example. In: Sarkis, J. (Ed.), Green Manufacturing and Operations: From Design to Delivery and Back. Greenleaf Publishing, Sheffield (UK), p. 150-160, 2001.

SEGNESTAM, L. Indicators of environmental and sustainable development: theories and practical experiences. World Bank, Washington DC, 2002.

SHIMIZU, T. Decisão nas organizações: introdução aos problemas de decisão encontrados nas organizações e nos sistemas de apoio à decisão. São Paulo: Atlas, 2001.

SIBIS - Statistical Indicators Benchmarking the Information Society. New Europe Indicator Handbook. European Comission, 2003. Disponível em: <http://www.sibiss-eu.org/files/Sibis_ Indicator_Handbook.pdf>. Acesso em: 15 set. 2012.

SINGH, A.; LOU, H. H.; YAWS, C. L.; HOPPER, J. R.; PIKE, R. W. Environmental impact assessment of different design schemes of an industrial ecosystem. Resources, Conservation and Recycling 51(2): p. 294-313, 2007. 
SOKKA, L.; LEHTORANTA, S.; NISSINEN, A.; MELANEN, M. Analyzing the environmental benefits of industrial symbiosis: life cycle assessment applied to a finnish forest industry complex. Journal of Industrial Ecology 15 (1), p. 137-155, 2011.

SOPHA, B. M.; FET, A. M.; KEITSCH, M. M.; HASKINS C. Using systems engineering to create a framework for evaluating industrial symbiosis options. Systems Engineering, v. 13(2), p.149-160, 2010.

SORATA, K.; LANDIS, A. E. Evaluating industrial symbiosis and algae cultivation from a life cycle perspective. Bioresource Technology, 102 (13), p. 6892-6901, 2011.

SPIEGELMAN, J. Beyond the food web: connections to a deeper industrial ecology. Journal of Industrial Ecology, v. 7, p.17-23, 2003.

SPIEGEL, M. Estatística. São Paulo: McGraw-Hill, 1972.

STARLANDER, J. E. Industrial Symbiosis: A Closer Look on Organizational Factors, a study based on the Industrial Symbiosis project in Landskrona. Thesis of the Master of Science in Environmental Management and Policy Lund, Sweden, 2003.

STERMAN, J. D. Business dynamics: system thinking and modeling for a complex world. Irwin McGraw-Hill, New York, 2000.

SUSTAINABLE MEASURE, 2008. Disponível em: <http://www.sustainablemeasures.com/Indicators/ Index.html>. Acesso em: 09 out. 2012.

THE WORLD BANK. Expanding the measure of wealth: indicators of environmentally sustainable development. Washington, D.C.:Editora. 110p. Environmenrally sustainable development studies and monographs series, n.17, 1997.

TOCCHETTO, M. R. L.; SOARES, M. R. K. O gerenciamento dos resíduos sólidos industriais. Programa de Desenvolvimento de Recursos Humanos. ABES - Associação Brasileira de Engenharia Sanitária e Ambiental, Porto Alegre, Edição revisada, 2003.

TUDOR, T.; ADAM E.; BATES, M. Drivers and limitations for the successful development and functioning of EIPs (eco-industrial parks): a literature review. Ecological Economics, 2007.

VELEVA, V.; ELLENBECKER, M. Indicators of sustainable production: framework and methodology. Journal of Cleaner Production, n. 9, p. 519-549, 2001.

WANG, G.; FENG, X.; CHU, K.H. A novel approach for stability analysis of industrial symbiosis systems. Journal of clean production, v. 39, p. 9-16, 2013.

WINOGRAD, M.; FARROW, A. Sustainable development indicators for decision making: concepts, methods, definition and use. In: SEIDLER,R.(Org). Dimensions of sustainable development. Boston: EOLSS Publishers, v.1 e 2, 2009.

YOUNG R. By-product synergy: a demonstration project. Tampico, Mexico, Business Council for Sustainable Development - Gulf of Mexico, Austin, TX, 1999.

ZHAOHUA, W.; BIN, Z.; GUILONG, L. Research on industrial symbiosis patterns in ecoindustrial park based on industrial ecology theory. In: Computer Application and System Modeling (ICCASM), v. 7, p. 669-672, 2010.

ZHU, L.; ZHOU, J.; CUI, Z.; LIU L. A method for controlling enterprises access to an ecoindustrial park. Science of the Total Environment, p. 4817-4825, 2010. 


\section{APÊNDICE A: PROTOCOLO DE REVISÃO BIBLIOGRÁFICA SISTEMÁTICA}

\section{Planejamento da RBS}

Nesta seção definem-se as seguintes atividades: formulação do problema, coleta de dados, avaliação dos dados, e finalmente, análise e interpretação dos dados.

\subsection{Formulação do problema}

A formulação do problema determina o tipo de evidência que deve ser incluída na revisão, definindo o objetivo, as áreas beneficiadas, e os resultados esperados (BIOLCHINI et al.,2005)

O problema definido foi a ausência de instrumentos que apoiem os sistemas e as práticas de gestão num EIP e como consequência, a dificuldade de medir com precisão o desenvolvimento e funcionamento desses parques. Logo, a questão a ser respondida na RBS era: "Quais indicadores são utilizados para avaliar o desempenho de um EIP?".

Assim, o objetivo da RBS é identificar e analisar estudos que apresentam indicadores ambientais utilizadas em EIPs para avaliar o seu desempenho.

\subsection{Coleta de dados}

A coleta de dados foca na definição do procedimento que o pesquisador deve adotar para encontrar as evidências relevantes, de acordo com as definições estabelecidas na formulação do problema. Isso inclui a determinação das fontes de dados que podem providenciar estudos relevantes, seleção das palavras-chave e termos de pesquisa (BIOLCHINI et al., 2005).

Utilizou-se para esta pesquisa bases de dados eletrônicas, nas quais se pesquisaram artigos nacionais e internacionais em revistas indexadas, artigos em anais de eventos. Também foram fontes de informação elegível, teses e dissertações nacionais e internacionais, livros e sites correlatos ao tema em estudo. Abaixo, estão listados os sítios utilizados para a pesquisa:

Quadro 8. Lista de base de dados utilizada na pesquisa

\begin{tabular}{cc}
\hline Sites de busca em bases de dados & Endereço virtual \\
\hline Scielo & http://www.scielo.org \\
Science Direct & http://www.sciencedirect.com \\
Biblioteca Digital de Teses/Dissertações & http://www.teses.usp.br \\
\hline
\end{tabular}




\begin{tabular}{cc}
\hline Sites de busca em bases de dados & Endereço virtual \\
\hline Web of Knowledge & http://isiknowledge.com \\
Google & $\mathrm{http}: / / w w w . g o o g l e . c o m . b r$ \\
Scopus & $\mathrm{http://www.scopus.com}$ \\
\hline
\end{tabular}

As principais termos e palavras-chave utilizadas foram: Eco-industrial park(EIP), Industrial Symbiosis, Indicators, environmental impacts, indicator system, environmental indicador, self-organizing system, eco-efficiency.

\subsection{Avaliação dos dados}

A avaliação dos dados ocorre a partir da definição de critérios de inclusão e exclusão de artigos, são eles:

- Tratar sobre EIPs e simbiose industrial;

- Apresentar/descrever indicadores ambientais que analise, avalie ou colabore para a gestão do EIP;

- Estar disponível integralmente para que possa ser compreendido e utilizado.

Os estudos encontrados foram inseridos numa tabela contendo os seguintes campos: título, autor(es), tipo(artigo, tese, dissertação ou relatório), palavras-chave, ano da publicação, e resumo.

1.4. Interpretação e análise dos dados

Os estudos encontrados foram sintetizados e, as suas informações relevantes foram utilizadas para compor o item 2.4 e 4.3 do presente trabalho. 


\section{APÊNDICE B: PROTOCOLO DA VISITA DE CAMPO AO PARQUE TECNOLÓGICO - CASO I E II}

\section{OBJETIVOS}

- Descrever o Perfil do Parque e porque ele pode ser considerado um EIP;

- Descrever o processo de atração e inclusão de empresas no parque;

- Descrever o papel do agenciador no processo descrito;

- Buscar as principais questões e dificuldades que o parque enfrenta;

\section{DESDOBRAMENTO DOS OBJETIVOS LIGADOS AO QUESTIONÁRIO}

\begin{tabular}{|l|l|}
\hline \multicolumn{1}{|c|}{ OBJETIVOS } & \multicolumn{1}{|c|}{ PERGUNTAS } \\
\hline $\begin{array}{l}\text { Descrever o Perfil do Parque e porque } \\
\text { ele pode ser considerado um Eco- } \\
\text { Parque }\end{array}$ & $1,2,3,4,7,12,13,14$ \\
\hline $\begin{array}{l}\text { Descrever o processo de atração e } \\
\text { inclusão de empresas no parque }\end{array}$ & $5,6,11$ \\
\hline $\begin{array}{l}\text { Descrever o papel do agenciador no } \\
\text { processo descrito }\end{array}$ & $8,9,10$ \\
\hline $\begin{array}{l}\text { Buscar as principais questões e e } \\
\text { dificuldades que o Parque enfrenta }\end{array}$ & $7,8,9,10,11,12,14$ \\
\hline
\end{tabular}

\section{QUESTIONÁRIO}

1) Quais são as ações de sustentabilidade? Como funciona a distribuição de energia, o reuso de água e a estação de tratamento de esgoto? Como são as edificações sustentáveis?

2) Por que o parque pode ser considerado um EIP?

3) Existe simbiose? Quais os recursos utilizados no processo? Existem necessidades atuais referentes a recursos?

4) Qual o perfil das empresas participantes? 
5) Quanto aos processos de entrada, quais os critérios e quais variáveis são levados em consideração?

6) Como funciona o sistema de incentivo à Cooperação?

7) Todas as relações de cooperação só ocorrem nos limites do parque?

8) Qual é o papel do agenciador?

9) Como funciona a estrutura centralizada dos responsáveis pelo planejamento, desenvolvimento e controle do parque? Qual foi a maior dificuldade encontrada no desenvolvimento das atividades e qual a atual necessidade deste órgão controlador?

10)Como é o gerenciamento de resíduos e a economia de recursos?

11)Existe algum critério de entrada para as empresas que desejam participar do parque? Todas as empresas participantes possuem algum tipo de cooperação?

12)Como é a relação do parque com a comunidade local? Existe algum programa de qualificação da mão de obra local?

13)Qual foi a importância do desenvolvimento de políticas de incentivo para a criação do parque?

14)Quais são as ferramentas utilizadas e quais são para facilitar as sinergias entre as empresa? Existe algum software ou banco de dados? 
ANEXO A: CRITÉRIOS DE AVALIAÇÃO DO GRAU DO RESÍDUO CIRCULANTE E EXTERNO

\begin{tabular}{|c|c|c|}
\hline \multicolumn{3}{|c|}{ Legislação } \\
\hline 1 - Boas Práticas & 3 - Requisito Geral & 5 - Requisito Legal Específico \\
\hline 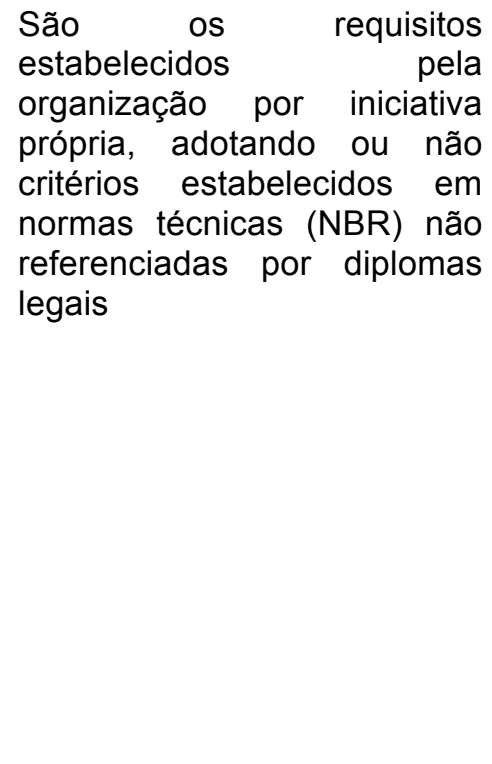 & $\begin{array}{l}\text { São os requisitos legais de } \\
\text { nível federal, estadual ou } \\
\text { municipal, classificados } \\
\text { como "Geral", ou seja, são } \\
\text { diplomas legais que não } \\
\text { estabelecem requisitos } \\
\text { que indique "o que deve } \\
\text { ser feito"(Genérico). }\end{array}$ & $\begin{array}{l}\text { São aqueles requisitos que se } \\
\text { enquadram em uma ou mais } \\
\text { situações descritas abaixo: } \\
\text { a)Requisito Legal, de nível } \\
\text { federal, estadual ou municipal, } \\
\text { classificados como "específicos", } \\
\text { ou seja, requisitos que } \\
\text { estabelecem "o que deve ser } \\
\text { feito"; b)Requisito de norma } \\
\text { técnica referenciada por algum } \\
\text { diploma legal específico; c) } \\
\text { Outros requisitos subscritos } \\
\text { constantes em: Licenças } \\
\text { Ambientais/ do Exército/ da } \\
\text { Política Federal, Termos de } \\
\text { Ajustamento de Conduta, } \\
\text { Programas de auto } \\
\text { monitoramento e ou solicitações } \\
\text { formais do órgão competente. }\end{array}$ \\
\hline
\end{tabular}

\begin{tabular}{|c|c|c|}
\hline \multicolumn{3}{|c|}{ Classe do Resíduo } \\
\hline $\begin{array}{c}1 \text { - Não perigosos - Inertes } \\
\text { (Classe IIB) }\end{array}$ & $\begin{array}{l}3 \text { - Não perigosos - Não } \\
\text { inertes (Classe IIA) }\end{array}$ & 5 - Perigosos (Classe I) \\
\hline $\begin{array}{l}\text { São quaisquer resíduos que, } \\
\text { quando amostrados de uma } \\
\text { forma representativa, } \\
\text { segundo a Norma NBR } \\
\text { 10.007, e submetidos a um } \\
\text { contato estático ou dinâmico } \\
\text { com água destilada ou } \\
\text { desionizada, à temperatura } \\
\text { ambiente, conforme Norma } \\
\text { NBR 10.006, não tiverem } \\
\text { nenhum de seus constituintes } \\
\text { solubilizados a concentrações } \\
\text { superiores aos padrõ de } \\
\text { potabilidade de água, } \\
\text { excetuando-se aspecto, cor, } \\
\text { turbidez, dureza e sabor, } \\
\text { conforme anexo X da Norma } \\
\text { NBR 10.004. }\end{array}$ & 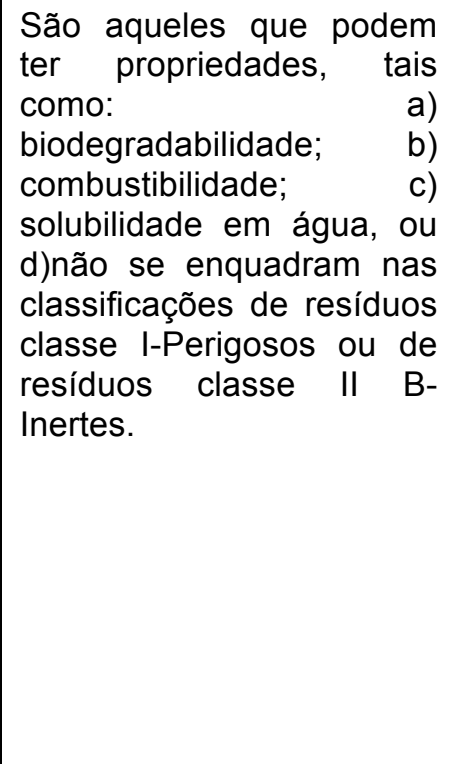 & $\begin{array}{l}\text { São aqueles requisitos que se } \\
\text { enquadram em uma ou mais } \\
\text { situações descritas abaixo: } \\
\text { a)Requisito Legal, de nível } \\
\text { federal, estadual ou municipal, } \\
\text { classificados como "específicos", } \\
\text { ou seja, requisitos que } \\
\text { estabelecem "o que deve ser } \\
\text { feito"; b)Requisito de norma } \\
\text { técnica referenciada por algum } \\
\text { diploma legal específico; c) } \\
\text { Outros requisitos subscritos } \\
\text { constantes em: Licenças } \\
\text { Ambientais/ do Exército/ da } \\
\text { Política Federal, Termos de } \\
\text { Ajustamento de Conduta, } \\
\text { Programas de auto } \\
\text { monitoramento e ou solicitações } \\
\text { formais do órgão competente. }\end{array}$ \\
\hline
\end{tabular}




\begin{tabular}{|c|c|c|}
\hline \multicolumn{3}{|c|}{ Uso do Resíduo no Parque } \\
\hline $\begin{array}{c}1 \text { - Há tratamento do resíduo } \\
\text { na empresa doadora e } \\
\text { receptora. }\end{array}$ & $\begin{array}{c}3 \text { - Há tratamento na } \\
\text { empresa receptora do } \\
\text { resíduo. }\end{array}$ & $\begin{array}{c}5 \text { - Não é necessário tratamento } \\
\text { em nenhuma das empresas. }\end{array}$ \\
\hline
\end{tabular}

\begin{tabular}{|c|c|c|}
\hline \multicolumn{3}{|c|}{ Destinação do Resíduo } \\
\hline $\begin{array}{c}|c| \\
\text { - Outro EIP com pré- } \\
\text { tratamento }\end{array}$ & $\begin{array}{c}3 \text { - Outro EIP sem pré- } \\
\text { tratamento }\end{array}$ & 5 - Aterro Industrial (Classe I e \\
II)
\end{tabular}

\begin{tabular}{|c|c|c|}
\hline \multicolumn{3}{|c|}{ Problemas e/ou Riscos Operacionais } \\
\hline 1 - Inexistente & 3 - Eventuais/ Isolados & 5 - Frequentes \\
\hline $\begin{array}{l}\text { Quando não houver } \\
\text { evidências, registros ou } \\
\text { relatos de problemas ou } \\
\text { riscos } \\
\text { associados operacionais } \\
\text { práticas/procedimentos } \\
\text { adotados no gerenciamento } \\
\text { do resíduo em análise. }\end{array}$ & \begin{tabular}{lrr} 
Quando & \multicolumn{2}{r}{ houver } \\
acidências, registros ou & ou \\
relatos isolados de & de \\
problemas ou riscos \\
operacionais associados \\
às práticas/procedimentos \\
adotados r no \\
gerenciamento do resíduo \\
em análise.
\end{tabular} & $\begin{array}{l}\text { Quando houver evidências, } \\
\text { registros ou relatos frequentes } \\
\text { de problemas ou riscos } \\
\text { operacionais associados às } \\
\text { práticas/procedimentos } \\
\text { adotados no gerenciamento do } \\
\text { resíduo em análise. }\end{array}$ \\
\hline
\end{tabular}

